\title{
Discovery of Selective Inhibitors Targeting Acetylcholinesterase 1 from Disease-Transmitting Mosquitoes
}

Cecilia Engdahl, ${ }^{\dagger, \$}$ Sofie Knutsson, ${ }^{\dagger, \$}$ Fredrik Ekström,,$^{+*}$ and Anna Linusson ${ }^{\dagger *}$

†Department of Chemistry, Umeå University, SE-901 87 Umeå, Sweden

¥Swedish Defense Research Agency, CBRN Defense and Security, SE-906 21 Umeå, Sweden

*Corresponding author

${ }^{\$}$ These authors contributed equally

E-mail address: anna.linusson@umu.se; fredrik.ekstrom@foi.se

\section{Table of contents}

Inhibition data from the HTS campaigns against $A g \mathrm{AChE} 1, A a \mathrm{AChE} 1$, and $h \mathrm{AChE}$..................

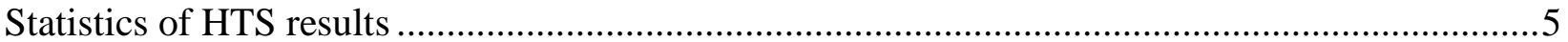

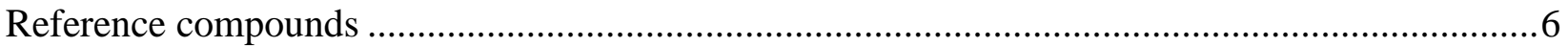

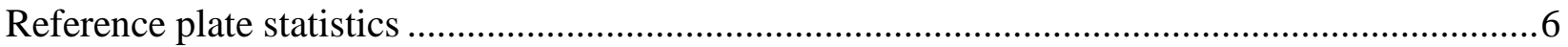

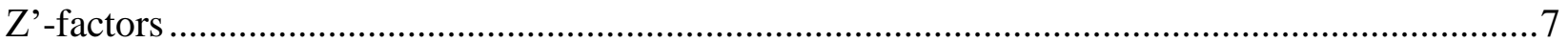

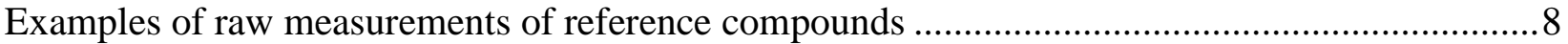

Reference plate - Estimation of false positives and false negatives ........................................12

Overview of the PCA models describing the AChE1 hits .....................................................13

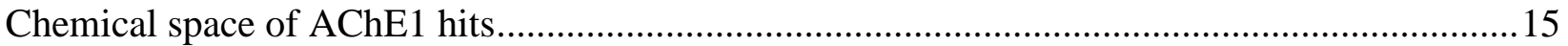

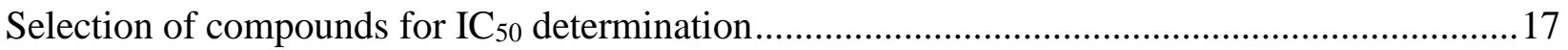

Complete inhibition results for all the re-tested compounds...................................................25

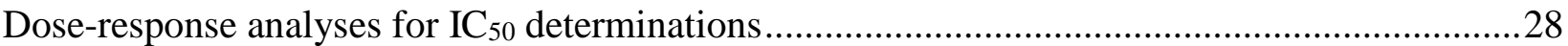

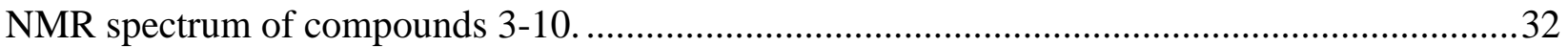

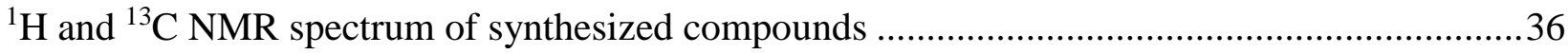

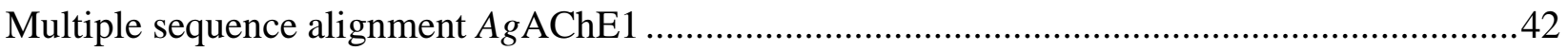




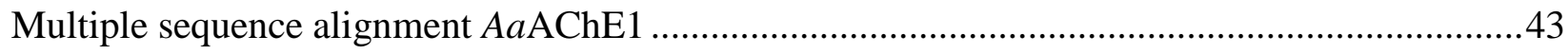

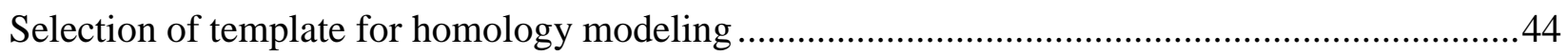

Angles of Tyr337 in homology models of AgAChE1 and AaAChE1 .....................................45

Evaluation of $A g \mathrm{AChE1}$ and $A a \mathrm{AChE1}$ homology models ...............................................45

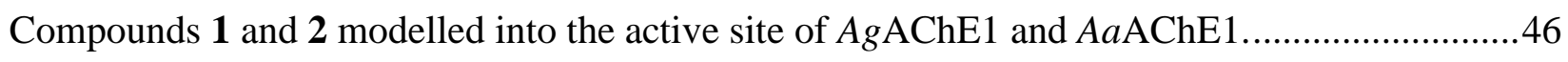

Data collection and refinement statistics for 5FUM ...........................................................48

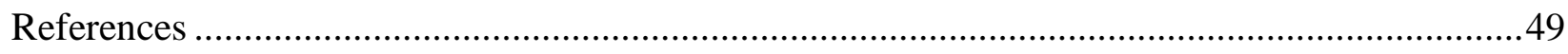


Inhibition data from the HTS campaigns against $A g \mathrm{AChE1}, A a \mathrm{AChE1}$, and $h \mathrm{AChE}$

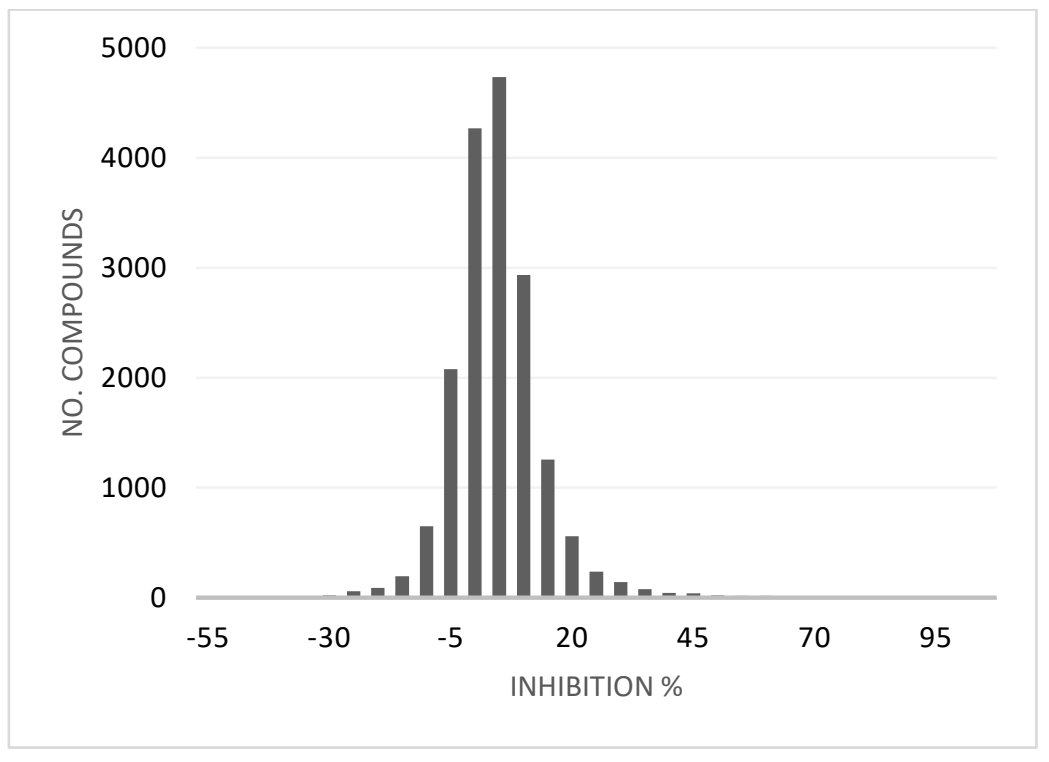

Figure S1. Histogram showing the distribution of the HTS inhibition data for AgAChE1 used in the differential HTS study.

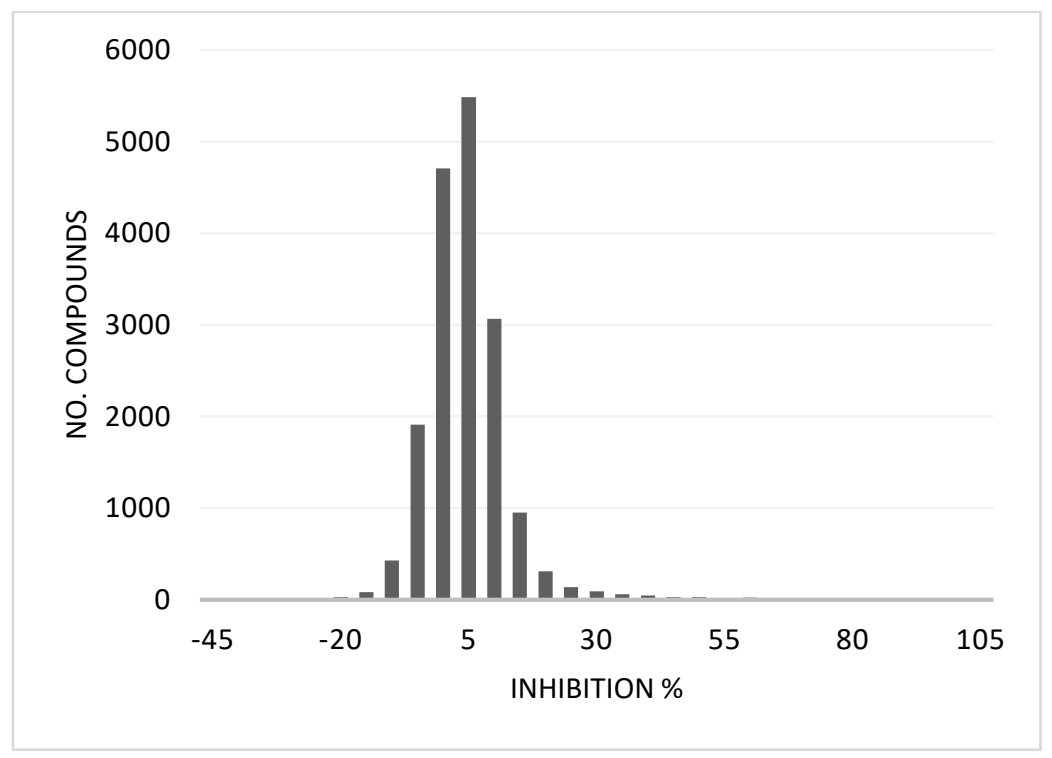

Figure S2. Histogram showing the distribution of the HTS inhibition data for AaAChE1 used in the differential HTS study. 


\section{SUPPORTING INFORMATION}

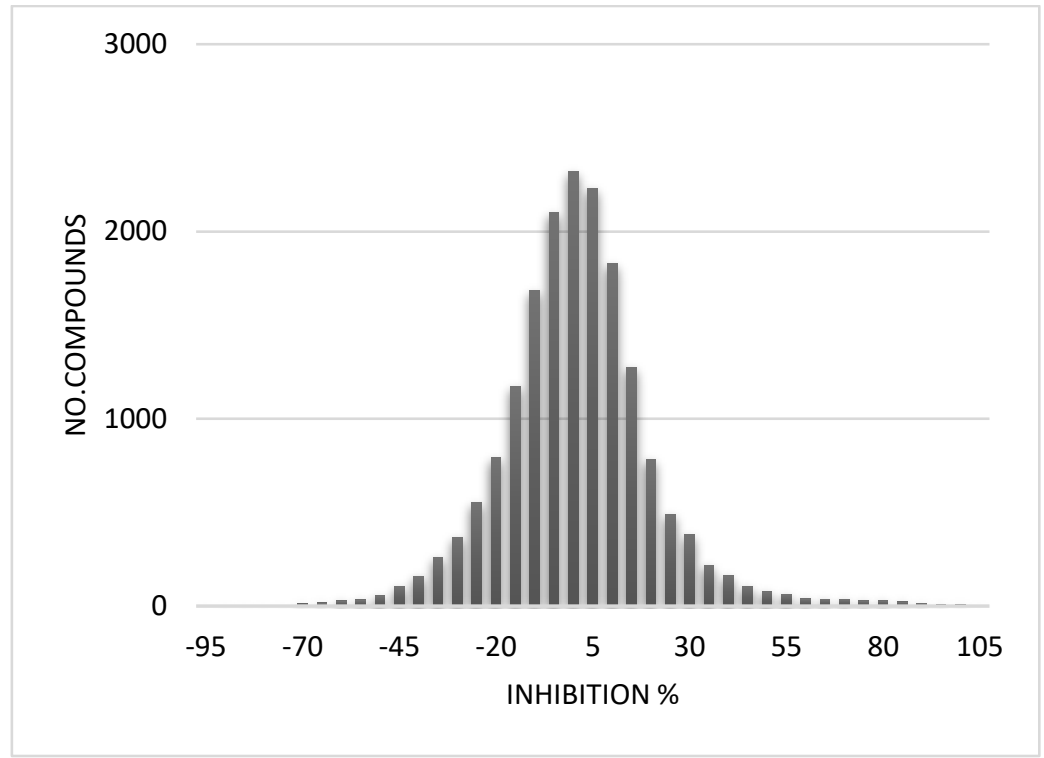

Figure S3. Histogram showing the distribution of the HTS inhibition data for $h \mathrm{AChE}$ used in the differential HTS study. ${ }^{1}$ 


\section{SUPPORTING INFORMATION}

\section{Statistics of HTS results}

Data was normalized as \% of control according to the following equation:

$$
\frac{x_{i}}{\bar{c}_{+}} \times 100
$$

Where

$x_{i} \quad$ raw measurement

$\bar{c}_{+} \quad$ mean of eight positive controls within plate (maximum activity)

Table S1. AChE1 HTS statistics based on the screened compounds' inhibition of activity in relation to positive controls.

$\operatorname{AgAChE1}$

\begin{tabular}{|lcc|}
\hline Mean (\%) & 3 & 3 \\
\hline Median (\%) & 2 & 2 \\
\hline Standard deviation (\%) & 10 & 9 \\
\hline Cut-off (\%) & 33 & 31 \\
\hline No. of hits & 235 & 286 \\
\hline Hit-rate (\%) & 1.3 & 1.6 \\
\hline
\end{tabular}

No. of unique hits of $\mathrm{AgAChE1}$ and/or $\mathrm{AaAChE1}$
338 


\section{SUPPORTING INFORMATION}

\section{Reference compounds}<smiles>Cc1ccc(C(=O)NCCO)cc1[N+](=O)[O-]</smiles>

AL045<smiles>Cc1ccc(C(=O)NCCC[n+]2ccccc2)cc1[N+](=O)[O-]</smiles>

AL053<smiles>O=S(=O)(NCCn1cccc1)c1ccccc1F</smiles>

AL056

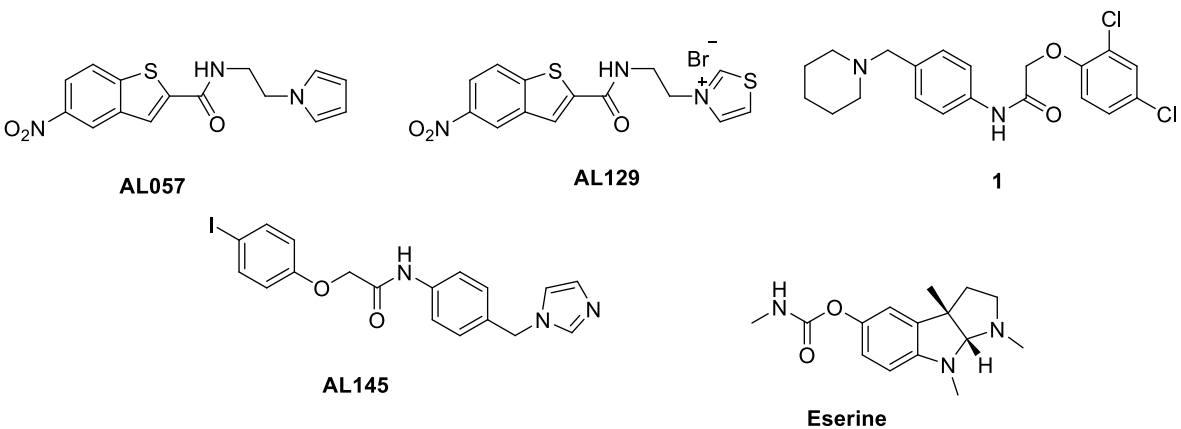

Figure S4. Chemical structures of compounds on reference plate. At $50 \mu \mathrm{M}$, these compounds exhibited mean inhibition values ranging from $0-95 \%$ for both enzymes, and all but one compound had a standard deviation of 3-8\%. The higher standard deviation of the mean observed for compound 1 (17-18\%) was probably due to a handling error whereby no compound was added to in total six and three wells of the $A g \mathrm{AChE} 1$ and $\mathrm{A} a \mathrm{AChE} 1$ experiments, respectively.

\section{Reference plate statistics}

Table S2. Reference plate statistics.

\begin{tabular}{|c|c|c|c|c|c|c|c|c|c|}
\hline & & AL045 & AL053 & AL056 & AL057 & AL129 & 1 & AL145 & Eserine \\
\hline \multirow{2}{*}{$\mathrm{IC}_{50}$} & $A g \mathrm{AChE} 1$ & 1000 & 62 & 1000 & 1000 & 46 & 0.26 & 100 & 0.005 \\
\hline & AaAChE1 & 1000 & 38 & 1000 & 1000 & 37 & 0.44 & 100 & 0.007 \\
\hline \multirow{2}{*}{ mean $(\%)$} & $A g \mathrm{AChE}^{\mathrm{a}}$ & 2 & 18 & 0 & -3 & 25 & 90 & 7 & 95 \\
\hline & $A a \mathrm{AChE}^{\mathrm{b}}$ & 1 & 26 & 0 & -3 & 24 & 89 & 11 & 94 \\
\hline \multirow{2}{*}{ median $(\%)$} & $A g \mathrm{AChE}^{\mathrm{a}}$ & 2 & 19 & 0 & -4 & 25 & 93 & 8 & 96 \\
\hline & $A a \mathrm{AChE}^{\mathrm{b}}$ & 1 & 26 & 0 & -4 & 24 & 92 & 10 & 94 \\
\hline \multirow{2}{*}{ SD } & $A g \mathrm{AChE}^{\mathrm{a}}$ & 7 & 7 & 8 & 7 & 8 & 18 & 8 & 8 \\
\hline & $A a \mathrm{AChE}^{\mathrm{b}}$ & 5 & 6 & 6 & 7 & 7 & 17 & 7 & 3 \\
\hline \multirow{2}{*}{$\begin{array}{l}\text { total no. of } \\
\text { replicates }\end{array}$} & $A g \mathrm{AChE}^{\mathrm{a}}$ & 216 & 216 & 216 & 216 & 216 & 216 & 216 & 216 \\
\hline & $A a \mathrm{AChE}^{\mathrm{b}}$ & 96 & 96 & 96 & 96 & 96 & 96 & 96 & 96 \\
\hline \multirow{2}{*}{$\begin{array}{c}\text { no. scored } \\
\text { as hits }\end{array}$} & $A g \mathrm{AChE}^{\mathrm{a}}$ & 0 & 7 & 1 & 0 & 19 & 210 & 0 & 215 \\
\hline & $A a \mathrm{AChE}^{\mathrm{b}}$ & 0 & 14 & 0 & 0 & 9 & 93 & 0 & 96 \\
\hline \multirow{2}{*}{$\begin{array}{l}\text { no. scored } \\
\text { as inactive }\end{array}$} & $A g \mathrm{AChE}^{\mathrm{a}}$ & 216 & 209 & 215 & 216 & 197 & 6 & 216 & 1 \\
\hline & $A a \mathrm{AChE}^{\mathrm{b}}$ & 96 & 82 & 96 & 96 & 87 & 3 & 96 & 0 \\
\hline
\end{tabular}

${ }^{\mathrm{a} B a s e d}$ on $\%$ inhibition from 27 plates with eight replicates/plate ${ }^{\mathrm{b}}$ based on \% inhibition from 12 plates with eight replicates/plate 
SUPPORTING INFORMATION

Z'-factors

a) Z'-factor AgAChE1 screen

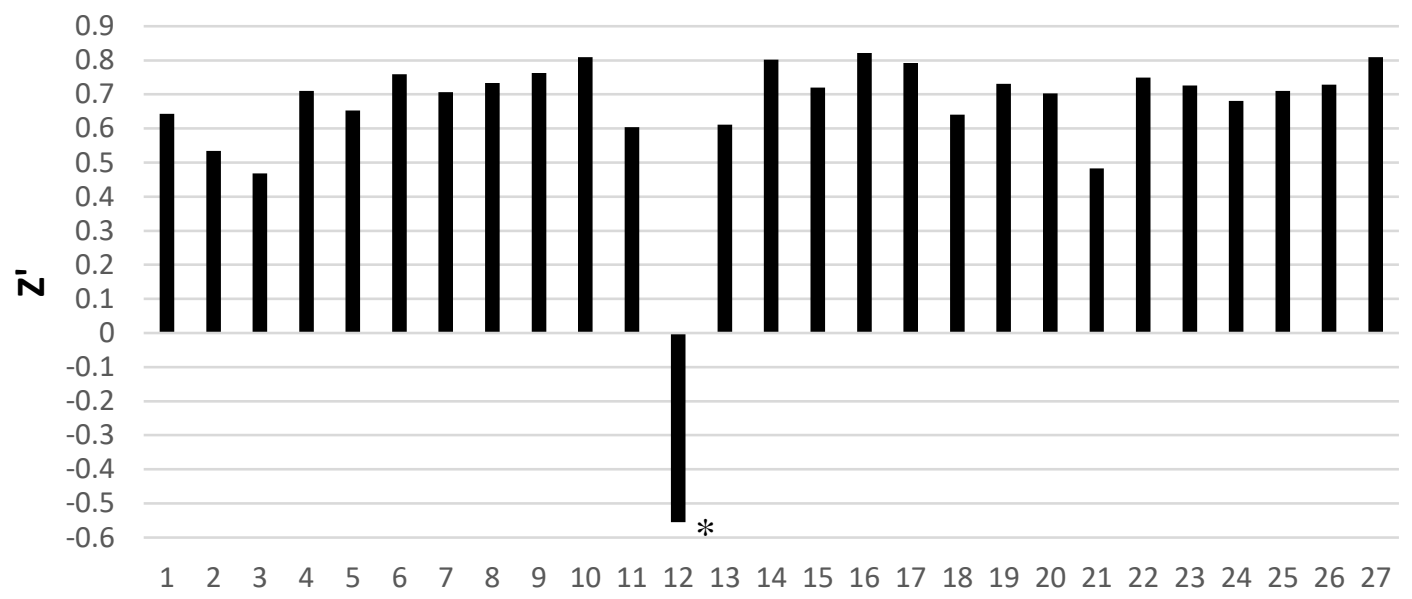

Plate

b)

Z'-factor $\mathrm{AaAChE1}$ screen

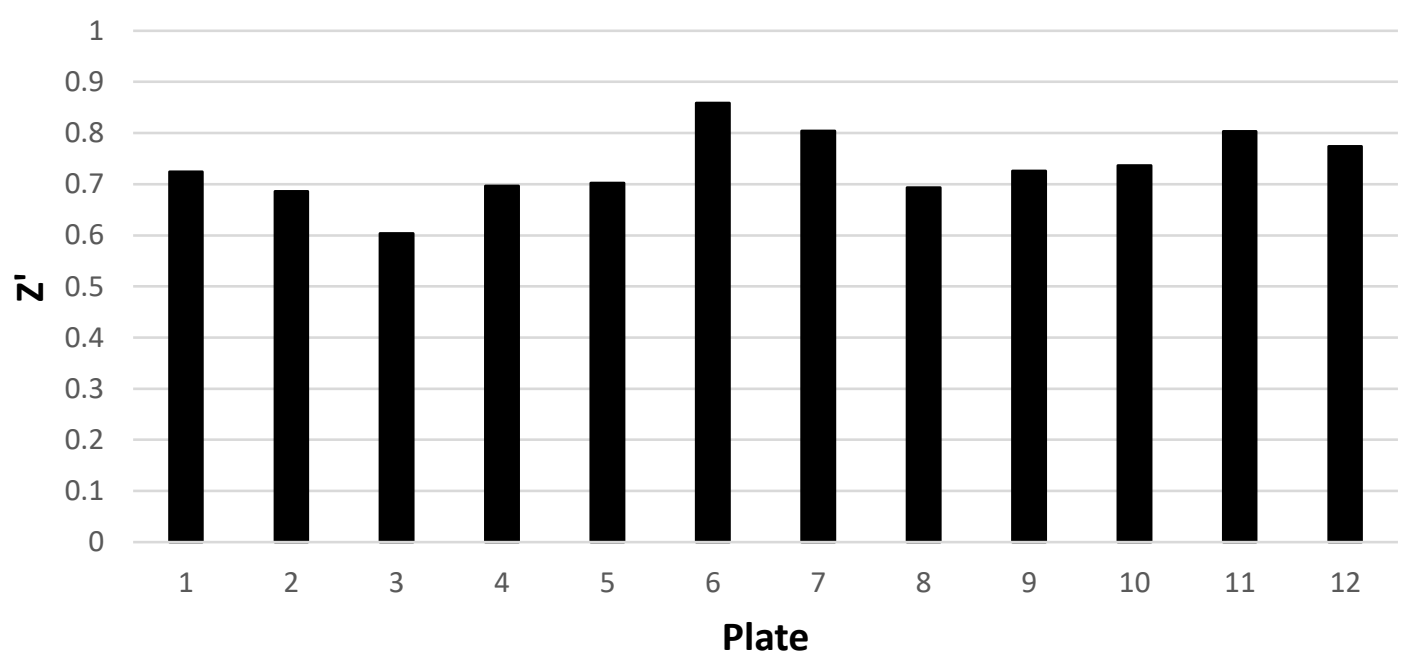

Figure S5. Z'-factors based on eserine and AL045 for each of the reference plate run during the screens against $A g \mathrm{AChE} 1$ (a) and $A a \mathrm{AChE} 1$ (b). *The negative Z'-factor for this plate was due to one measurement for eserine being an extreme outlier, probably due to a handling error whereby no compound was added to the well (see Figure S5c). Excluding this one measurement resulted in Z'-factor of 0.64 for this plate. 
Examples of raw measurements of reference compounds

a)

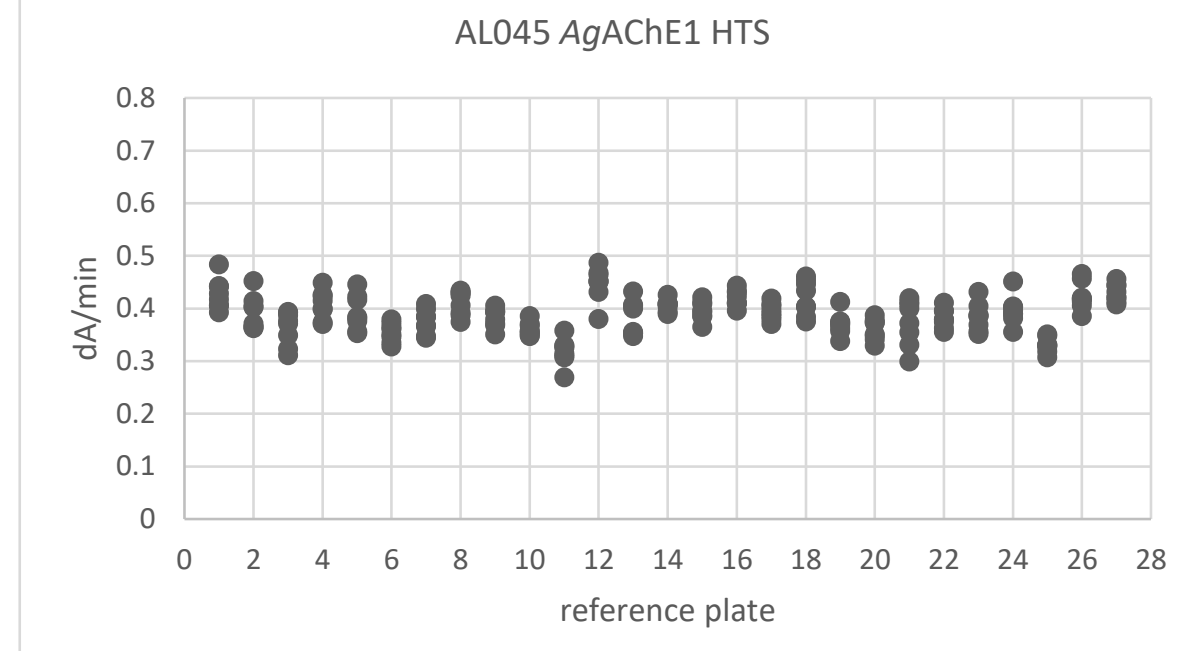

b)

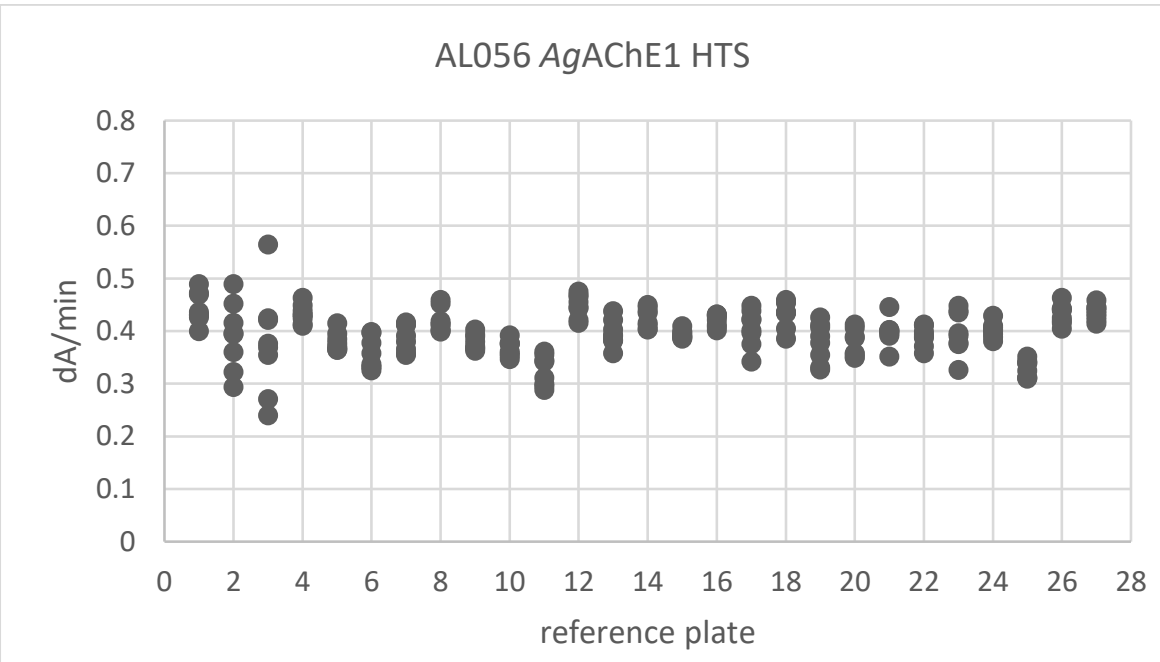

c)

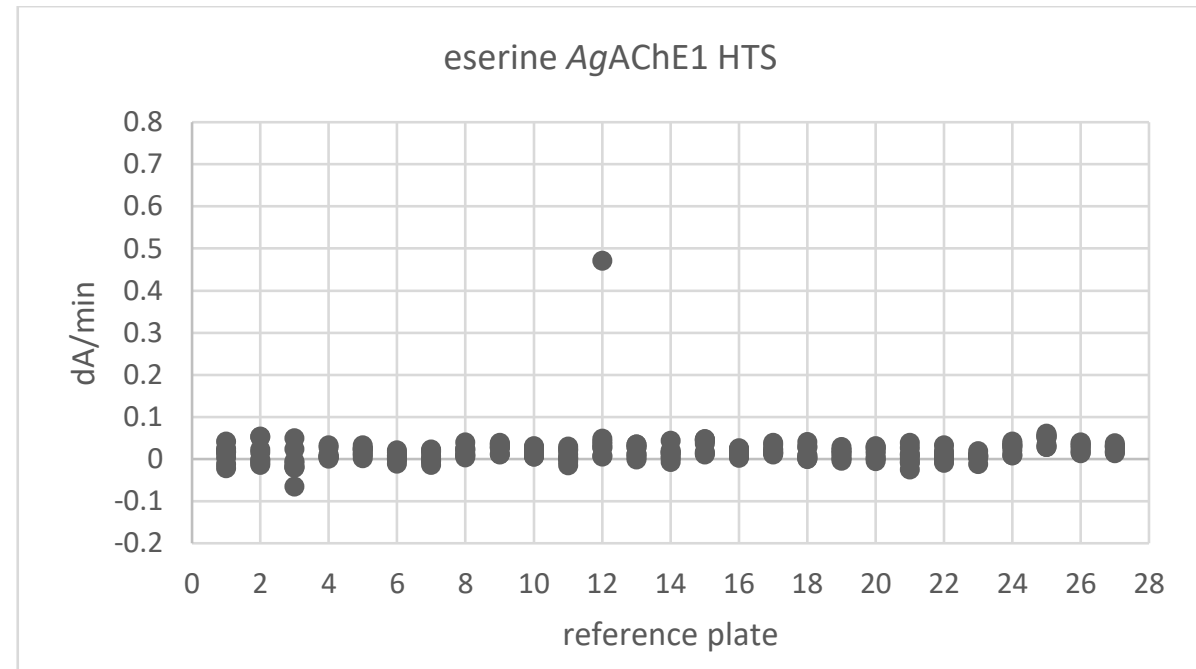




\section{SUPPORTING INFORMATION}

d)

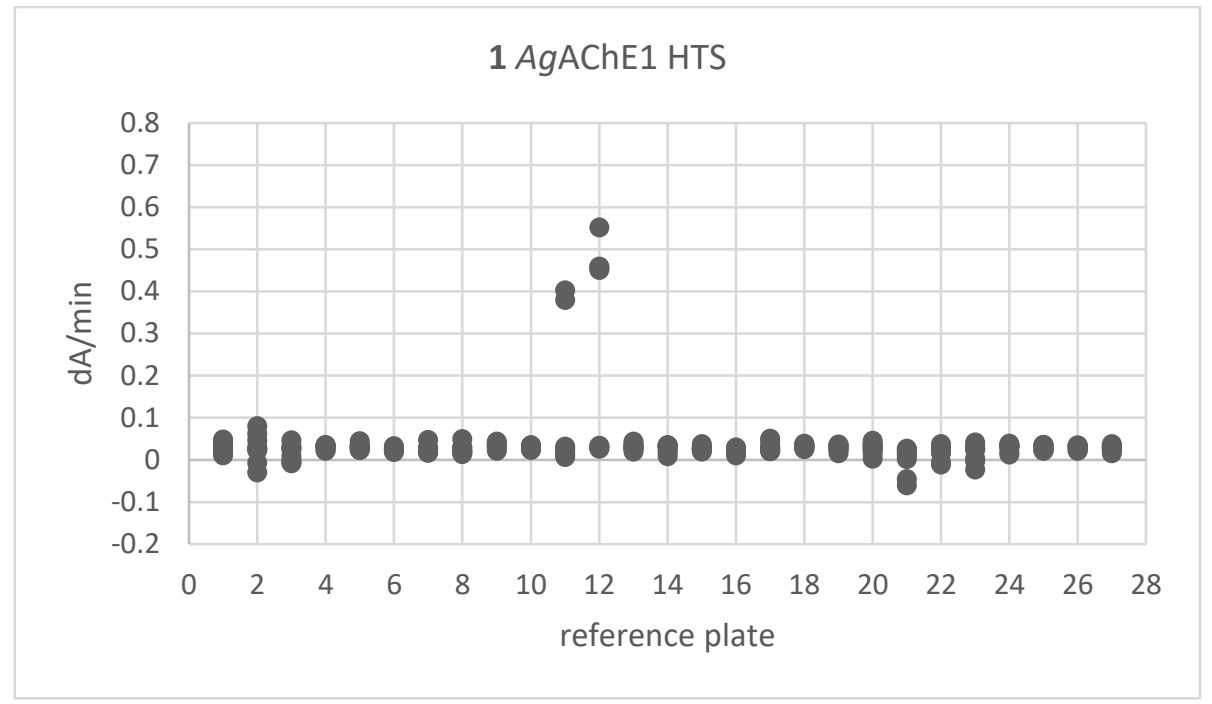

Figure S6. Examples of the change in absorbance over time ( $\mathrm{dA} / \mathrm{min})$ of four compounds from the reference plate run 27 times during the $A g A C h E 1$ screen. Each compound was present in eight replicates on the reference plate. a) Positive control AL045 used for determination of Z'-factor. b) Positive control AL056. C) Negative control eserine used for determination of Z'-factor, one visible outliers (plate $12 ; \mathrm{dA} / \mathrm{min}>0.45$ ) probably due to a handling error whereby no compound was added to that well. d) Negative control 1, six visible outliers (plate 9 and 12; dA/min > 0.35) probably due to a handling error whereby no compound was added to those wells. 


\section{SUPPORTING INFORMATION}

a)

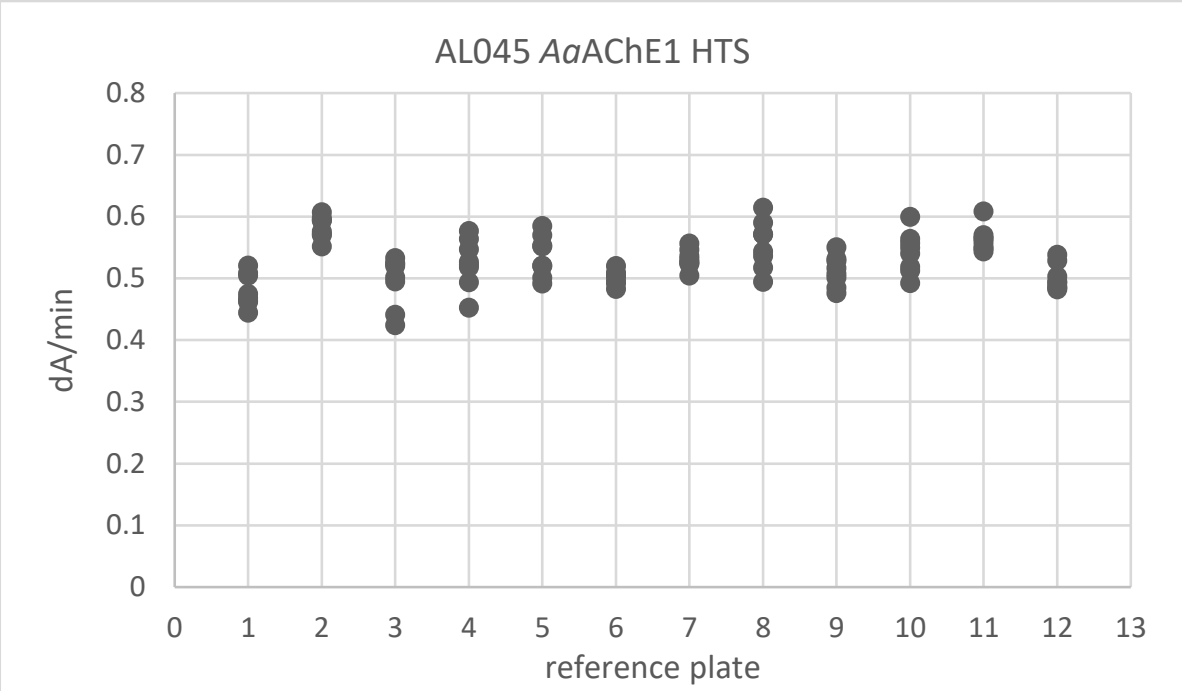

b)

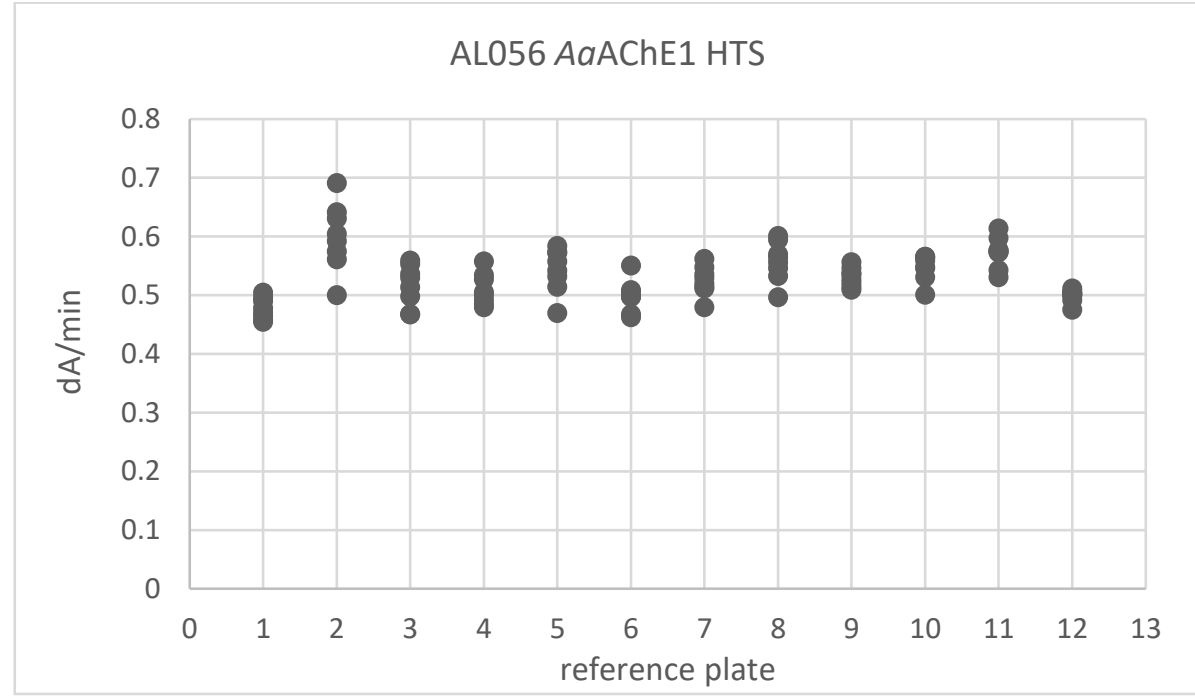

c)

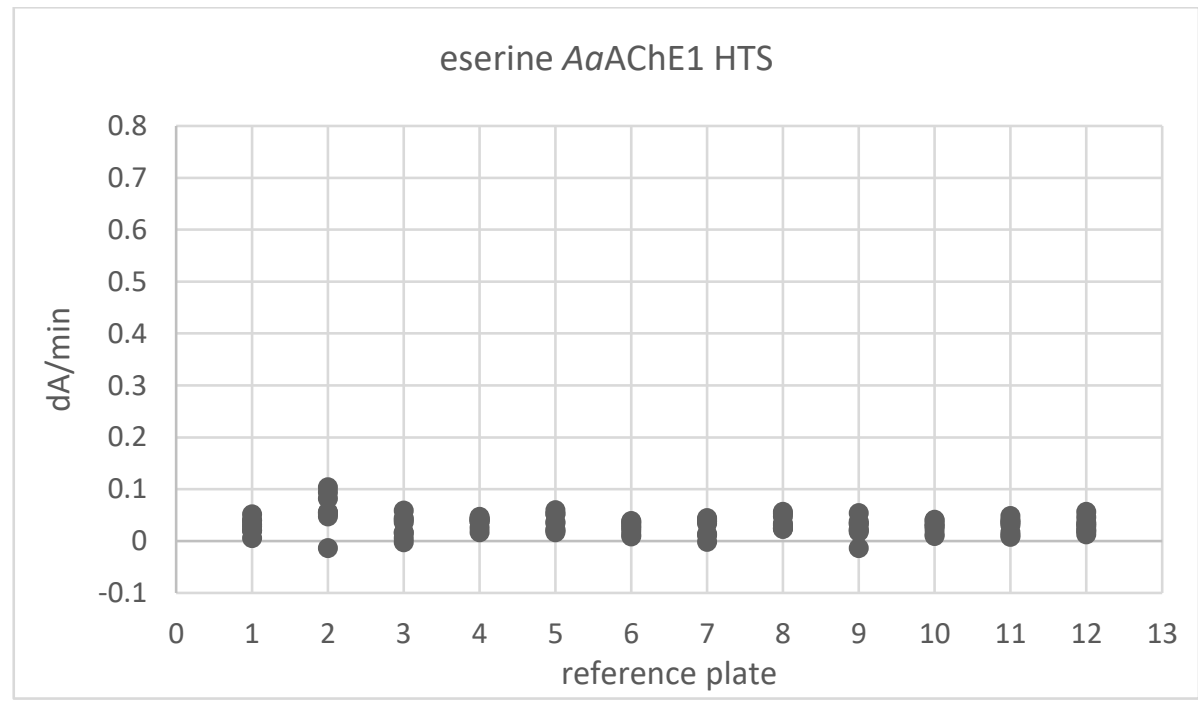




\section{SUPPORTING INFORMATION}

d)

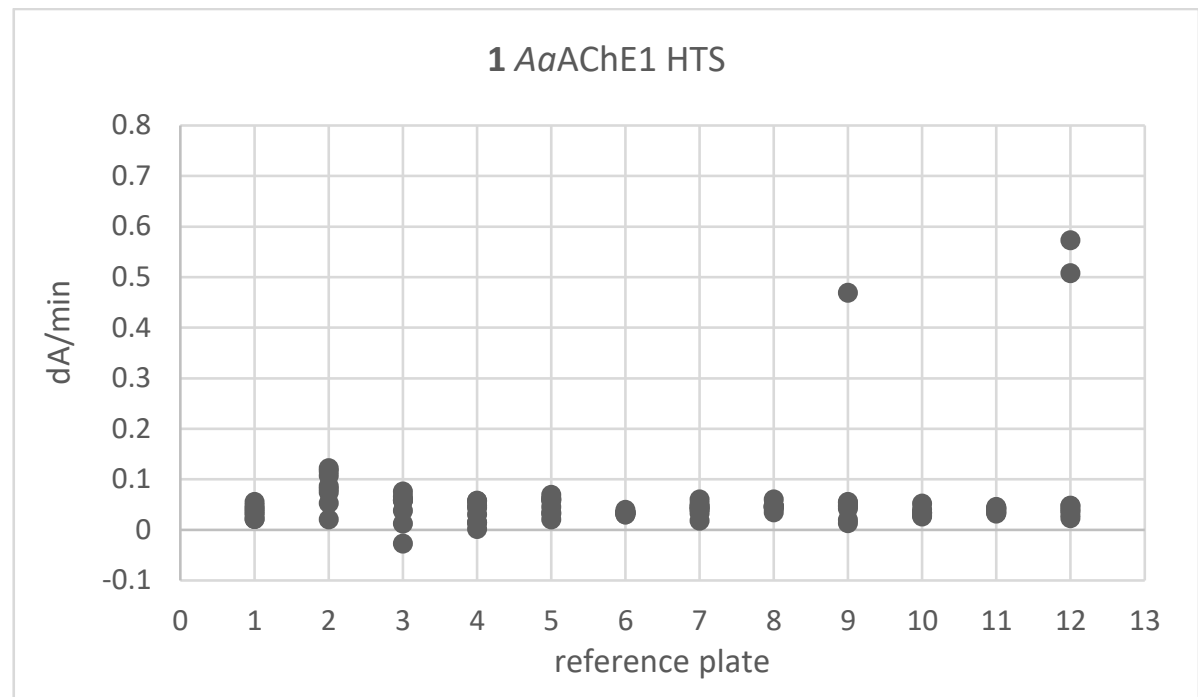

Figure S7. Examples of the change in absorbance over time (dA/min) of four compounds from the reference plate run 12 times during the $A a \mathrm{AChE} 1$ screen. Each compound was present in eight replicates on the reference plate. a) Positive control AL045 used for determination of Z'-factor. b) Positive control AL056. C) Negative control eserine used for determination of Z'-factor. d) Negative control 1, three visible outliers (plate 9 and 12; dA/min $>0.45$ ) probably due to no compound being added to those wells. 


\section{SUPPORTING INFORMATION}

\section{Reference plate - Estimation of false positives and false negatives}

Table S3. Estimation of false positives and false negatives based on reference plate data for the eight compounds loaded on the reference plate (Figure S3 and Table S2).

\section{AgAChE1 AaAChE1}

\begin{tabular}{lcc} 
No. false positives (wells) $^{\mathrm{a}}$ & $27(6 \%)$ & $23(11 \%)$ \\
No. true positives (wells) & 425 & 189 \\
No. false negatives (wells) $^{\mathrm{b}}$ & $7(0.5 \%)$ & $3(0.5 \%)$ \\
\hline No. true negatives (wells) & 1269 & 553 \\
\hline
\end{tabular}

Definition of false positive: a measurement (well) for which reference compound $\mathrm{r}_{\mathrm{i}}$ exhibited \% inhibition $\geq$ hit cut-off; where $\bar{r}_{i}<$ hit cut-off. ${ }^{b}$ Definition of false negative: a measurement (well) for which reference compound $r_{i}$ exhibited $\%$ inhibition $\leq$ hit cut-off; where $\bar{r}_{i}>$ hit cut-off. 


\section{SUPPORTING INFORMATION}

\section{Overview of the PCA models describing the AChE1 hits}

Table S4. Model statistics of principal component analysis (PCA) used to describe and visualize the chemical diversity of the AChE1 hits and selection of compounds for $\mathrm{IC}_{50}$ determinations. PCA is an unsupervised regression method used here to extract the main variation in the $2 \mathrm{D}$-descriptor data (i.e. principal components). The PCA models were calculated on mean-centered data scaled to unit variance using software SIMCA-P+ ${ }^{2}$ and the number of significant components for each model were determined using scree-plots.

\begin{tabular}{|c|c|c|c|c|c|c|c|}
\hline & Model & $\begin{array}{l}\text { No of } \\
\text { hits }\end{array}$ & $\begin{array}{c}\text { No of } \\
\text { descriptors }\end{array}$ & $\begin{array}{c}\text { No of } \\
\text { components }\end{array}$ & $\begin{array}{c}\text { Eigenvalue of } \\
\text { last } \\
\text { component }\end{array}$ & $\begin{array}{c}R^{2} X \\
\text { (cum) }\end{array}$ & $\begin{array}{c}Q^{2} X \\
\text { (cum) }\end{array}$ \\
\hline 1 & all AChE1 hits & 338 & 73 & 4 & 3.72 & 0.85 & 0.82 \\
\hline 2 & $\begin{array}{l}\text { hits } \geq 70 \% \\
\text { inhibition }\end{array}$ & 55 & 73 & 4 & 3.42 & 0.83 & 0.74 \\
\hline 3 & $\begin{array}{l}\text { hits } 69-31 \% \\
\text { inhibition }\end{array}$ & 248 & 73 & 4 & 3.61 & 0.86 & 0.83 \\
\hline 4 & $\begin{array}{c}\text { hits } \geq 30 \% \\
\text { difference } \\
\text { between } A a- \\
\text { and } A g A C h E 1\end{array}$ & 35 & 73 & 3 & 3.88 & 0.84 & 0.78 \\
\hline 5 & $\begin{array}{c}\text { hit sets } A \text { and } \\
\text { B }\end{array}$ & 47 & 73 & 3 & 7 & 0.83 & 0.74 \\
\hline
\end{tabular}




\section{SUPPORTING INFORMATION}

Table S5. Physicochemical descriptors used to describe the chemical space spanned by the AChE1 hits. The 2D-descriptors were calculated using $\mathrm{MOE}^{3}$ on structures prepared as described in the Experimental section.

\begin{tabular}{|c|c|c|c|c|c|}
\hline No. & Descriptor & No. & Descriptor & No. & Descriptor \\
\hline 1 & apol & 26 & chiO_C & 51 & PEOE_VSA_NEG \\
\hline 2 & a_acc & 27 & chi1 & 52 & PEOE_VSA_PNEG \\
\hline 3 & a_aro & 28 & chi1v & 53 & PEOE_VSA_POL \\
\hline 4 & a_count & 29 & chi1v_C & 54 & PEOE_VSA_POS \\
\hline 5 & a_donacc & 30 & chi1_C & 55 & PEOE_VSA_PPOS \\
\hline 6 & a_heavy & 31 & density & 56 & radius \\
\hline 7 & a_hyd & 32 & diameter & 57 & rings \\
\hline 8 & a_IC & 33 & Kier1 & 58 & SlogP \\
\hline 9 & a_ICM & 34 & Kier2 & 59 & SMR \\
\hline 10 & a_nC & 35 & Kier3 & 60 & TPSA \\
\hline 11 & a_nH & 36 & KierA1 & 61 & VAdjEq \\
\hline 12 & a_no & 37 & KierA2 & 62 & VAdjMa \\
\hline 13 & balabanJ & 38 & KierA3 & 63 & VDistEq \\
\hline 14 & bpol & 39 & KierFlex & 64 & VDistMa \\
\hline 15 & b_1rotN & 40 & $\log S$ & 65 & vdw_area \\
\hline 16 & b_1rotR & 41 & PEOE_PC+ & 66 & vdw_vol \\
\hline 17 & b_ar & 42 & PEOE_PC- & 67 & vsa_hyd \\
\hline 18 & b_count & 43 & PEOE_RPC- & 68 & vsa_other \\
\hline 19 & b_heavy & 44 & PEOE_VSA_FHYD & 69 & vsa_pol \\
\hline 20 & b_rotN & 45 & PEOE_VSA_FNEG & 70 & Weight \\
\hline 21 & b_rotR & 46 & PEOE_VSA_FPNEG & 71 & weinerPath \\
\hline 22 & b_single & 47 & PEOE_VSA_FPOL & 72 & weinerPol \\
\hline 23 & chio & 48 & PEOE_VSA_FPOS & 73 & zagreb \\
\hline 24 & chi0v & 49 & PEOE_VSA_FPPOS & & \\
\hline 25 & chiOv_C & 50 & PEOE_VSA_HYD & & \\
\hline
\end{tabular}




\section{Chemical space of AChE1 hits}

a)

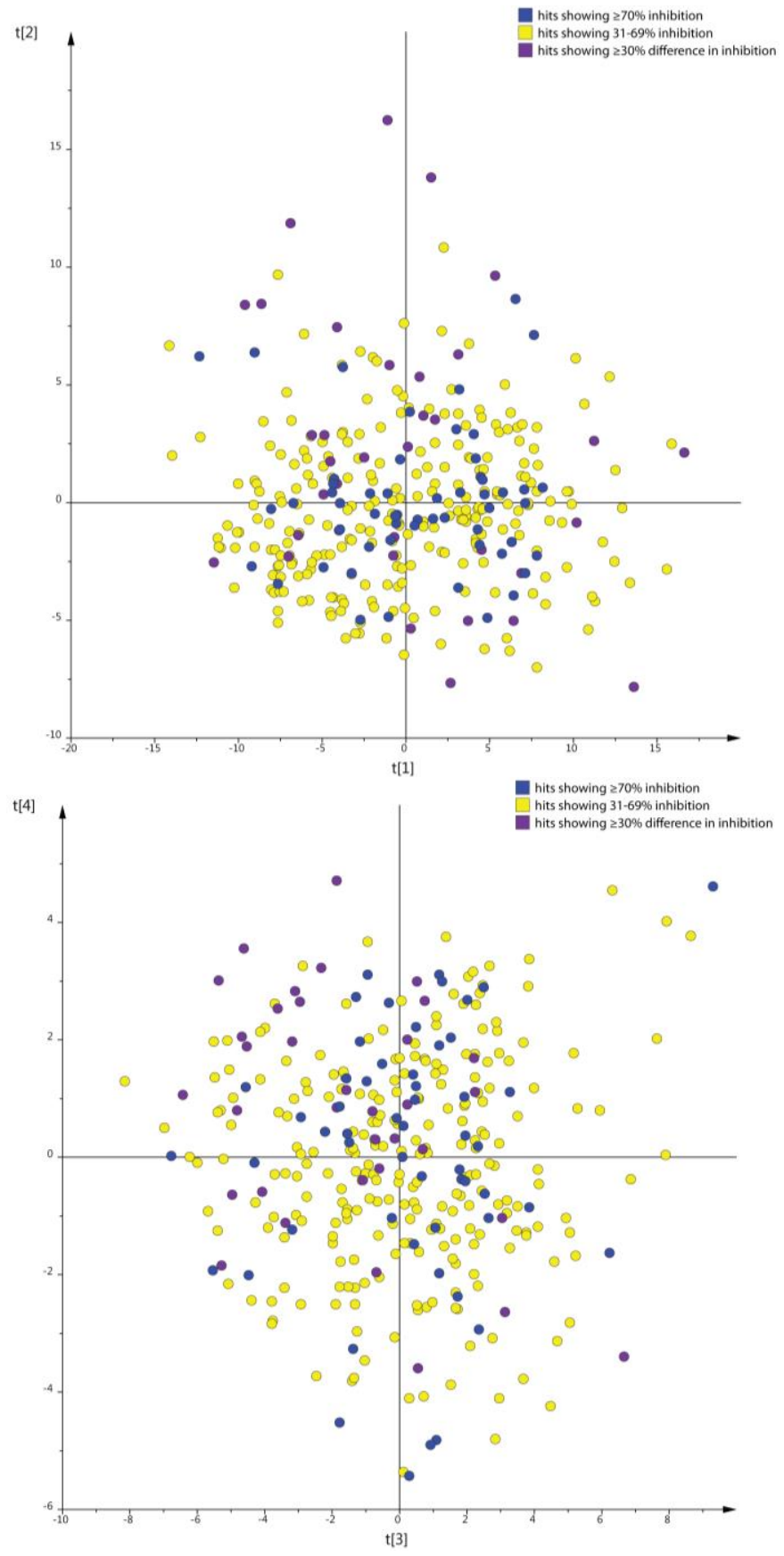

Figure S8. Chemical space of AChE1 hits. Score plots from PCA of the physicochemical properties of the identified hits colored according to their inhibition in the HTS. Hits with $\geq 70 \%$ inhibition in blue, 31-69\% inhibition in yellow, and hits with $\geq 30 \%$ difference inhibition between $A a$ - and $A g A C h E 1$ in purple. The first and second components describe the size and hydrophobicity of the hits (a) and the third and fourth components show diversity relating to flexibility and charge (b). 


\section{SUPPORTING INFORMATION}

a)

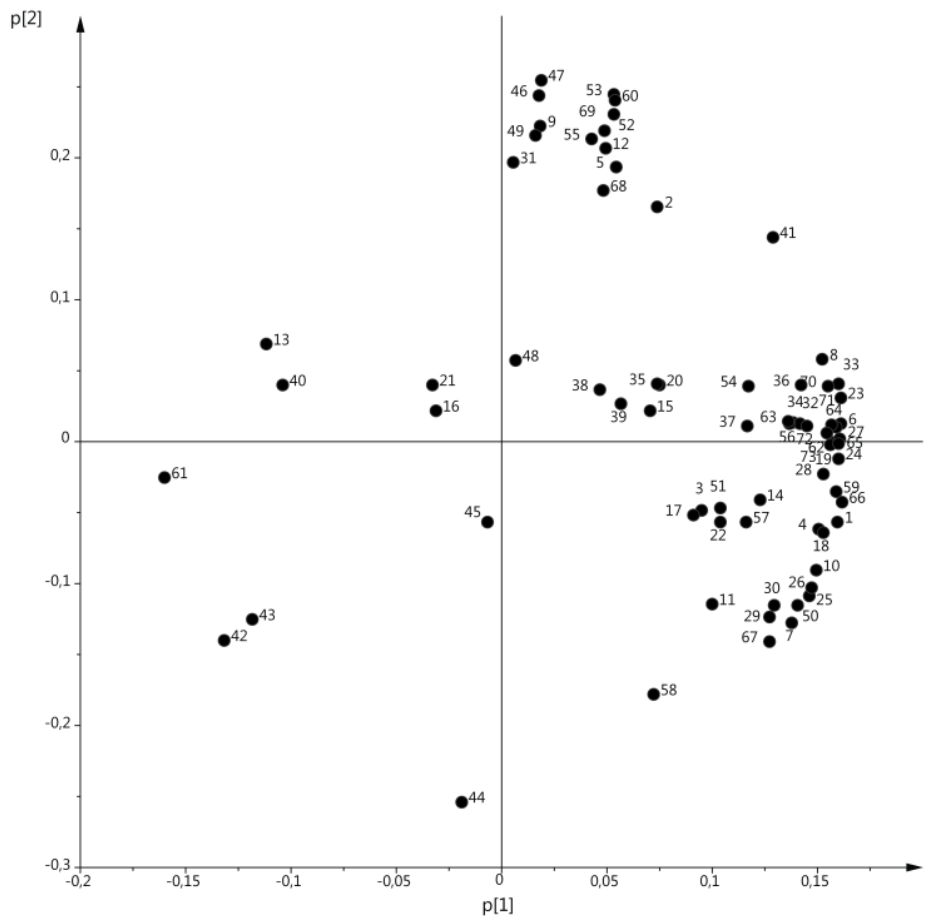

b)

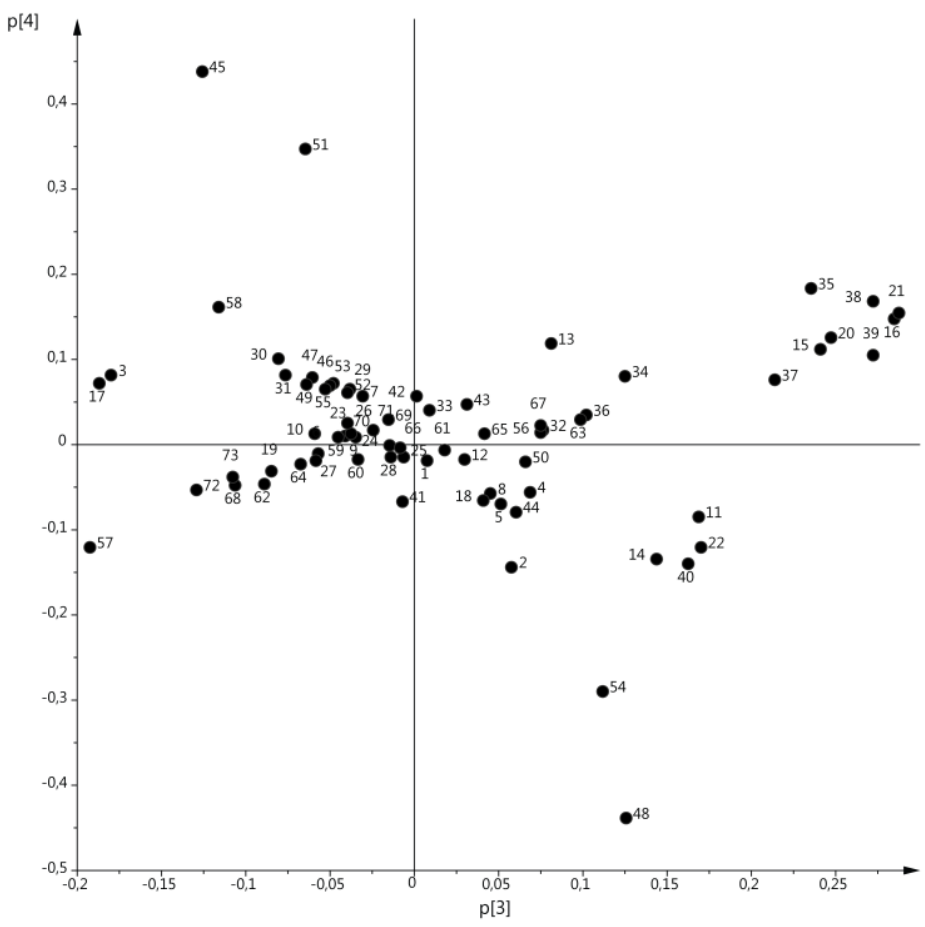

Figure S9. Chemical space of AChE1 hits. PCA loading plots of (a) p1 versus p2 and (b) p3 versus p4. The physicochemical descriptors included in the model are labeled with the numbers assigned in Table S5. 


\section{SUPPORTING INFORMATION}

Selection of compounds for $\mathrm{IC}_{50}$ determination

a)

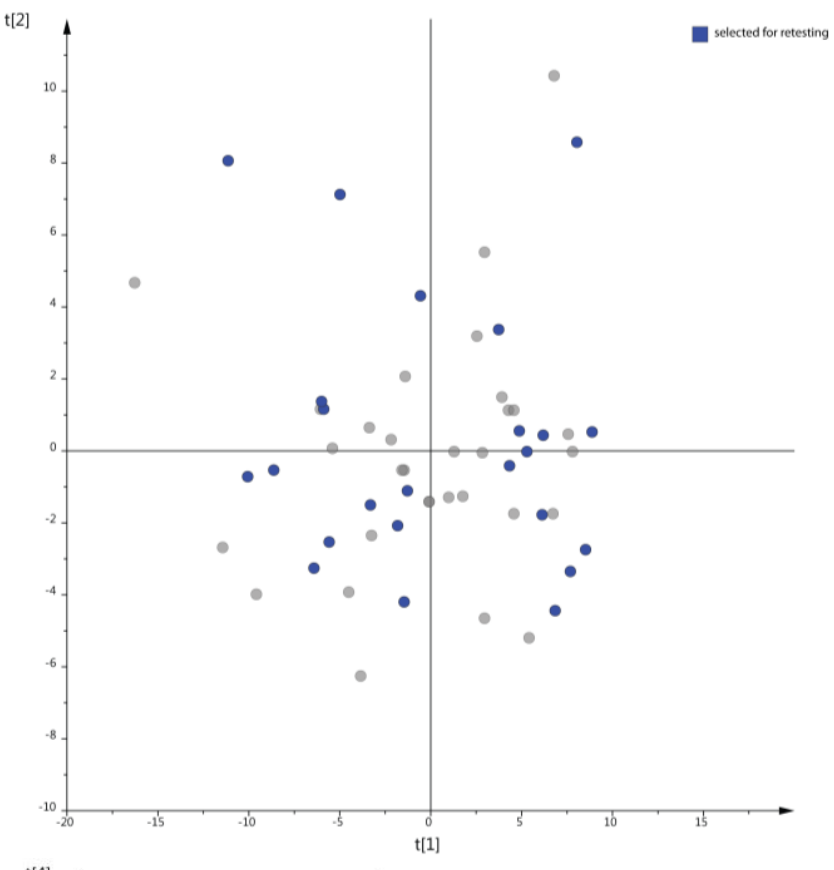

b)

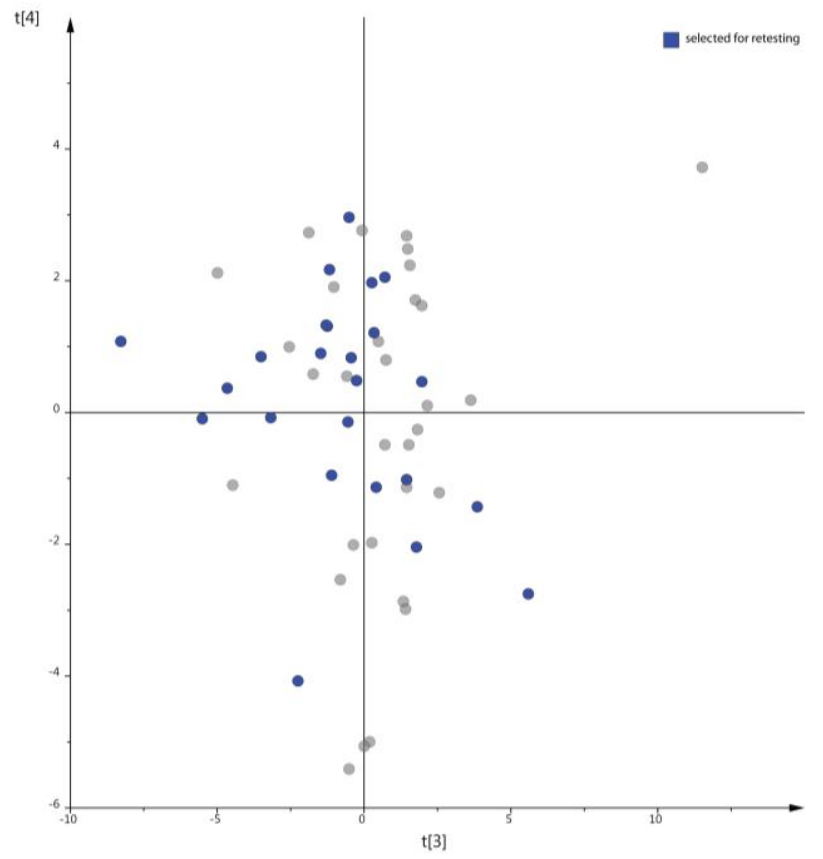

Figure S10. Chemical space of AChE1 hits showing $\geq 70 \%$ inhibition. Score plots from PCA of the physicochemical properties of the 55 hits showing at least $70 \%$ inhibition in the HTS, hits manually selected for $\mathrm{IC}_{50}$ determination colored in blue (set A). The first and second components describe the size and hydrophobicity of the hits (a) and the third and fourth components show diversity relating to flexibility and charge (b). 


\section{SUPPORTING INFORMATION}

a)

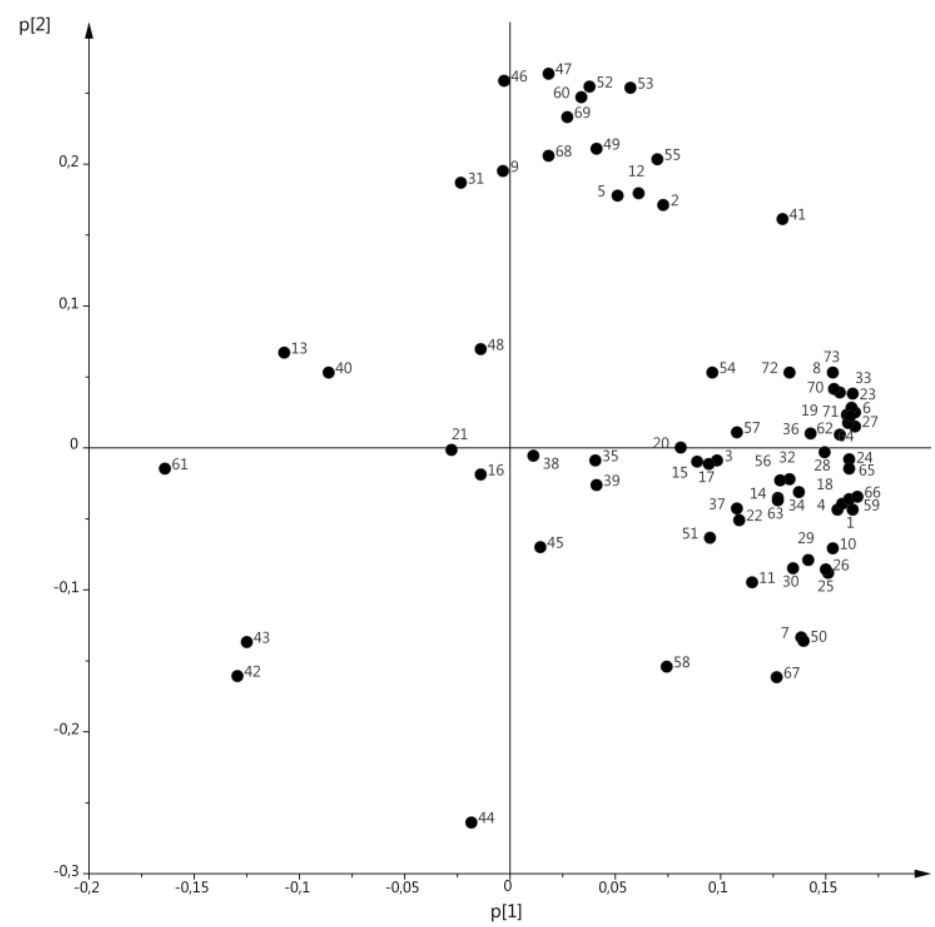

b)

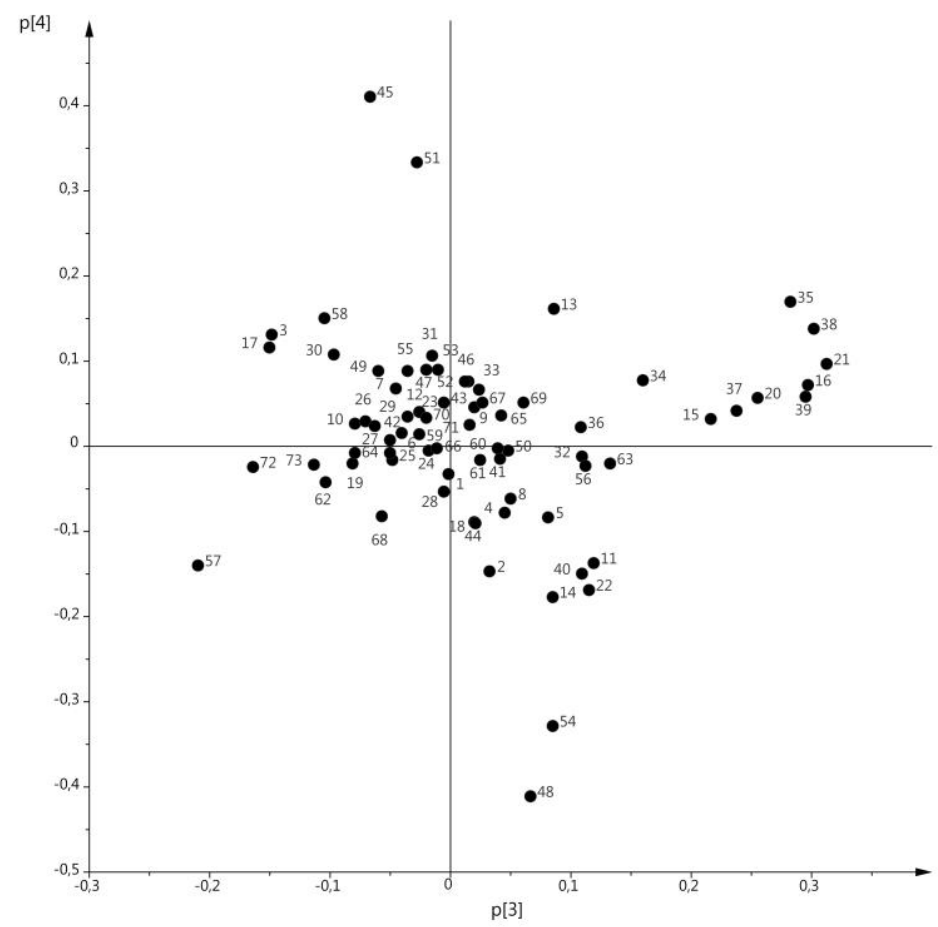

Figure S11. Chemical space of AChE1 hits showing $\geq 70 \%$ inhibition. PCA loading plots of (a) p1 versus p2 and (b) p3 versus p4. The physicochemical descriptors included in the model are labeled with the numbers assigned in Table S5. 
SUPPORTING INFORMATION

a)

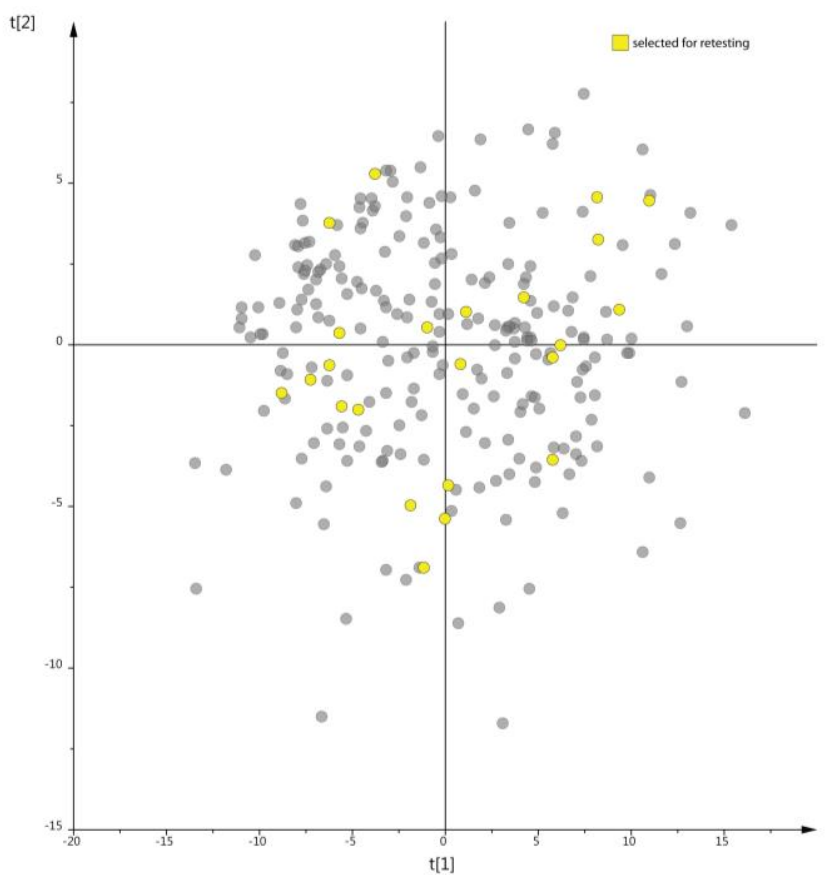

b)

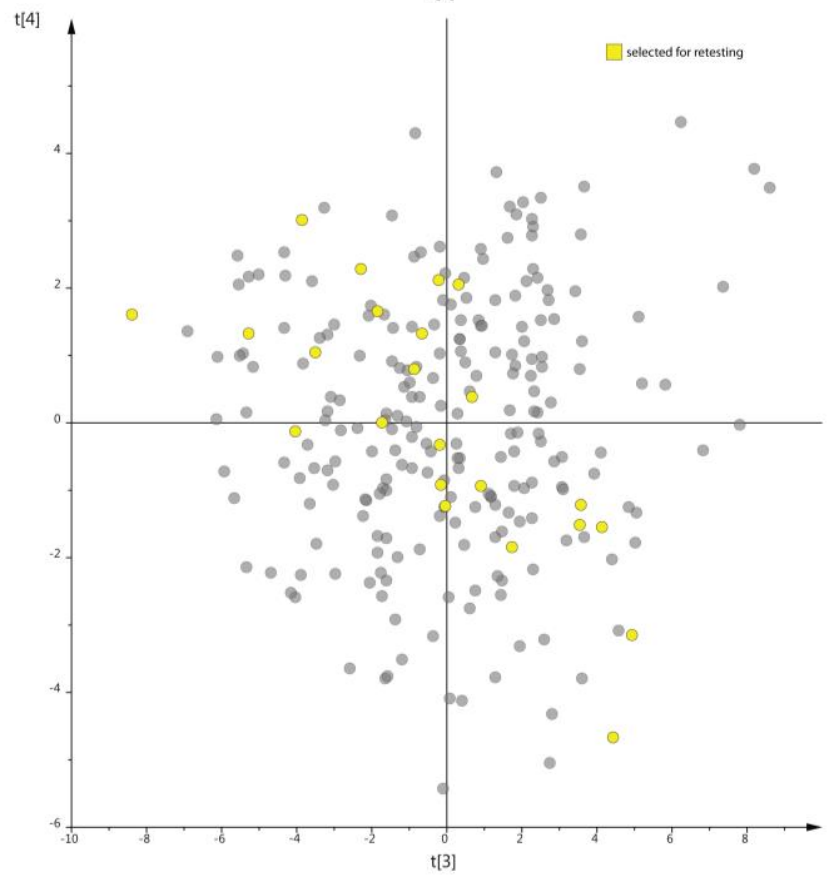

Figure S12. Chemical space of AChE1 hits showing 31-69\% inhibition. Score plots from PCA of the physicochemical properties of the 248 hits showing at least $31-69 \%$ inhibition in the HTS, hits manually selected for $\mathrm{IC}_{50}$ determination colored in yellow (set B). The first and second components describe the size and hydrophobicity of the hits (a) and the third and fourth components show diversity relating to flexibility and charge (b). 


\section{SUPPORTING INFORMATION}

a)

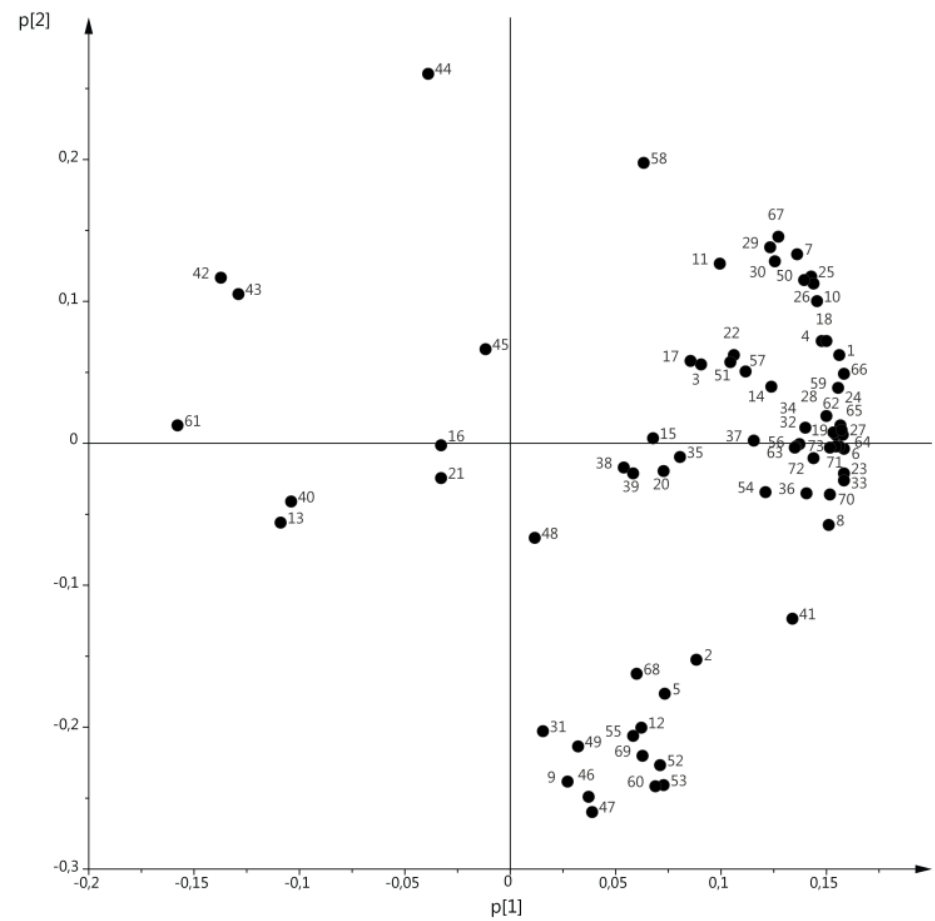

b)

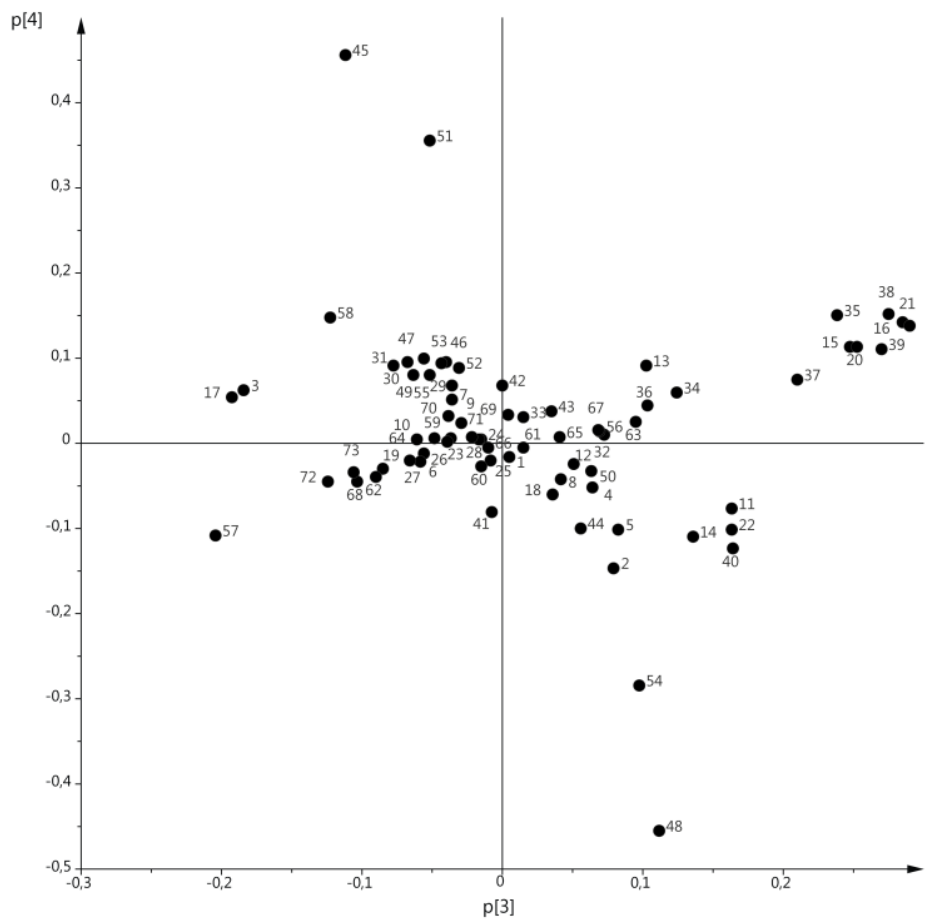

Figure S13. Chemical space of AChE1 hits showing 31-69\% inhibition. PCA loading plots of (a) p1 versus $\mathrm{p} 2$ and (b) p3 versus p4. The physicochemical descriptors included in the model are labeled with the numbers assigned in Table S5. 
SUPPORTING INFORMATION

a)

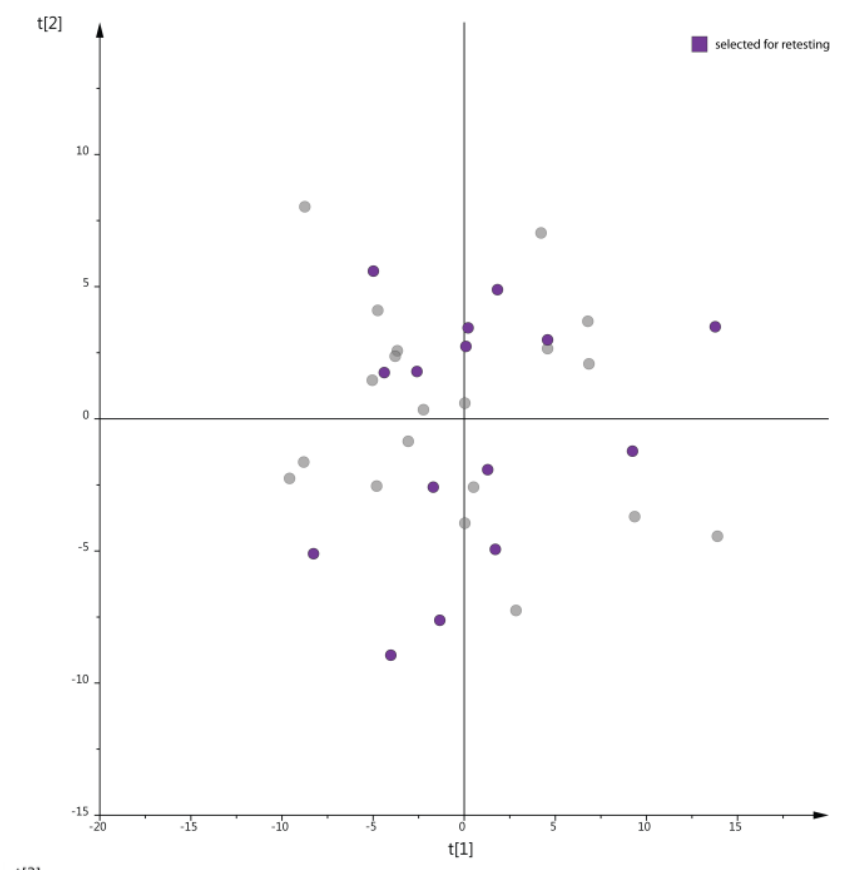

b)

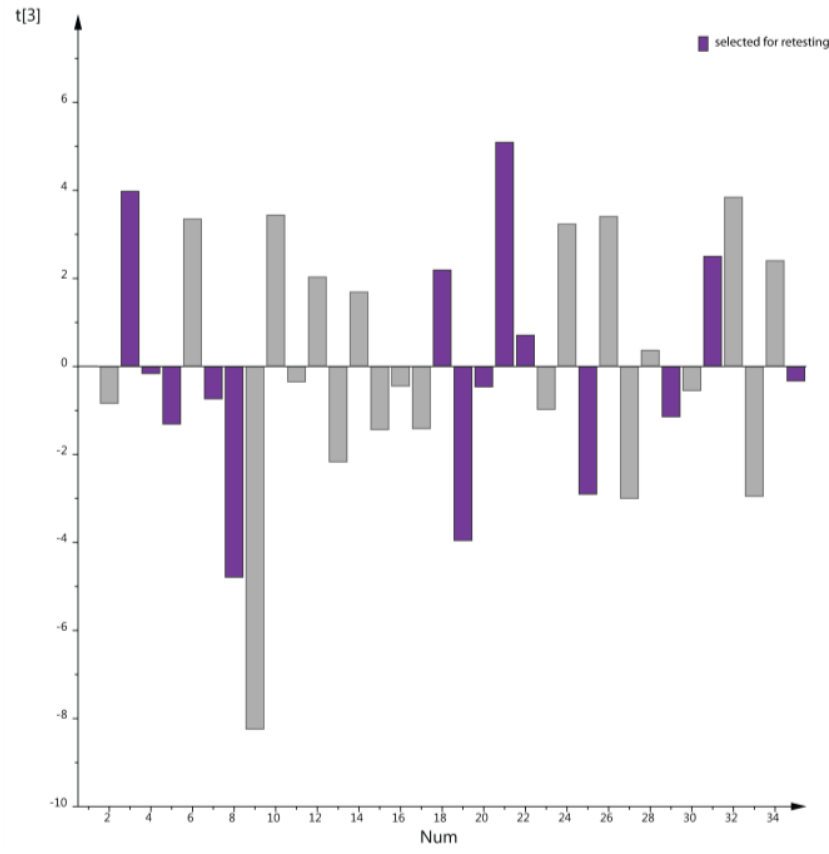

Figure S14. Chemical space of AChE1 hits showing $\geq 30 \%$ difference in inhibition between $A g$ and AaAChE1. PCA of the physicochemical properties of the 35 hits showing at least $30 \%$ difference in inhibition between $A a$ - and $A g A C h E 1$ in the HTS, hits manually selected for $\mathrm{IC}_{50}$ determination colored in purple (set D1 and D2). The first and second components describe the size and hydrophobicity of the hits (a) and the third component shows diversity relating to flexibility (b). 
SUPPORTING INFORMATION

a)

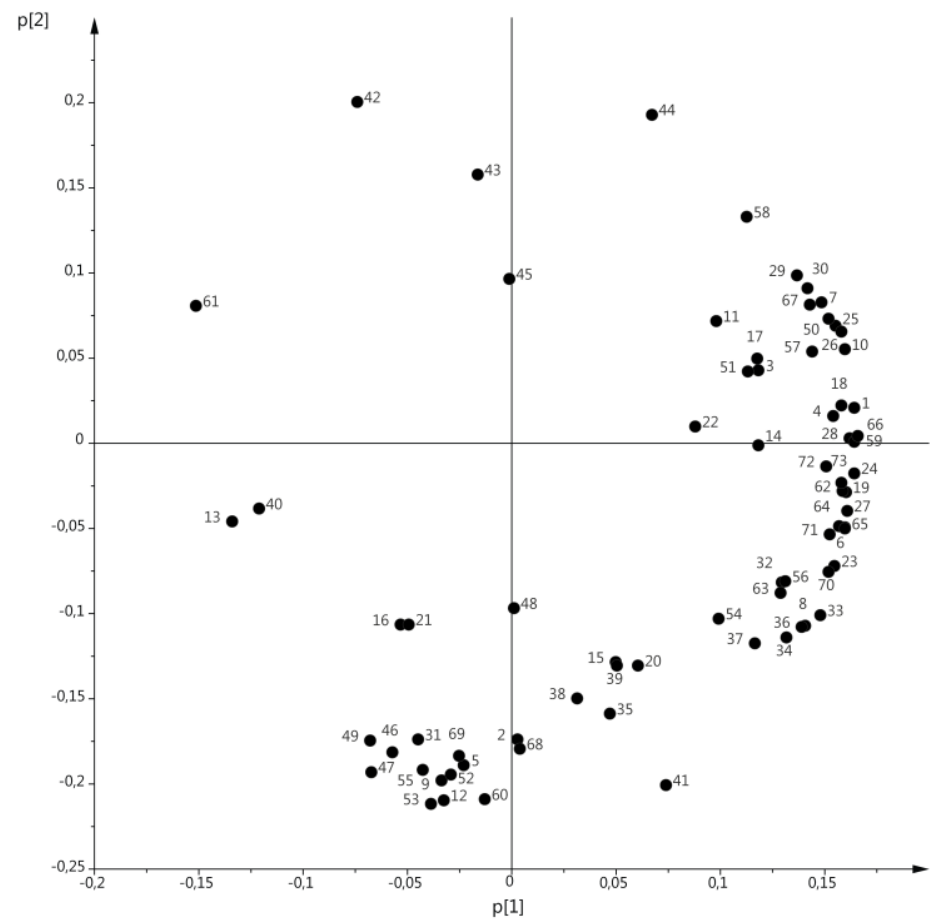

b)

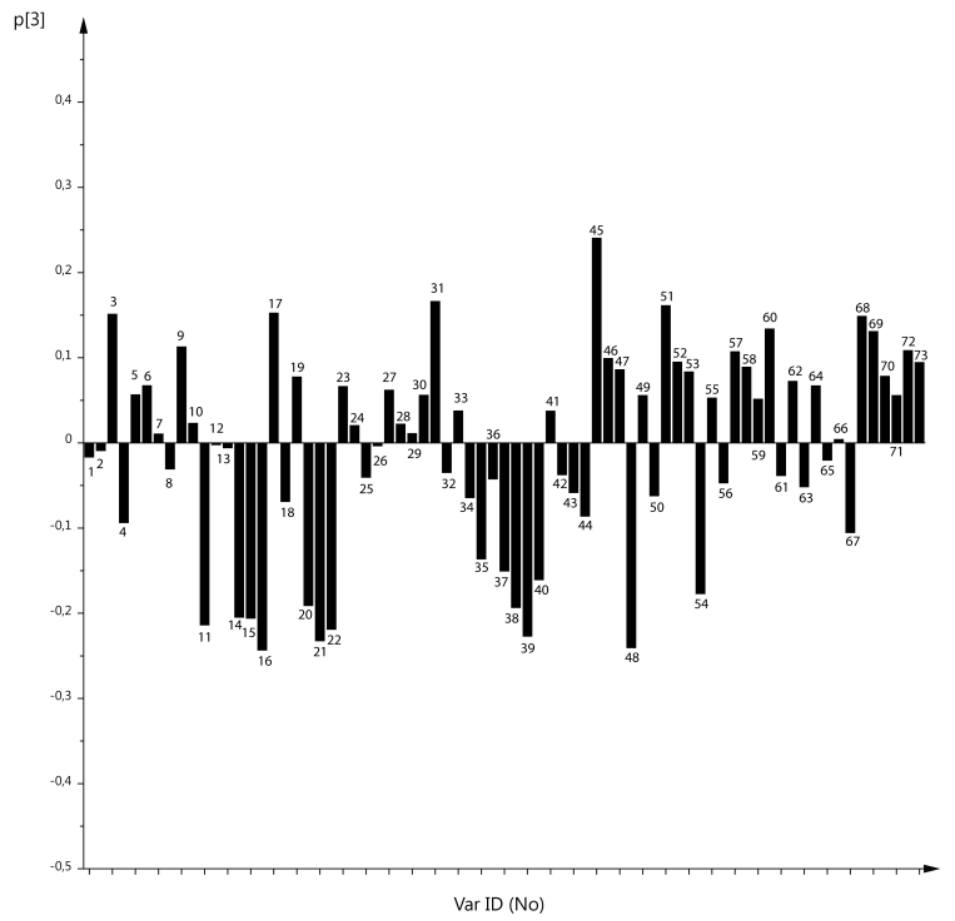

Figure S15. Chemical space of AChE1 hits showing $\geq 30 \%$ difference in inhibition between $\mathrm{Ag}$ and AaAChE1. PCA loading plots of (a) p1 versus p2 and (b) p3. The physicochemical descriptors included in the model are labeled with the numbers assigned in Table S5. 
SUPPORTING INFORMATION

a)

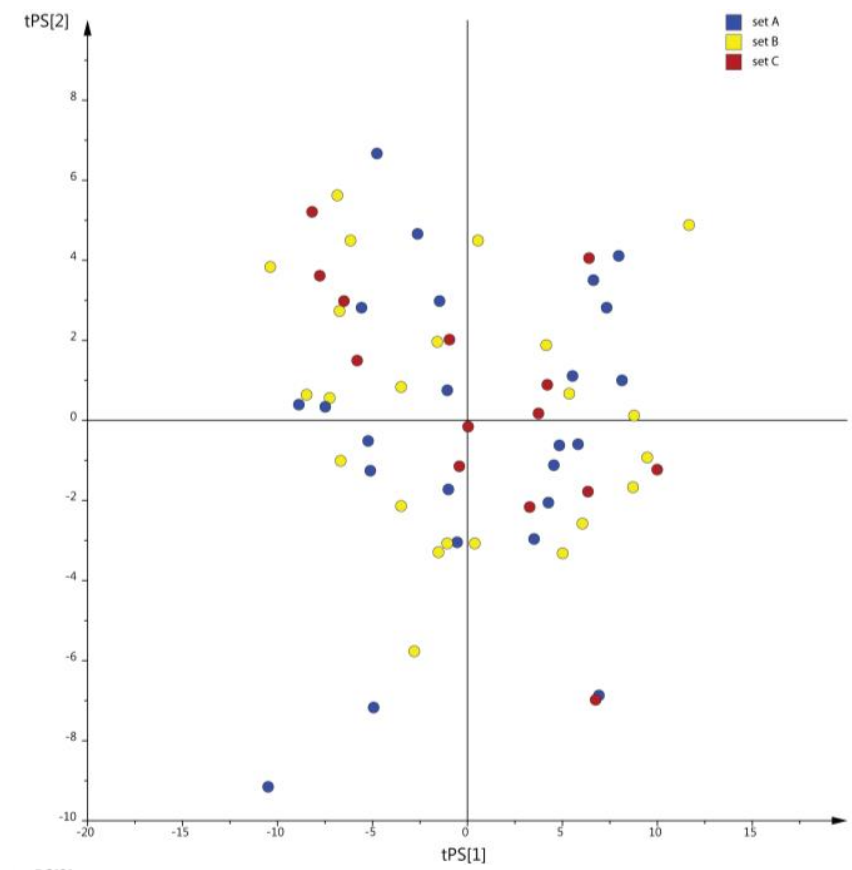

b)

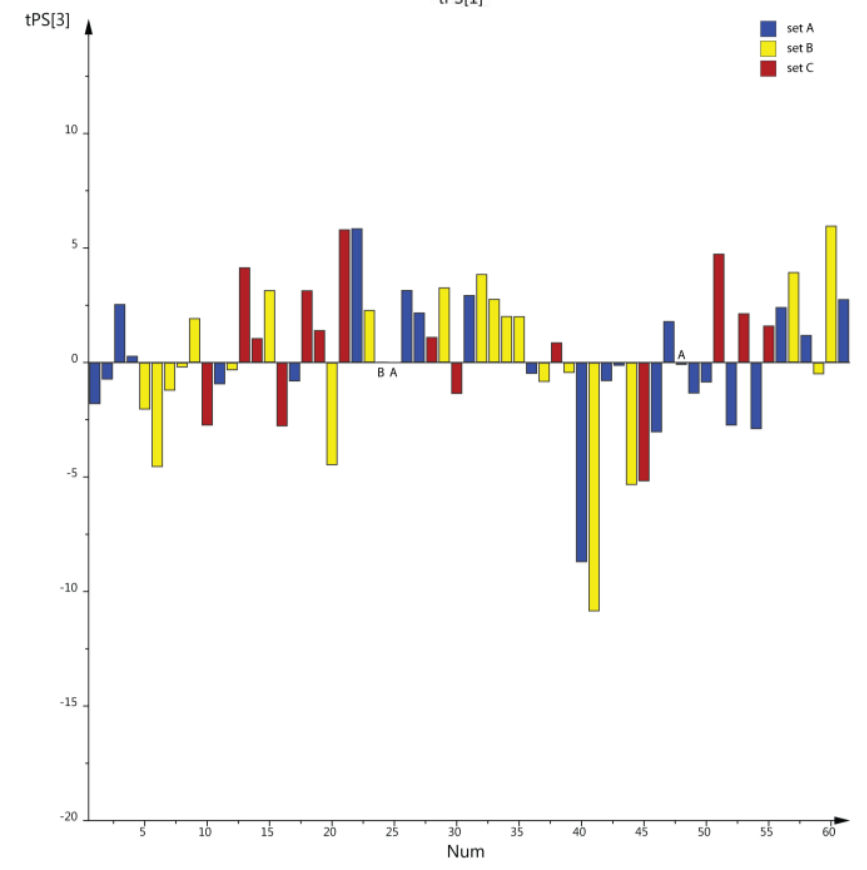

Figure S16. Chemical space of AChE1 hits in sets A and B. Score plots from PCA of the physicochemical properties of the 47 hits in sets A (blue) and B (yellow) selected for $\mathrm{IC}_{50}$ determinations. Compounds of set $\mathrm{C}(\leq 30 \%$ inhibition; red) were manually selected from compounds with similar structures and physicochemical properties as the compounds in set A and $\mathrm{B}$ and have here been projected into the chemical space. The first and second components describe the size and flexibility of the hits (a) and the third component shows diversity relating to polarity and charge (b). 


\section{SUPPORTING INFORMATION}

a)

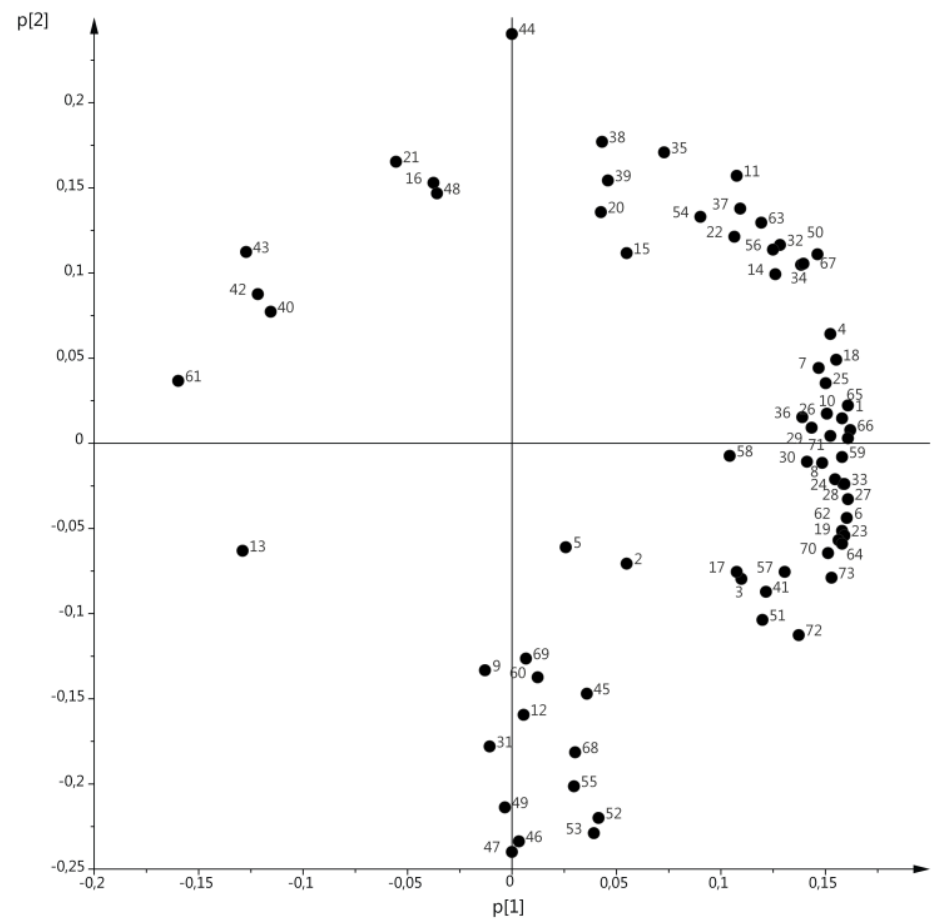

b)

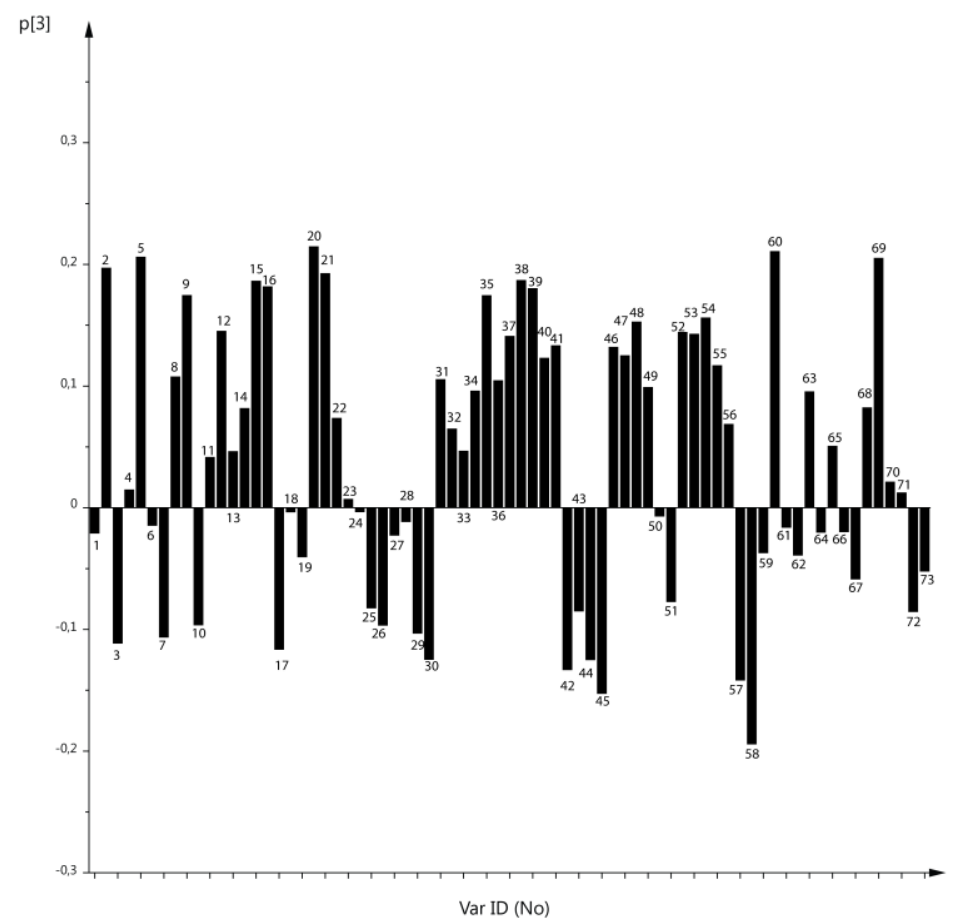

Figure S17. Chemical space of AChE1 hits in sets A and B. PCA loading plots of (a) p1 versus p2 and (b) p3. The physicochemical descriptors included in the model are labeled with the numbers assigned in Table S5. 


\section{SUPPORTING INFORMATION}

Complete inhibition results for all the re-tested compounds

Table S6. The complete inhibition results for all the re-tested compounds.

\begin{tabular}{|c|c|c|c|c|c|c|c|c|c|c|c|c|}
\hline \multirow[b]{2}{*}{ ID } & \multirow[b]{2}{*}{ set } & \multicolumn{3}{|c|}{ HTS (\%) } & \multicolumn{3}{|c|}{$\mathrm{IC}_{50}(\mu \mathrm{M})^{\mathrm{a}}$} & \multicolumn{3}{|c|}{$\%$ activity at $200 \mu \mathrm{M}^{\mathrm{b}}$} & \multicolumn{2}{|c|}{ S.R. } \\
\hline & & AgAChE1 & AaAChE1 & hAChEc & AgAChE1 & AaAChE1 & hAChE & AgAChE1 & AaAChE1 & hAChE & HTS $^{d}$ & $\mathrm{IC}_{50} \mathrm{e}$ \\
\hline 2 & A & 92 & 76 & 12 & 0.21 & 0.22 & 31 & & & & 6.3 & 141 \\
\hline 3 & $A$ & 86 & 90 & 33 & $>100$ & $>100$ & $>200$ & 50 & 49 & 71 & 2.6 & \\
\hline 4 & A & 94 & 93 & 56 & 8 & 9 & 5 & & & & 1.7 & 0.6 \\
\hline 5 & $A$ & 76 & 82 & -12 & $>1000$ & $>1000$ & $>1000$ & 84 & 91 & 78 & 76 & \\
\hline C0076 & A & 81 & 78 & -14 & $>1000$ & $>1000$ & $>1000$ & 87 & 96 & 92 & 78 & \\
\hline C0147 & $A$ & 94 & 95 & 2 & 0.7 & 0.8 & $>200$ & & & 45 & 47 & $>250$ \\
\hline C0656 & A & 69 & 79 & -1 & 2 & 2 & 80 & & & & 69 & 40 \\
\hline C0710 & A & 88 & 88 & 57 & 0.7 & 0.7 & 7 & & & & 1.5 & 10 \\
\hline C1457 & A & 87 & 89 & 66 & 0.4 & 0.3 & 5 & & & & 1.3 & 13 \\
\hline C2681 & A & 86 & 88 & -11 & 1 & 1 & $>1000$ & & & 88 & 86 & $>1000$ \\
\hline C2810 & A & 89 & 93 & 6 & 1 & 2 & $>200$ & & & 58 & 14.8 & $>100$ \\
\hline С3029 & A & 74 & 78 & -16 & 3 & 3 & $>1000$ & & & 80 & 74 & $>333$ \\
\hline C4127 & A & 92 & 96 & 85 & 0.4 & 0.4 & 3 & & & & 1.1 & 7.5 \\
\hline C4514 & A & 92 & 78 & -9 & 10 & 9 & $>200$ & & & 56 & 67 & $>20$ \\
\hline C4584 & A & 76 & 72 & 7 & 16 & 6 & $>1000$ & & & 91 & 10.3 & $>63$ \\
\hline C5063 & A & 91 & 81 & -11 & 2 & 1 & 72 & & & & 81 & 36 \\
\hline C5651 & A & 96 & 95 & 83 & 5 & 4 & 3 & & & & 1.1 & 0.6 \\
\hline C6233 & A & 86 & 82 & 28 & 86 & 66 & $>1000$ & & & 83 & 2.9 & $>12$ \\
\hline C6483 & $A$ & 86 & 89 & 9 & 4 & 4 & $>300$ & & & 84 & 9.6 & $>75$ \\
\hline C7066 & A & 74 & 78 & -17 & 6 & 3 & $>1000$ & & & 80 & 74 & $>167$ \\
\hline C8319 & A & 80 & 78 & 81 & 5 & 5 & 2 & & & & 1 & 0.4 \\
\hline C8405 & A & 92 & 88 & -3 & 1 & 1 & $>200$ & & & 65 & 88 & $>200$ \\
\hline C9464 & A & 86 & 90 & -1 & 4 & 3 & $>300$ & & & 71 & 86 & $>75$ \\
\hline C9940 & A & 61 & 72 & 17 & 2 & 2 & 10 & & & & 3.6 & 5 \\
\hline 6 & B & 23 & 38 & -7 & $>500$ & $>500$ & $>500$ & 80 & 86 & 81 & 23 & \\
\hline 7 & B & 32 & 33 & 3 & 17 & 12 & $>200$ & & & 58 & 11 & $>12$ \\
\hline C0269 & B & 48 & 49 & -4 & 9 & 9 & $>1000$ & & & 86 & 48 & $>111$ \\
\hline C1687 & B & 13 & 36 & 57 & $>200$ & $>200$ & 19 & 54 & 49 & & 0.2 & $<0.1$ \\
\hline C1815 & B & 22 & 48 & 70 & n.d. & n.d. & n.d. & & & & 0.3 & \\
\hline C1844 & B & 34 & 37 & 31 & 7 & 6 & 13 & & & & 1.1 & 2 \\
\hline C2599 & B & 46 & 58 & -5 & 22 & 19 & $>400$ & & & 58 & 46 & $>18$ \\
\hline C2972 & B & 66 & 63 & -2 & 9 & 9 & $>1000$ & & & 68 & 63 & $>111$ \\
\hline C3732 & B & 24 & 43 & 3 & 11 & 12 & 129 & & & & 8 & 11 \\
\hline C3922 & B & 56 & 0 & 15 & $>300$ & $>300$ & $>300$ & 72 & 54 & 63 & 3.7 & \\
\hline C4233 & B & 47 & 30 & 37 & $>1000$ & $>1000$ & $>1000$ & 70 & 79 & 63 & 0.8 & \\
\hline C4790 & B & 44 & 50 & 1 & n.d. & n.d. & n.d. & & & & 44 & \\
\hline
\end{tabular}




\section{SUPPORTING INFORMATION}

Table S6. Continued.

\begin{tabular}{|c|c|c|c|c|c|c|c|c|c|c|c|c|}
\hline \multirow[b]{2}{*}{ ID } & \multirow[b]{2}{*}{ set } & \multicolumn{3}{|c|}{ HTS (\%) } & \multicolumn{3}{|c|}{$\mathrm{IC}_{50}(\mu \mathrm{M})^{\mathrm{a}}$} & \multicolumn{3}{|c|}{$\%$ activity at $200 \mu \mathrm{M}^{\mathrm{b}}$} & \multicolumn{2}{|c|}{ S.R. } \\
\hline & & AgAChE1 & AaAChE1 & hAChEc & AgAChE1 & AaAChE1 & hAChE & AgAChE1 & AaAChE1 & hAChE & HTS $^{d}$ & ${ }^{\prime} C_{50}{ }^{\mathrm{e}}$ \\
\hline C5737 & B & 65 & 67 & 0 & 5 & 6 & $>100$ & & & 48 & 65 & $>17$ \\
\hline C6103 & B & 46 & 51 & 22 & 6 & 5 & $>100$ & & & 45 & 2.1 & $>17$ \\
\hline C6176 & B & 57 & 66 & 81 & 8 & 10 & 12 & & & & 0.7 & 1 \\
\hline C6727 & B & 53 & 53 & -5 & 7 & 4 & $>100$ & & & 40 & 53 & $>14$ \\
\hline C7129 & B & 47 & 56 & 6 & 11 & 11 & $>500$ & & & 80 & 7.8 & $>45$ \\
\hline C7786 & B & 39 & 45 & 18 & 5 & 6 & $>300$ & & & 55 & 2.2 & $>50$ \\
\hline C7920 & B & 37 & 41 & 6 & $>400$ & $>400$ & $>400$ & 62 & 59 & 79 & 6.2 & \\
\hline C7951 & B & 58 & 53 & 32 & n.d. & n.d. & n.d. & & & & 1.7 & \\
\hline C8584 & B & 34 & 25 & 10 & n.d. & n.d. & n.d. & & & & 2.5 & \\
\hline C8678 & B & 41 & 57 & 19 & $>1000$ & $>1000$ & $>1000$ & 91 & 83 & 98 & 2.2 & \\
\hline C9503 & B & 57 & 69 & 12 & 2 & 2 & 47 & & & & 4.8 & 24 \\
\hline 8 & C & 24 & 18 & 2 & 21 & 19 & 43 & & & & 9 & 2 \\
\hline C0459 & C & 3 & 8 & -33 & $>1000$ & $>500$ & $>500$ & 94 & 61 & 73 & 3 & \\
\hline $\mathrm{C} 0890$ & C & 5 & -5 & 90 & $>1000$ & $>1000$ & $>1000$ & 109 & 101 & 96 & 0 & \\
\hline C1234 & C & 1 & 8 & 84 & $>1000$ & $>1000$ & $>100$ & 97 & 114 & 45 & 0 & \\
\hline C1409 & C & 4 & 13 & -28 & 69 & 54 & $>1000$ & 41 & 37 & 81 & 4 & 14 \\
\hline C3666 & C & 10 & 5 & 0 & $>1000$ & $>1000$ & $>200$ & 86 & 76 & 54 & 5 & \\
\hline C4098 & C & -10 & -11 & 84 & $>1000$ & $>1000$ & $>100$ & 62 & 94 & 44 & 0 & \\
\hline C5156 & C & -21 & -10 & 95 & 11 & 12 & 0.6 & & & & 0 & 0.05 \\
\hline C5504 & C & 2 & -3 & -20 & n.d. & n.d. & n.d. & & & & 1 & \\
\hline C7422 & C & 16 & 25 & -3 & 73 & 128 & $>600$ & & & 70 & 16 & $>5$ \\
\hline C8086 & C & 6 & 13 & 20 & $>100$ & $>100$ & $>500$ & 47 & 43 & 79 & 0.3 & \\
\hline C9083 & C & -1 & -1 & -6 & n.d. & n.d. & n.d. & & & & 1 & \\
\hline C9395 & C & 0 & -9 & -15 & $>1000$ & $>1000$ & $>1000$ & 102 & 98 & 93 & 1 & \\
\hline C9657 & $C$ & 2 & 2 & 3 & $>1000$ & $>1000$ & $>200$ & 85 & 86 & 58 & 0.7 & \\
\hline 9 & D1 & 63 & 1 & -14 & $>1000$ & $>1000$ & $>1000$ & 92 & 105 & 86 & 1 & \\
\hline $\mathrm{C} 0273$ & D1 & 45 & -1 & -11 & $>1000$ & $>1000$ & $>1000$ & 88 & 87 & 77 & 1 & \\
\hline C1183 & D1 & 52 & -4 & 43 & $>1000$ & $>1000$ & $>1000$ & 97 & 97 & 70 & 0 & \\
\hline C1301 & D1 & 48 & 0 & 11 & $>1000$ & $>1000$ & $>1000$ & 103 & 100 & 86 & 0.1 & \\
\hline C1647 & D1 & 58 & 2 & -23 & $>1000$ & $>1000$ & $>1000$ & 86 & 91 & 89 & 2 & \\
\hline C2956 & D1 & 53 & -5 & -1 & $>1000$ & $>1000$ & $>1000$ & 102 & 116 & 99 & 1 & \\
\hline C5320 & D1 & 42 & -3 & 11 & $>1000$ & $>1000$ & $>1000$ & 103 & 106 & 97 & 0.1 & \\
\hline C7765 & D1 & 40 & 2 & 8 & $>1000$ & $>1000$ & $>1000$ & 99 & 94 & 65 & 0.3 & \\
\hline C9077 & D1 & 37 & 0 & 35 & $>1000$ & $>1000$ & $>1000$ & 101 & 116 & 103 & 0 & \\
\hline 10 & D2 & 41 & 80 & 15 & 3 & 3 & $>200$ & & & 55 & 2.7 & $>67$ \\
\hline C0552 & D2 & -27 & 77 & 2 & 3 & 2 & $>100$ & & & 41 & 0.5 & $>33$ \\
\hline C0576 & $\mathrm{D} 2$ & -2 & 54 & 12 & $>1000$ & $>1000$ & $>1000$ & 104 & 115 & 94 & 0.1 & \\
\hline
\end{tabular}




\section{SUPPORTING INFORMATION}

Table S6. Continued.

\begin{tabular}{|c|c|c|c|c|c|c|c|c|c|c|c|c|}
\hline & & \multicolumn{3}{|c|}{ HTS (\%) } & \multicolumn{3}{|c|}{$\mathrm{IC}_{50}(\mu \mathrm{M})^{\mathrm{a}}$} & \multicolumn{3}{|c|}{$\%$ activity at $200 \mu \mathrm{M}^{\mathrm{b}}$} & \multicolumn{2}{|c|}{ S.R. } \\
\hline ID & set & AgAChE1 & AaAChE1 & $h \mathrm{AChE}^{\mathrm{c}}$ & AgAChE1 & AaAChE1 & hAChE & AgAChE1 & AaAChE1 & hAChE & HTS $^{d}$ & $\mathrm{IC}_{50} \mathrm{e}$ \\
\hline C4073 & D2 & -5 & 80 & 40 & n.d. & n.d. & n.d. & & & & 0 & \\
\hline C6303 & D2 & 17 & 47 & -16 & $>200$ & $>200$ & $>500$ & 69 & 58 & 87 & 17 & \\
\hline C9270 & D2 & -40 & 69 & 15 & n.d. & n.d. & n.d. & & & & 0.1 & \\
\hline 1 & & 93 & 91 & 99 & 0.26 & 0.44 & 0.030 & & & & 0.9 & 0.07 \\
\hline
\end{tabular}

${ }^{\mathrm{a}}$ Compounds denoted n.d. could not be determined due to poor solubility. ${ }^{\mathrm{b}}$ If the $\mathrm{IC}_{50}$ value could

not be determined from the used concentration range the enzyme activity at a compound

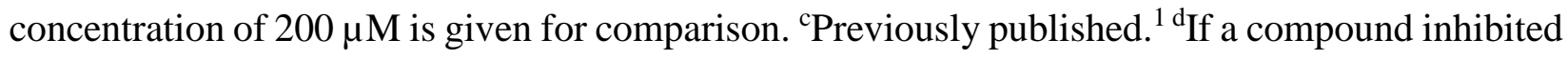
an enzyme by $\leq 0 \%$ in a HTS the inhibition was set to $1 \%$ prior to calculation. The selectivity ratios were computed by taking the lower of the compound's inhibition (\%) values against $A g \mathrm{AChE} 1 \mathrm{and}$ AaAChE1, and dividing by its inhibition (\%) value against $h \mathrm{AChE}$. ${ }^{\mathrm{S}}$ Selectivity ratios were computed by taking the compound's $\mathrm{IC}_{50}$ value against $h \mathrm{AChE}$ and dividing by the higher of its $\mathrm{IC}_{50}$ values against $A g \mathrm{AChE1}$ and $A a \mathrm{AChE} 1$. 


\section{Dose-response analyses for $\mathrm{IC}_{50}$ determinations}
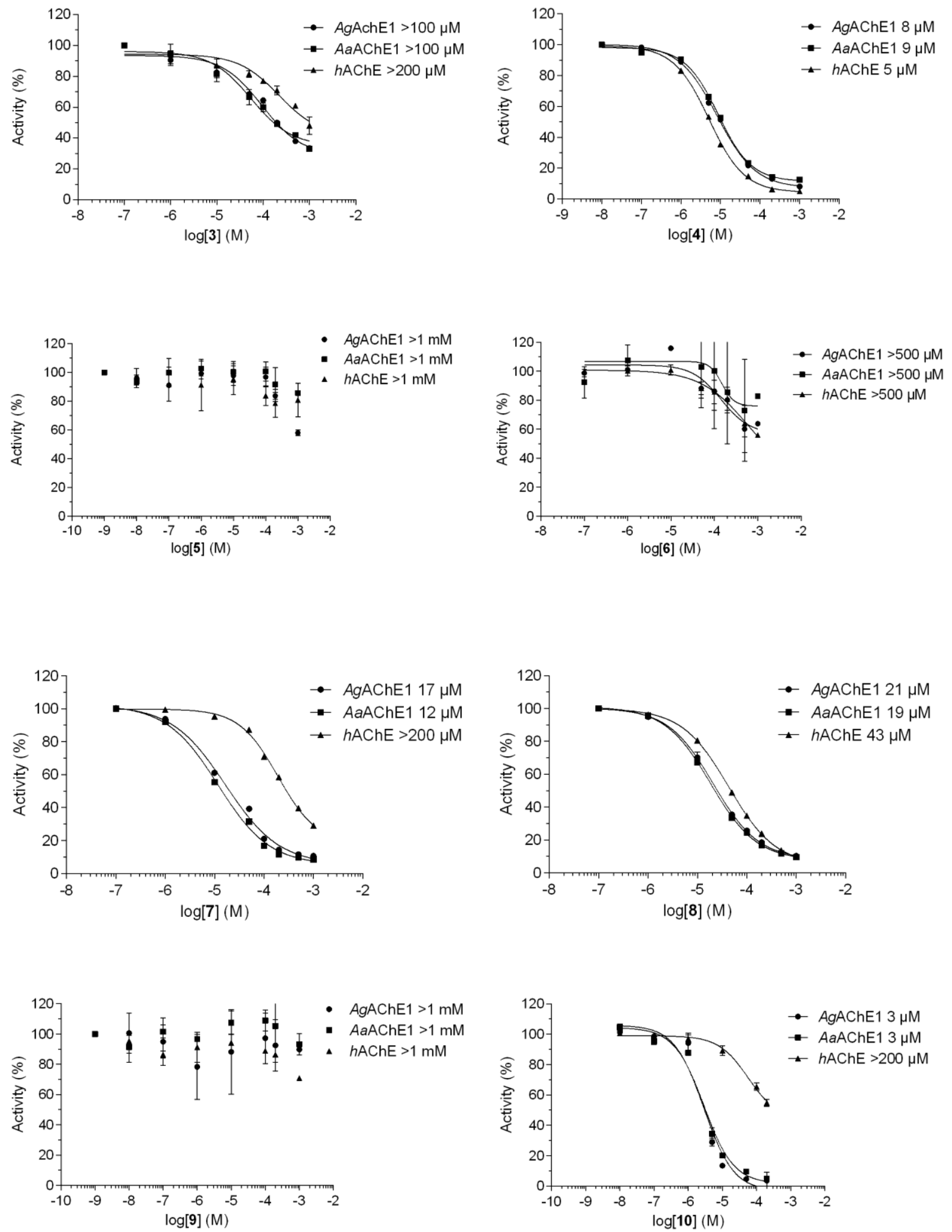

Figure S18. Graphs showing $I C_{50}$-determinations of compounds 3-10 in Table 2. 


\section{SUPPORTING INFORMATION}

OPLS-DA model of AChE1- and $h \mathrm{AChE}$ selective hits

Table S7. Model statistics of the refined OPLS-DA model used to separate variation in the physicochemical properties related to the difference between the AChE1- and $h \mathrm{AChE}$ selective hits.

\begin{tabular}{lc}
\hline No of hits & 157 \\
No of descriptors & 58 \\
No of components & $1+4$ \\
Eigenvalue of predictive component & 8.89 \\
Eigenvalue of last orthogonal component & 3.71 \\
$\mathrm{R}^{2} \mathrm{X}$ (cum) & 0.83 \\
$\mathrm{R}^{2} \mathrm{Y}$ (cum) & 0.52 \\
$\mathrm{Q}^{2}$ (cum) & 0.38 \\
\hline
\end{tabular}




\section{SUPPORTING INFORMATION}

Table S8. Physicochemical descriptors included in the refined OPLS-DA model.

\begin{tabular}{|c|c|c|c|c|c|c|c|}
\hline No. & Descriptor & $\begin{array}{c}\text { Equal } \\
\text { variance }^{\mathrm{a}}\end{array}$ & p-value ${ }^{b}$ & No. & Descriptor & $\begin{array}{c}\text { Equal } \\
\text { variance }^{\mathrm{a}}\end{array}$ & $p$-value ${ }^{b}$ \\
\hline 1 & a_aro & no & 0.0052 & 30 & PEOE_PC- & yes & 0.0033 \\
\hline 2 & a_heavy & yes & 0.00017 & 31 & PEOE_RPC+ & yes & 0.0027 \\
\hline 3 & a_IC & yes & 0.026 & 32 & PEOE_RPC- & no & $4.6 \times 10^{-5}$ \\
\hline 4 & a_ICM & yes & $6.0 \times 10^{-5}$ & 33 & PEOE_VSA_FHYD & yes & $7.3 \times 10^{-6}$ \\
\hline 5 & a_nC & yes & 0.037 & 34 & PEOE_VSA_FNEG & yes & 0.00033 \\
\hline 6 & a_nH & yes & 0.0011 & 35 & PEOE_VSA_FPNEG & yes & 0.00019 \\
\hline 7 & a_nO & yes & 0.00019 & 36 & PEOE_VSA_FPOL & yes & $7.3 \times 10^{-6}$ \\
\hline 8 & a_nS & yes & 0.028 & 37 & PEOE_VSA_FPOS & yes & 0.00033 \\
\hline 9 & bpol & yes & 0.066 & 38 & PEOE_VSA_FPPOS & yes & $7.8 \times 10-5$ \\
\hline 10 & b_1rotN & yes & 0.060 & 39 & PEOE_VSA_NEG & yes & $5.9 \times 10^{-5}$ \\
\hline 11 & b_1rotR & yes & 0.00012 & 40 & PEOE_VSA_PNEG & yes & 0.00017 \\
\hline 12 & b_ar & no & 0.0044 & 41 & PEOE_VSA_POL & yes & $1.3 \times 10^{-5}$ \\
\hline 13 & b_double & yes & $3.0 \times 10^{-8}$ & 42 & PEOE_VSA_PPOS & yes & $9.6 \times 10^{-5}$ \\
\hline 14 & b_heavy & yes & 0.00020 & 43 & rings & yes & 0.0027 \\
\hline 15 & b_max1len & yes & 0.063 & 44 & SlogP & yes & 0.0024 \\
\hline 16 & b_rotR & yes & 0.0023 & 45 & SMR & yes & 0.0032 \\
\hline 17 & b_single & yes & 0.032 & 46 & TPSA & yes & $2.8 \times 10^{-6}$ \\
\hline 18 & chiO & yes & $4.5 \times 10^{-5}$ & 47 & VAdjEq & no & $4.0 \times 10^{-5}$ \\
\hline 19 & chiOv & yes & 0.0017 & 48 & VAdjMa & no & $8.2 \times 10^{-5}$ \\
\hline 20 & chi1 & yes & 0.00043 & 49 & VDistMa & no & $2.7 \times 10^{-5}$ \\
\hline 21 & chi1v & yes & 0.032 & 50 & vdw_area & yes & 0.041 \\
\hline 22 & chi1_C & yes & 0.041 & 51 & vdw_vol & yes & 0.033 \\
\hline 23 & density & yes & $6.1 \times 10^{-6}$ & 52 & vsa_acc & yes & $6.5 \times 10^{-5}$ \\
\hline 24 & Kier1 & yes & 0.00022 & 53 & vsa_other & yes & $1.5 \times 10^{-9}$ \\
\hline 25 & KierA1 & yes & 0.066 & 54 & vsa_pol & yes & 0.00086 \\
\hline 26 & KierA3 & no & 0.011 & 55 & Weight & yes & 0.00016 \\
\hline 27 & KierFlex & yes & 0.028 & 56 & weinerPath & yes & 0.021 \\
\hline 28 & $\log S$ & yes & $3.2 \times 10^{-13}$ & 57 & weinerPol & yes & $3.0 \times 10^{-6}$ \\
\hline 29 & PEOE_PC+ & yes & 0.0033 & 58 & zagreb & yes & $3.6 \times 10^{-5}$ \\
\hline
\end{tabular}

${ }^{a}$ According to F-test for sample variance based on the sets of $h \mathrm{AChE}$ - and the AChE1 selective hits in the model $(\alpha=0.05)$. ${ }^{\mathrm{b}}$ According to Student's T-test (two-tailed with $\left.\alpha=0.05\right)$ assuming equal or unequal variance as decided by the F-test. 


\section{SUPPORTING INFORMATION}

a)

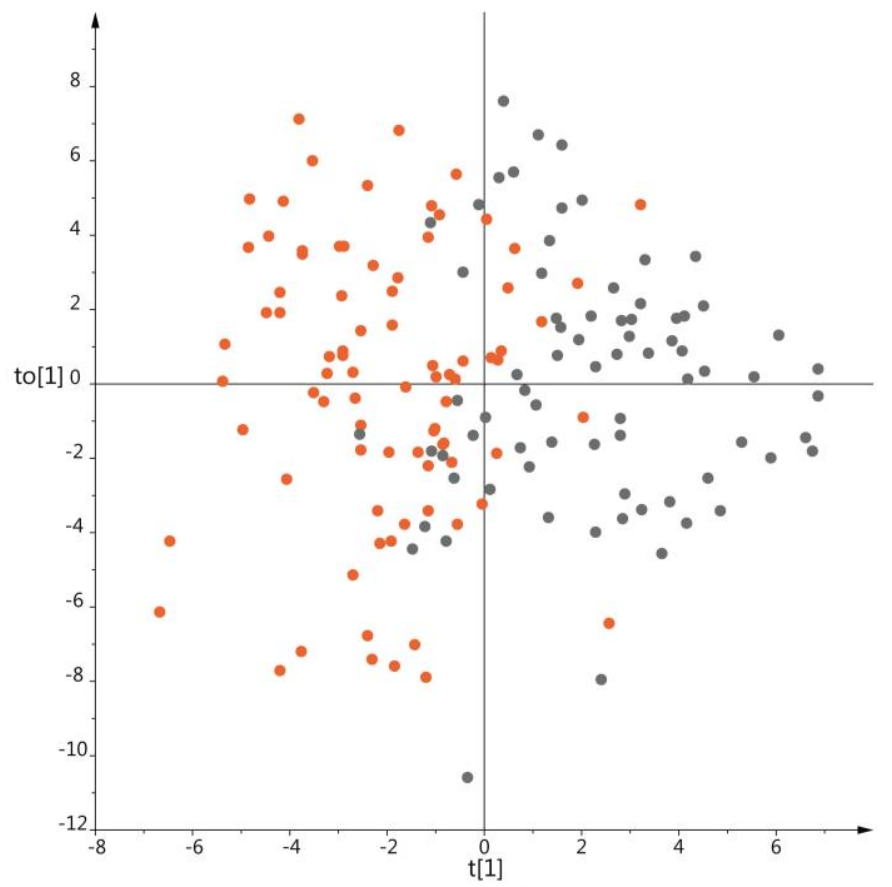

b)

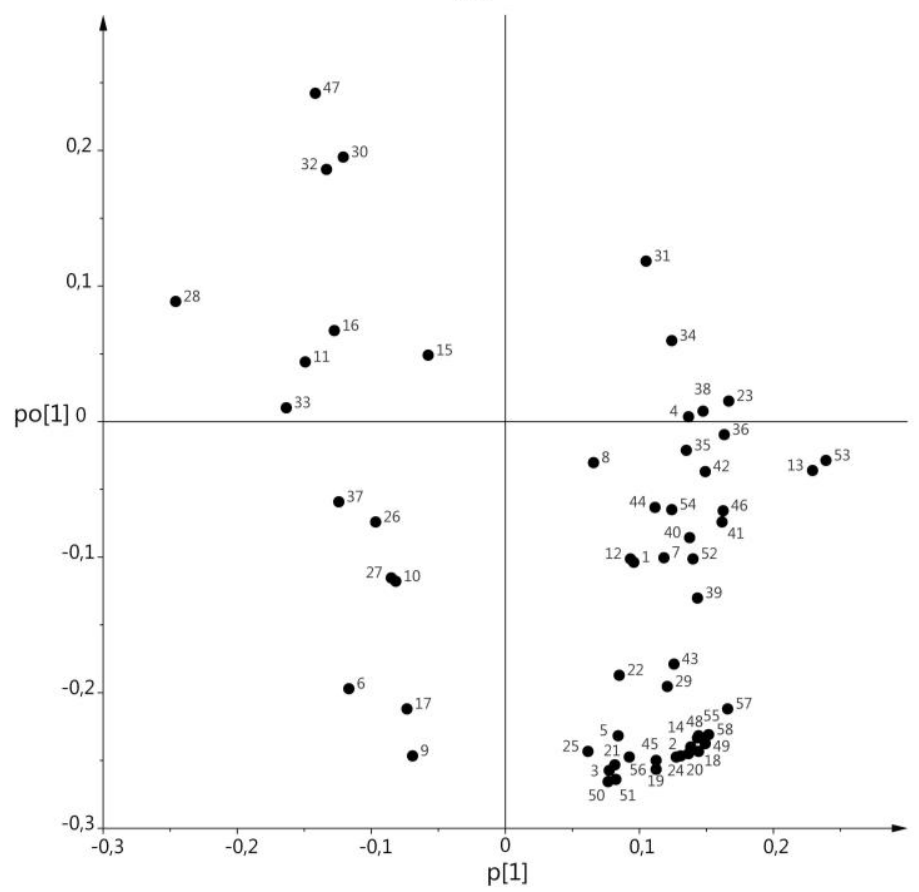

Figure S19. Score- and loading plot from the OPLS-DA model. a) Plot showing the score vectors of the predictive component (t[1]) vs. the first orthogonal component (to[1]). Hits showing potential selectivity for AChE1 and $h \mathrm{AChE}$ are shown as orange and grey dots, respectively. b) Plot showing the loading vectors of the predictive component $(\mathrm{p}[1])$ vs. the first orthogonal component (po[1]). The predictive component mainly show separation due to size and flexibility. 
NMR spectrum of compounds 3-10.

1-[3-(benzyloxy)-4-methoxybenzyl]-4-(4-fluorophenyl)-1,2,3,6-tetrahydropyridine $\quad(3) . \quad{ }^{1} \mathrm{H}$ NMR (400 MHz, $\left.\left(\mathrm{CD}_{3}\right)_{2} \mathrm{SO}\right)$; LC-MS (ES) calcd for $\mathrm{C}_{26} \mathrm{H}_{27} \mathrm{FNO}_{2}(\mathrm{M}+\mathrm{H})+404$, found 404

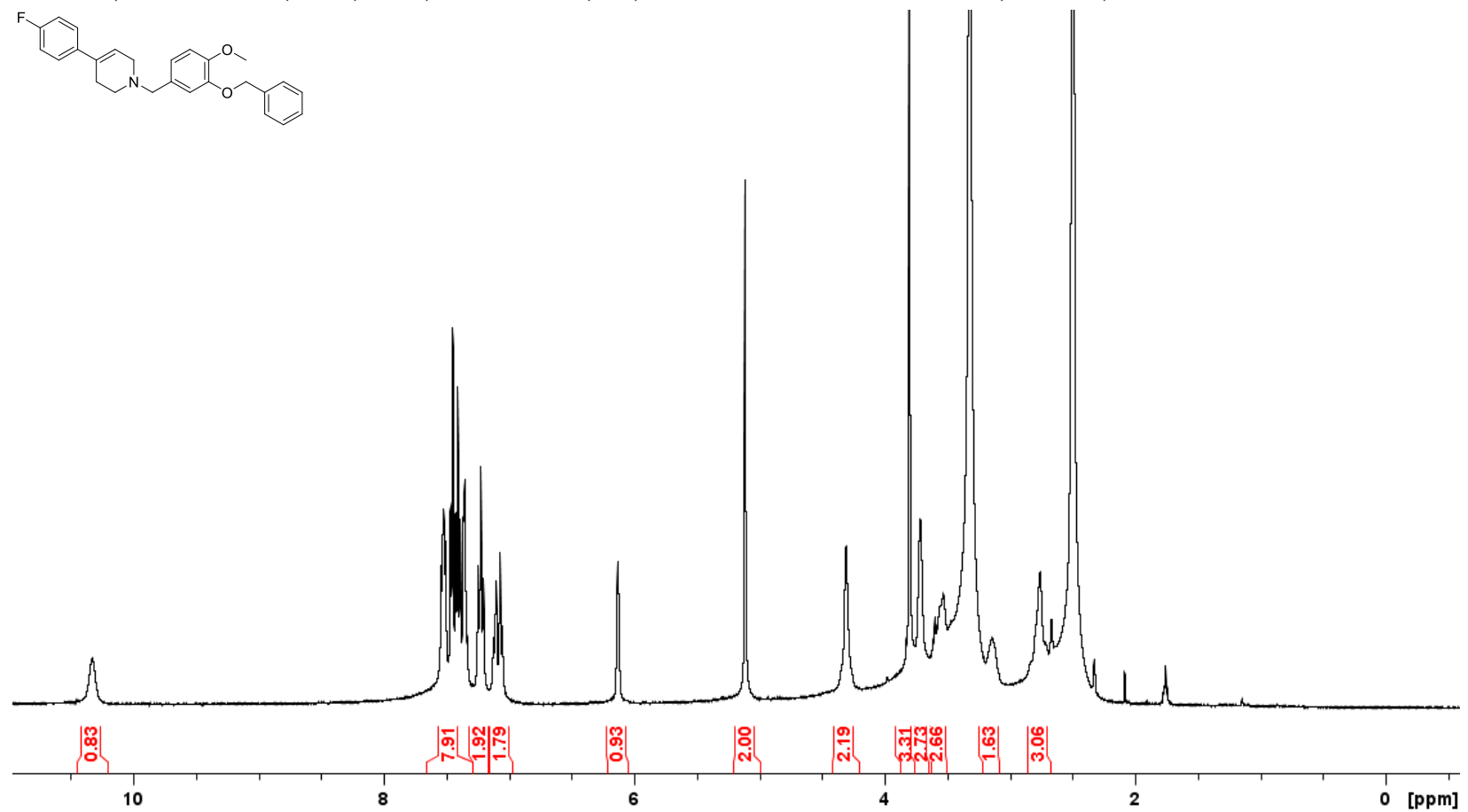

7-benzyl-2-(ethylthio)-3-phenyl-5,6,7,8-tetrahydropyrido[4',3':4,5]thieno[2,3-d]pyrimidin4(3H)-one (4). ${ }^{1} \mathrm{H} \mathrm{NMR}\left(400 \mathrm{MHz},\left(\mathrm{CD}_{3}\right)_{2} \mathrm{SO}\right)$; $\mathrm{LC}-\mathrm{MS}$ (ES) calcd for $\mathrm{C}_{24} \mathrm{H}_{24} \mathrm{~N}_{3} \mathrm{OS}_{2}(\mathrm{M}+\mathrm{H})+$ 435 , found 435
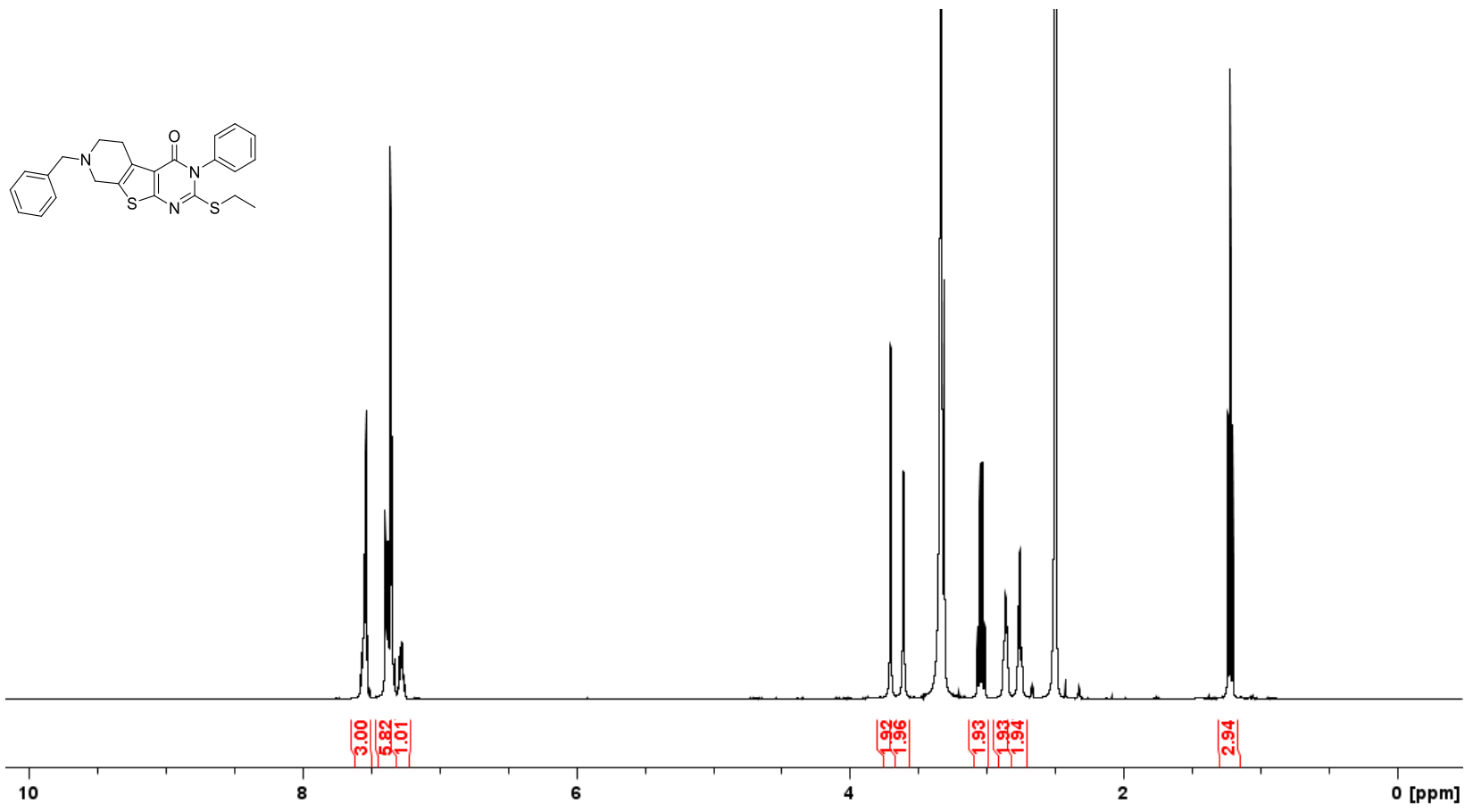
N-(2-\{[5-(2-furyl)-4-phenyl-4H-1,2,4-triazol-3-yl]thio\}ethyl)benzenesulfonamide $\quad$ (5). $\quad{ }^{1} \mathrm{H}$ NMR (400 MHz, $\left.\left(\mathrm{CD}_{3}\right)_{2} \mathrm{SO}\right)$; LC-MS calcd for $\mathrm{C}_{20} \mathrm{H}_{19} \mathrm{~N}_{4} \mathrm{O}_{3} \mathrm{~S}_{2}(\mathrm{M}+\mathrm{H})+428$, found 428

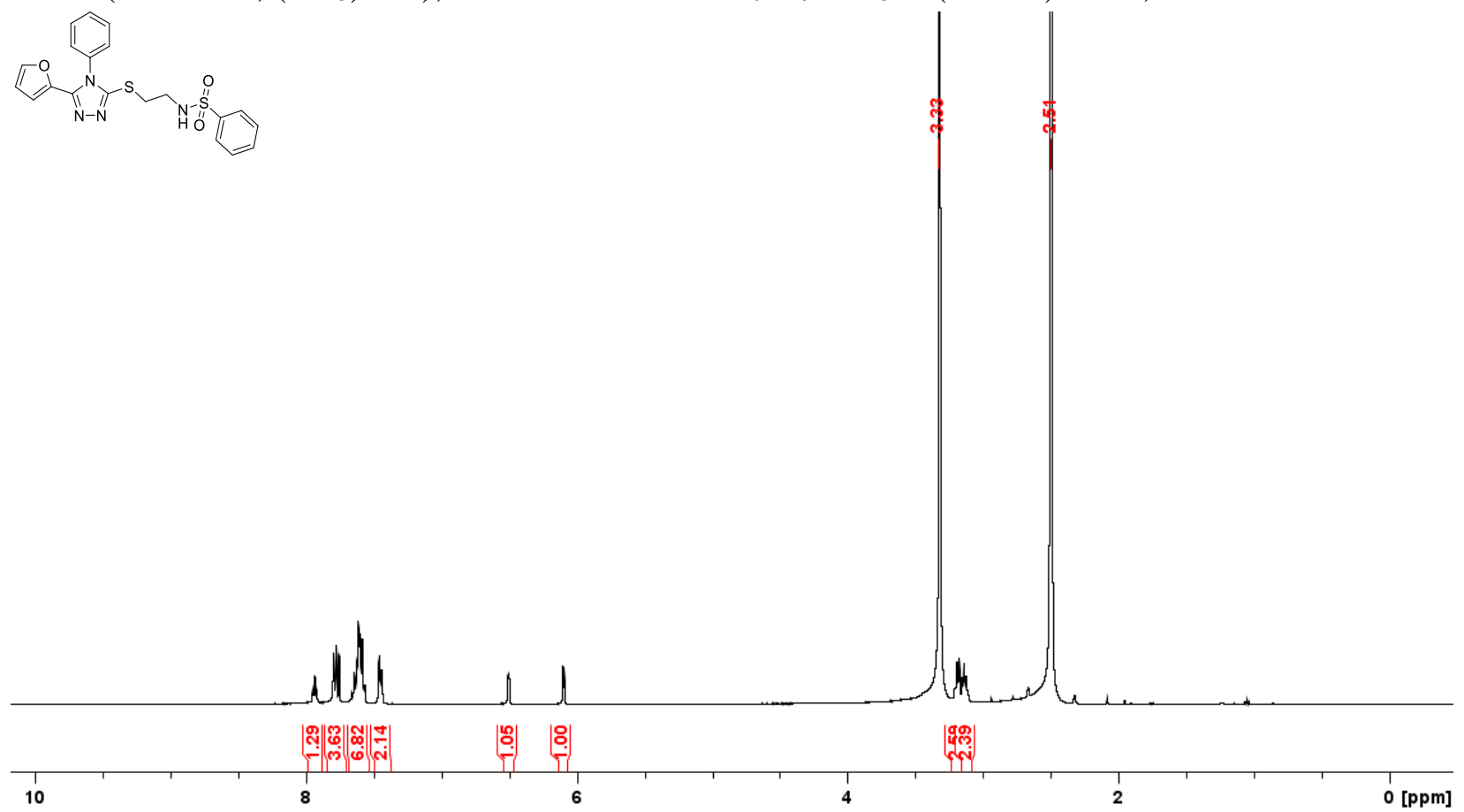

N-\{2-[(2-fluorobenzyl)oxy]benzyl\}-2-(4-morpholinyl)ethanamine dihydrochloride (6). ${ }^{1} \mathrm{H}$ NMR (400 MHz, $\left.\left(\mathrm{CD}_{3}\right)_{2} \mathrm{SO}\right)$; LC-MS calcd for $\mathrm{C}_{20} \mathrm{H}_{26} \mathrm{FN}_{2} \mathrm{O}_{2}(\mathrm{M}+\mathrm{H})+345$, found 345
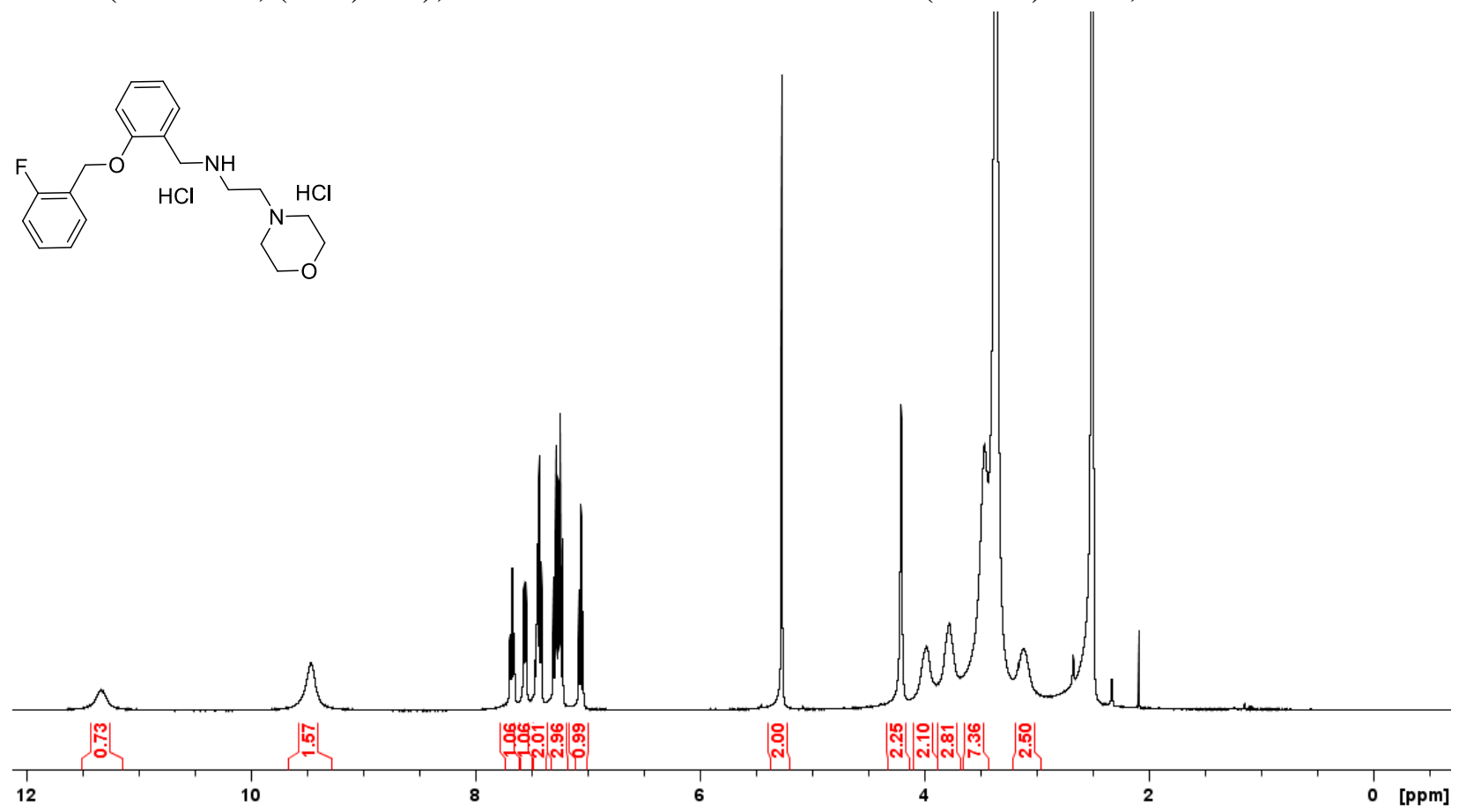
1-(1-benzyl-4-piperidinyl)-4-(2-fluorobenzoyl)piperazine (7). ${ }^{1} \mathrm{H} \mathrm{NMR}\left(400 \mathrm{MHz},\left(\mathrm{CD}_{3}\right)_{2} \mathrm{SO}\right.$, $328 \mathrm{~K})$; LC-MS calcd for $\mathrm{C}_{23} \mathrm{H}_{29} \mathrm{FN}_{3} \mathrm{O}(\mathrm{M}+\mathrm{H})+382$, found 382
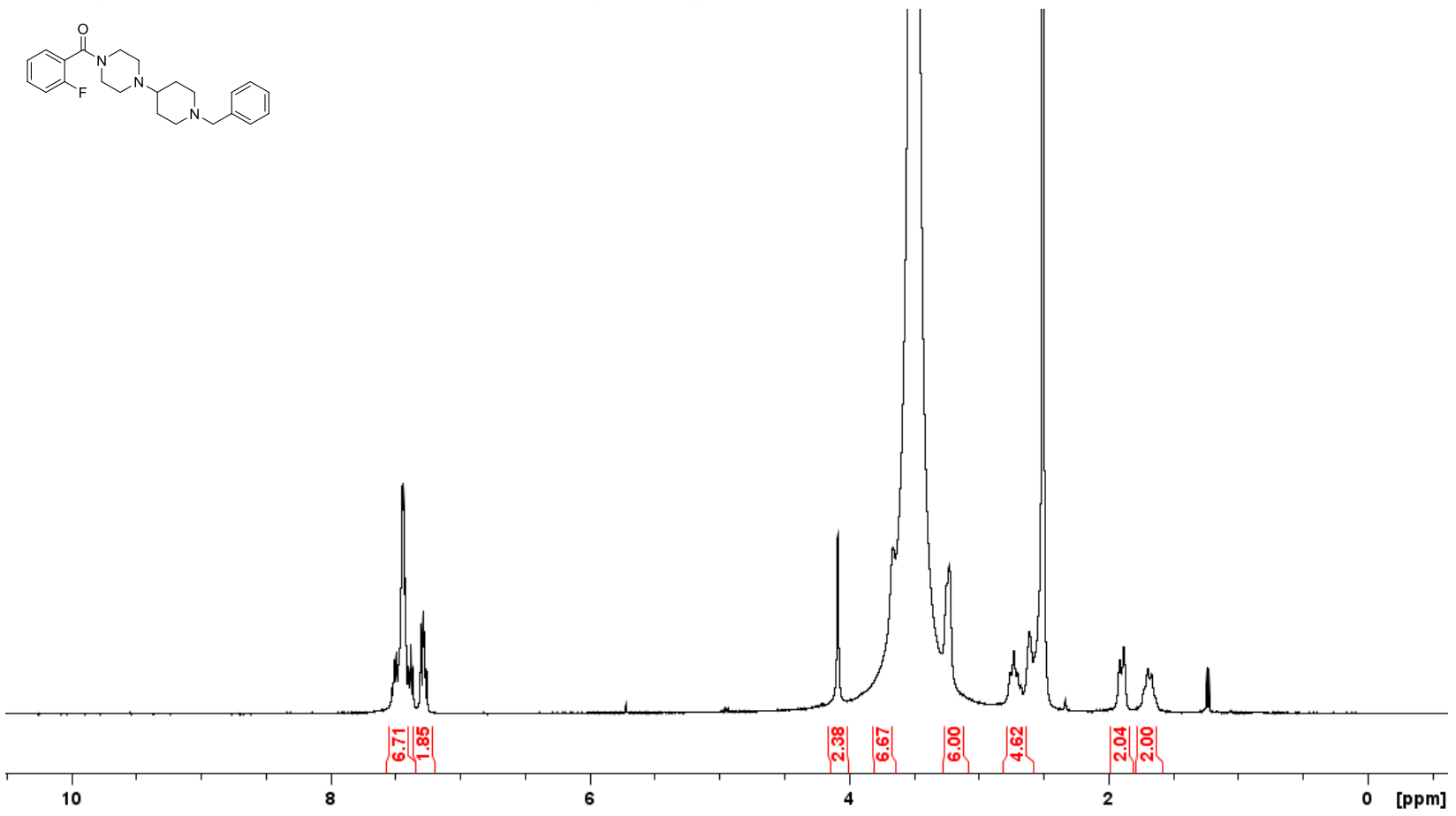

1-(1-benzyl-4-piperidinyl)-4-(phenoxyacetyl)piperazine (8). ${ }^{1} \mathrm{H}$ NMR $\left(400 \mathrm{MHz},\left(\mathrm{CD}_{3}\right)_{2} \mathrm{SO}\right.$, $328 \mathrm{~K})$; LC-MS calcd for $\mathrm{C}_{24} \mathrm{H}_{32} \mathrm{~N}_{3} \mathrm{O}_{2}(\mathrm{M}+\mathrm{H})+395$, found 395
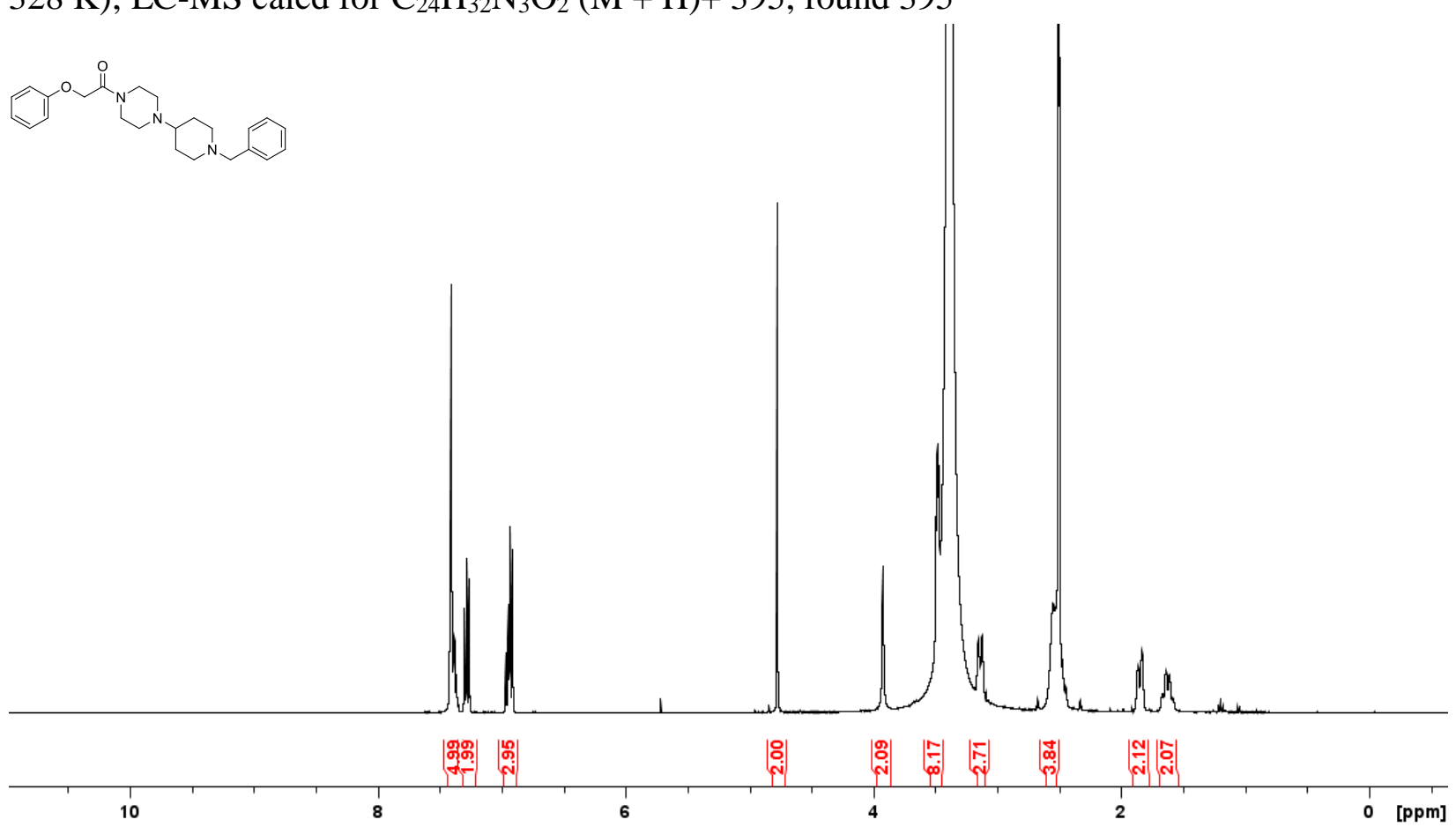
5-(\{[4-(4-ethoxyphenyl)-5-phenyl-4H-1,2,4-triazol-3-yl]thio\}methyl)-3-(2-methylphenyl)1,2,4-oxadiazole (9). ${ }^{1} \mathrm{H}$ NMR (400 MHz, $\left.\left(\mathrm{CD}_{3}\right)_{2} \mathrm{SO}\right)$; LC-MS calcd for $\mathrm{C}_{26} \mathrm{H}_{24} \mathrm{~N}_{5} \mathrm{O}_{2} \mathrm{~S}(\mathrm{M}+\mathrm{H})+$ 471 , found 471

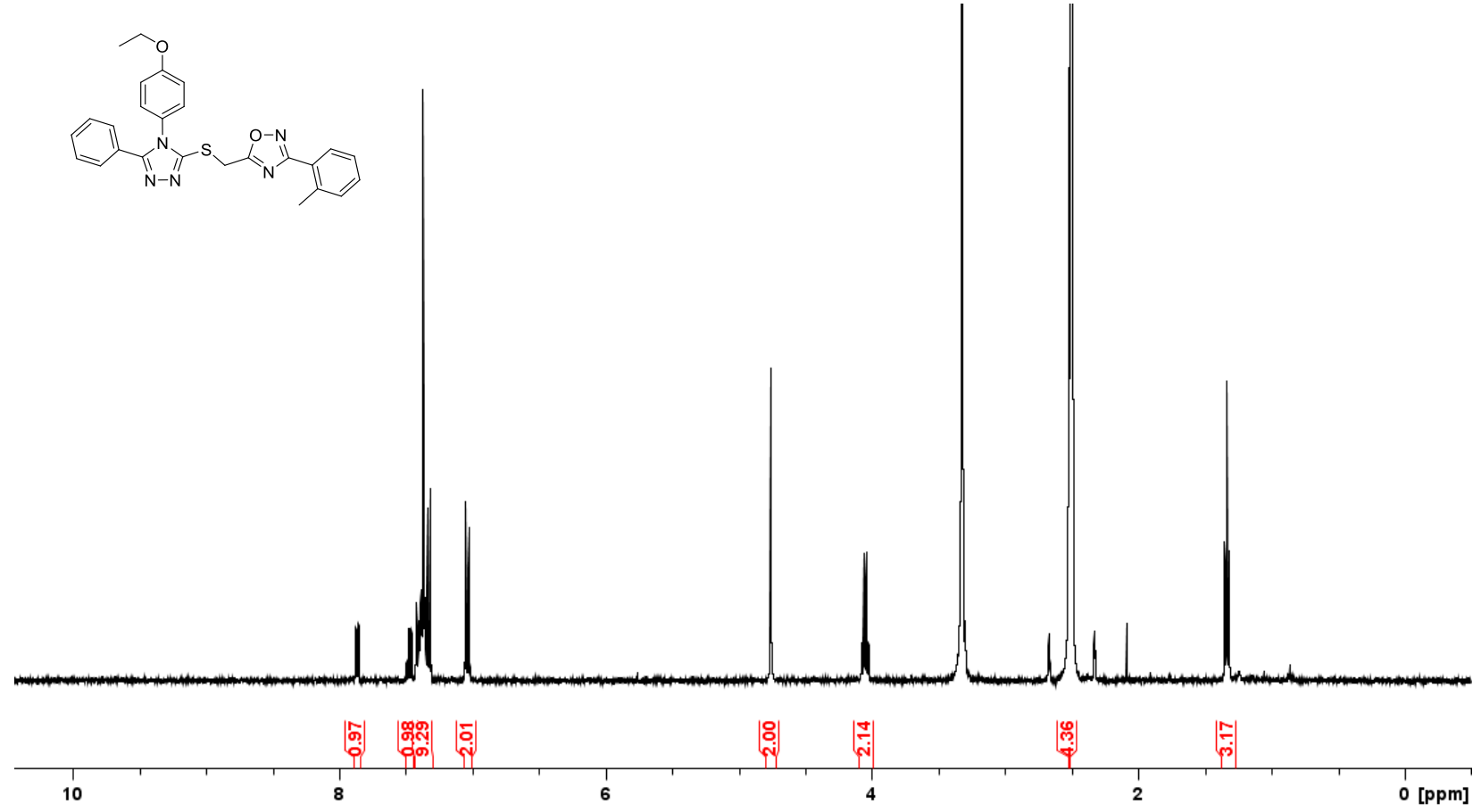

2-[4-(benzyloxy)benzyl]-1,2,3,4-tetrahydroisoquinoline (10). ${ }^{1} \mathrm{H}$ NMR (400 MHz, $\left.\left(\mathrm{CD}_{3}\right)_{2} \mathrm{SO}\right)$; LC-MS calcd for $\mathrm{C}_{23} \mathrm{H}_{24} \mathrm{NO}(\mathrm{M}+\mathrm{H})+330$, found 330

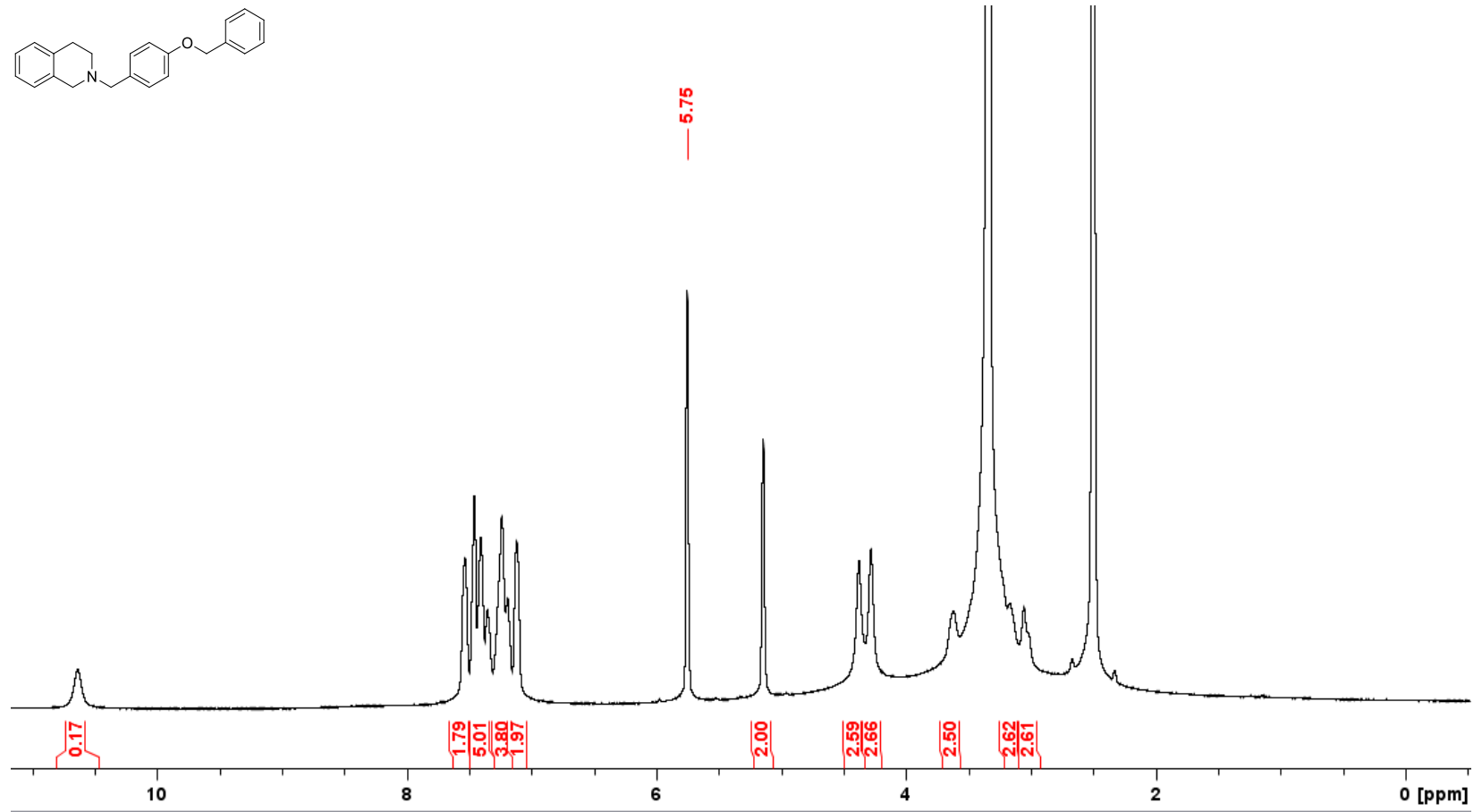




\section{${ }^{1} \mathrm{H}$ and ${ }^{13} \mathrm{C}$ NMR spectrum of synthesized compounds}
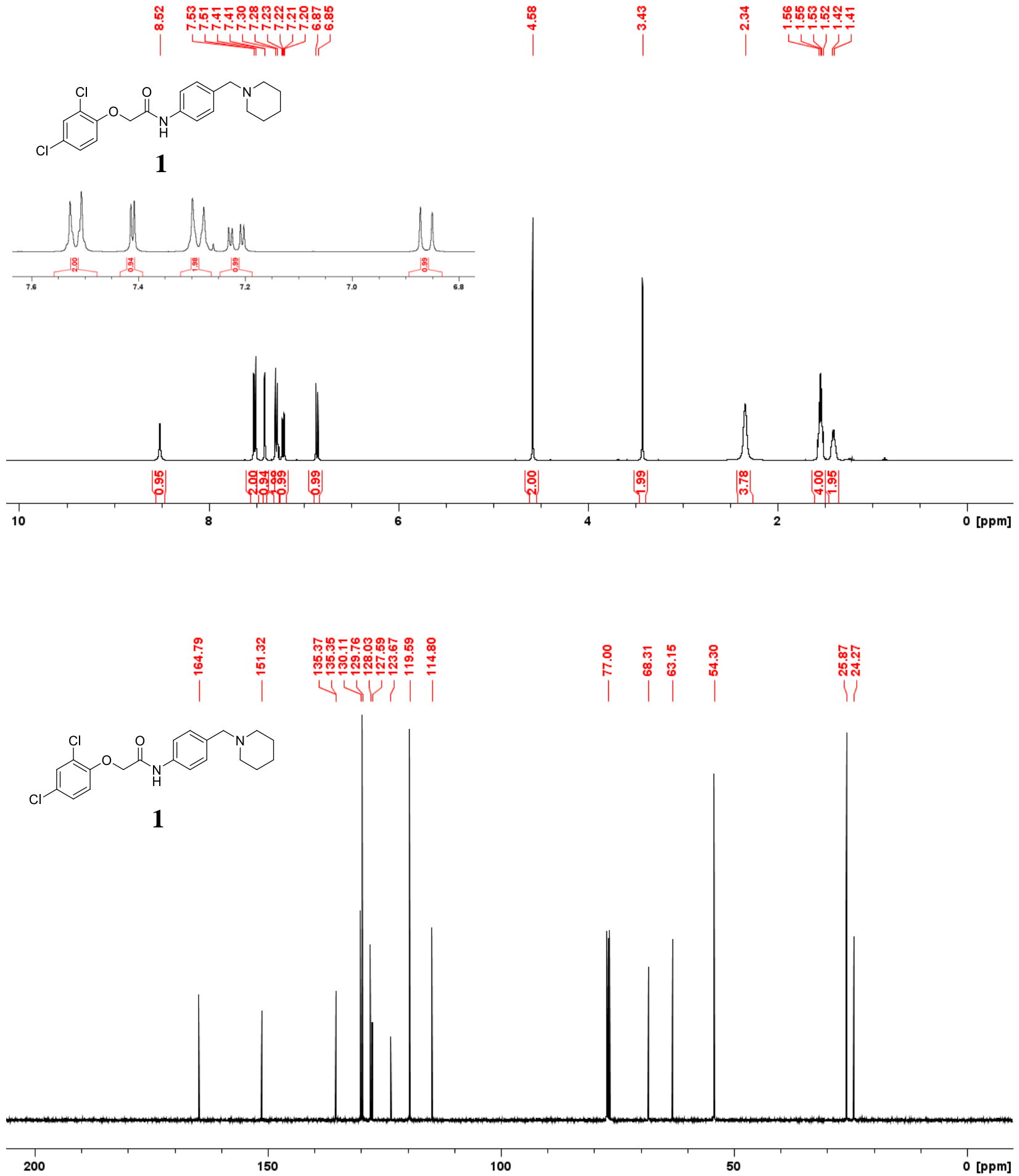

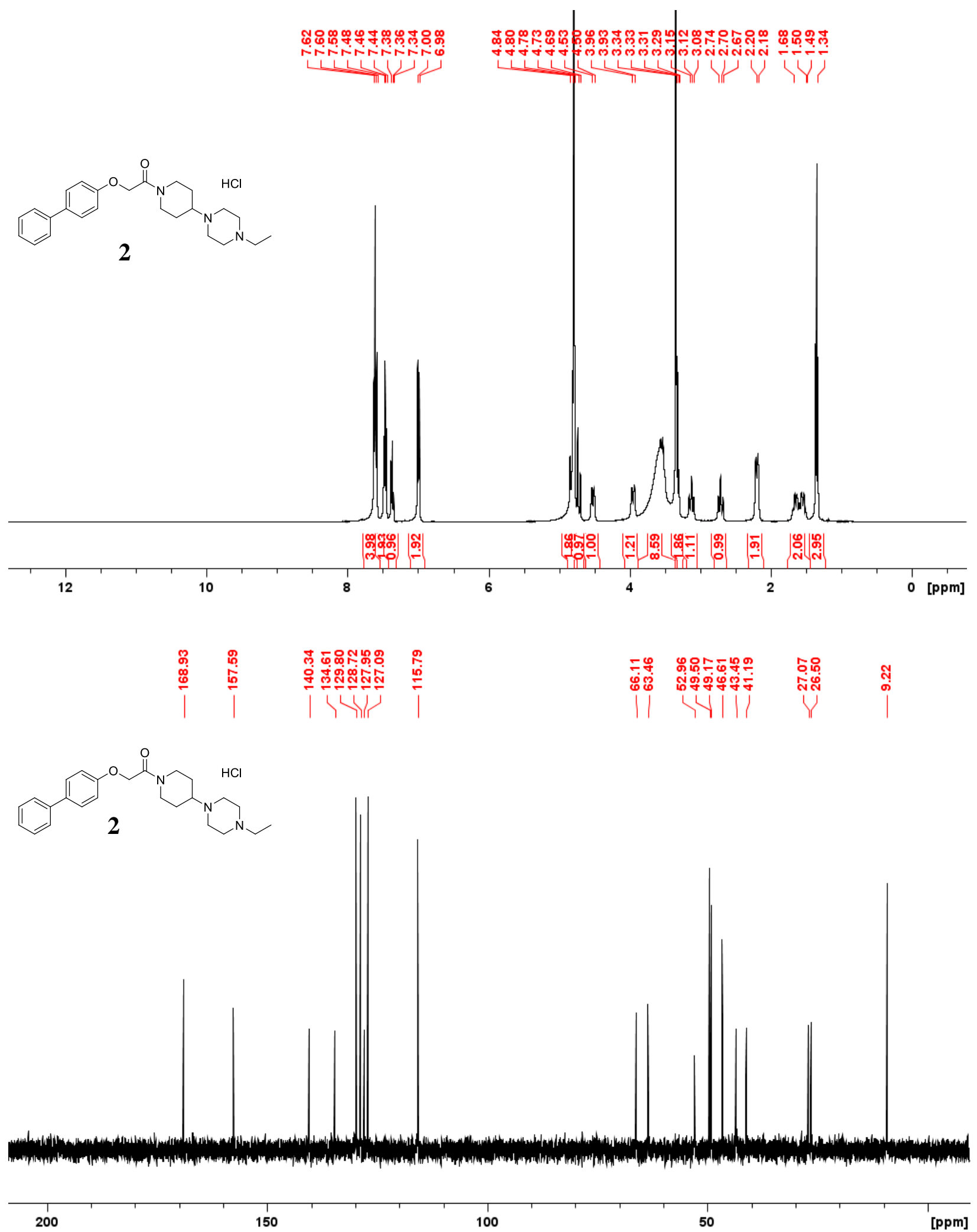


\section{SUPPORTING INFORMATION}

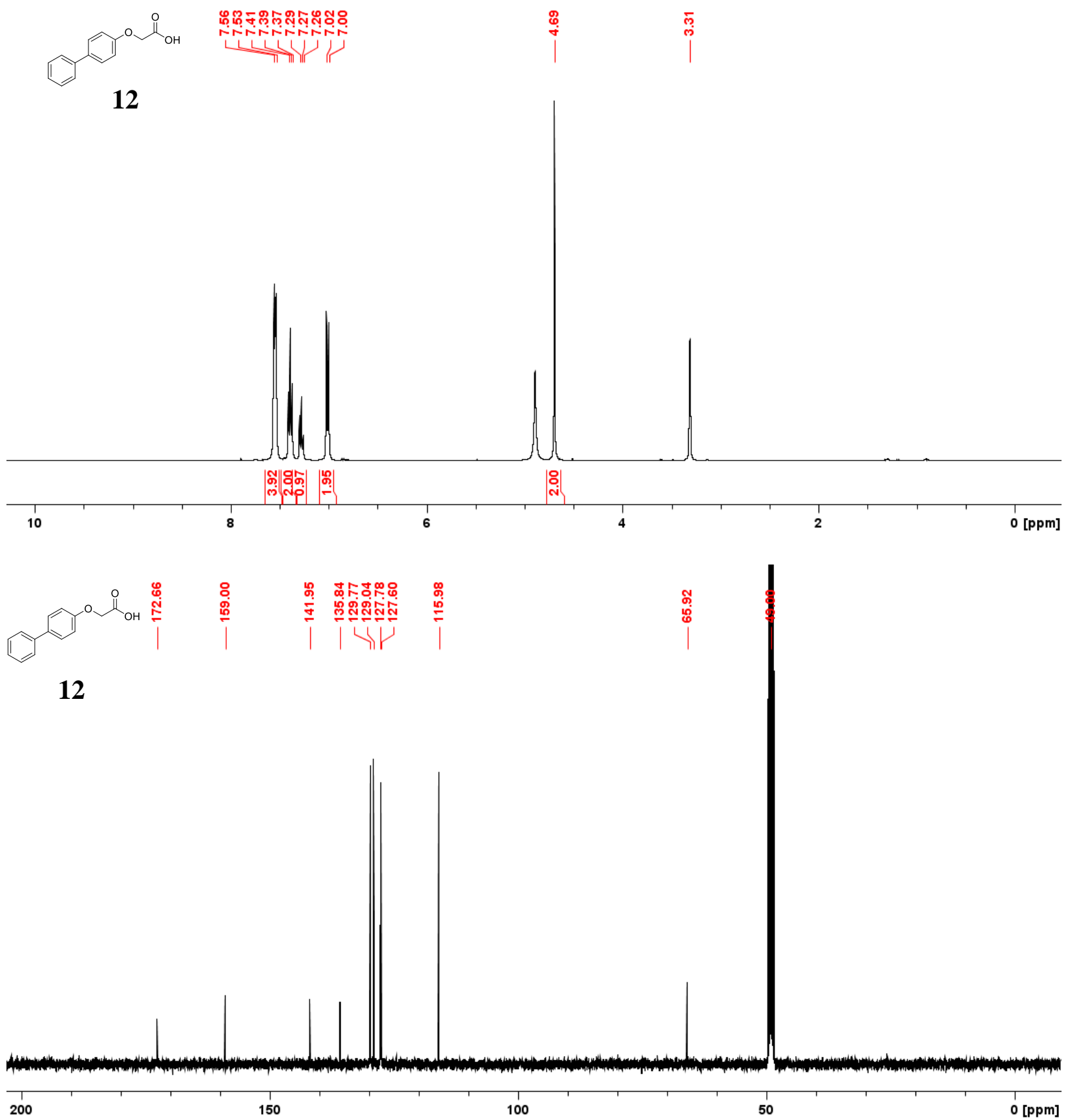




\section{SUPPORTING INFORMATION}
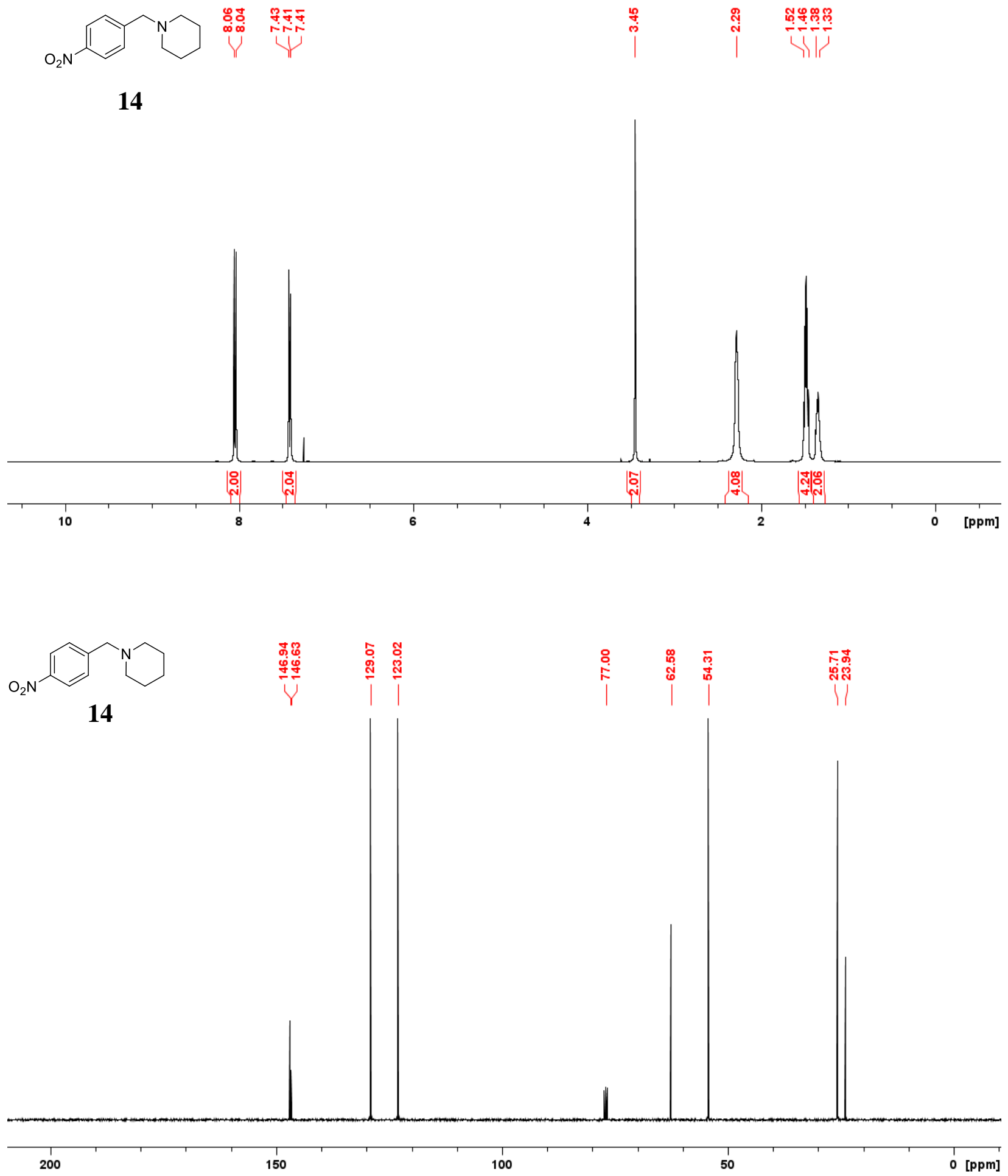


\section{SUPPORTING INFORMATION}

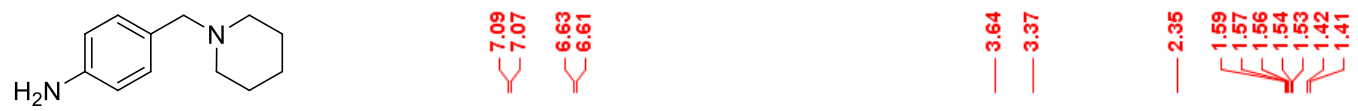

15
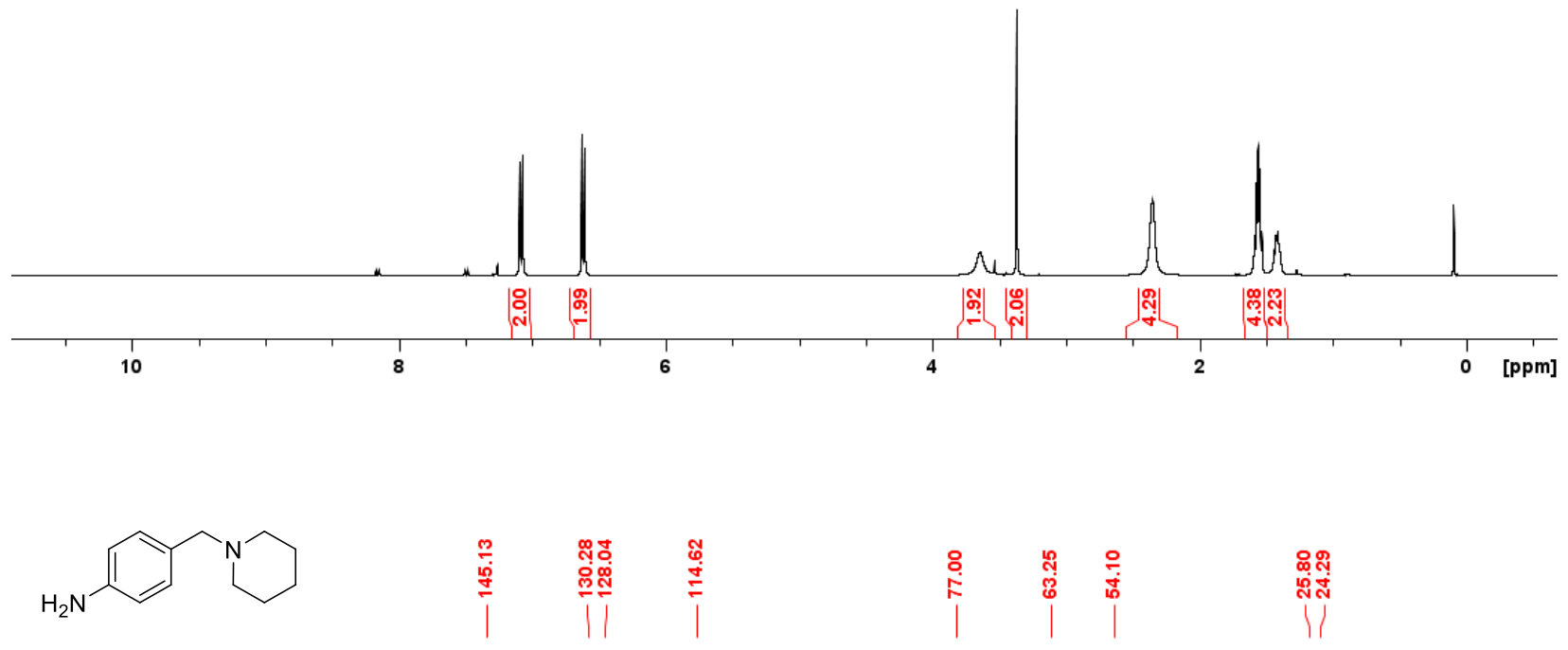

15

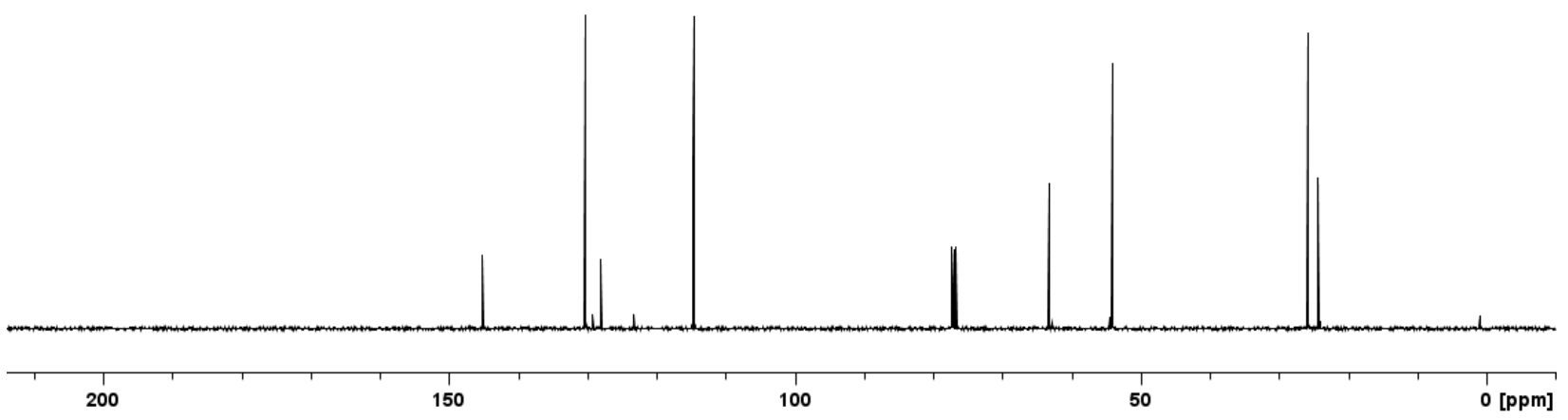




\section{SUPPORTING INFORMATION}

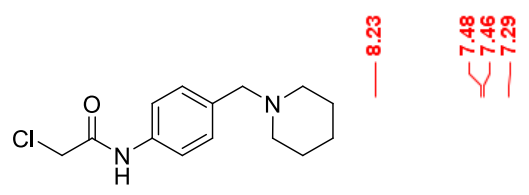

16
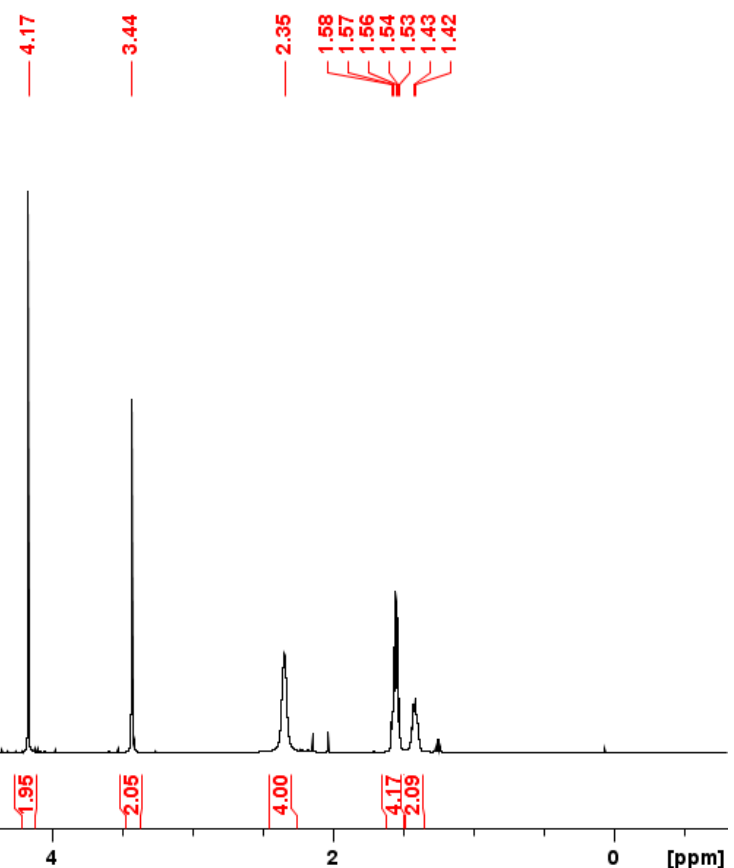<smiles>O=C(CCl)Nc1ccc(CN2CCCCC2)cc1</smiles>

16

|

|
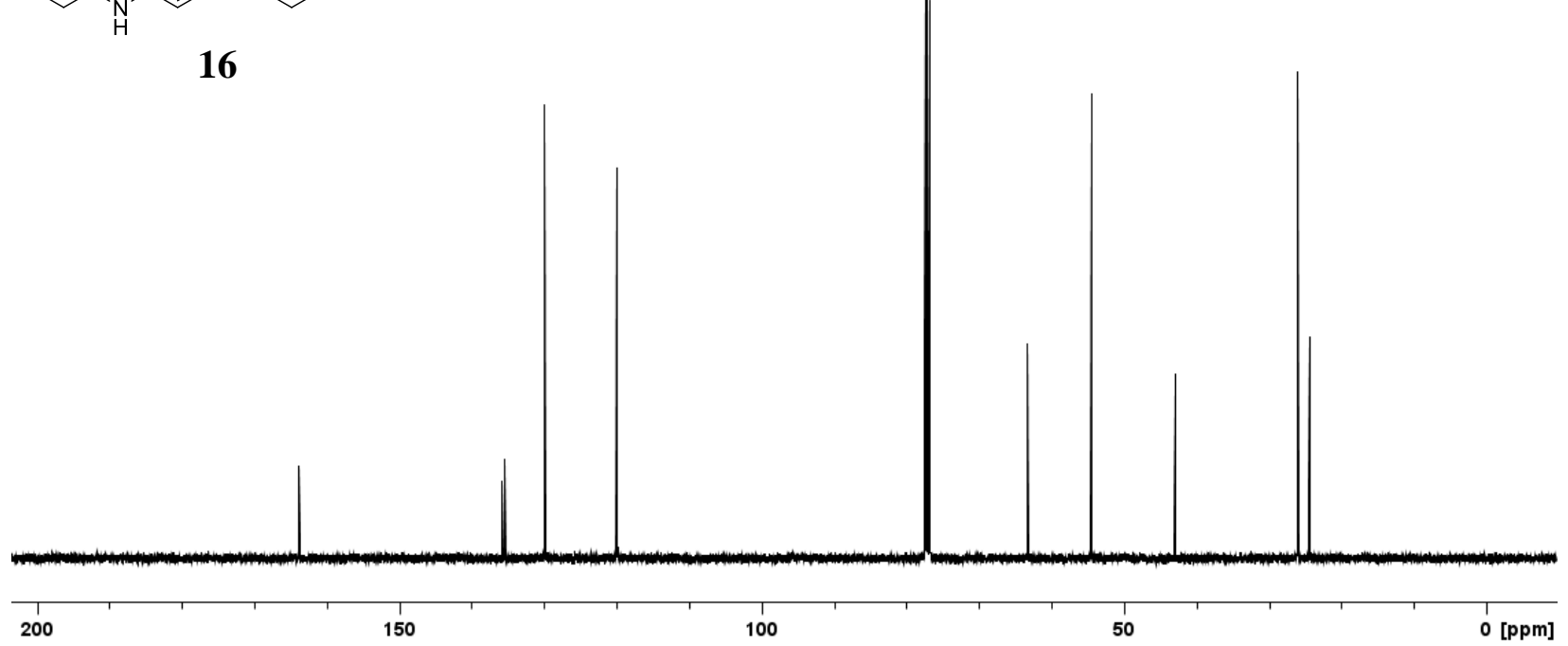


\section{SUPPORTING INFORMATION}

\section{Multiple sequence alignment $A g \mathrm{AChE} 1$}

AgAChE1 (accession no: XP_321792; UNIPROT code: ACES_ANOGA) after multiple alignment $^{3-4}$ with Torpedo californica (TcAChE, PDB code: 1EA5, UNIPROT code: ACES_TORCA), Homo sapiens ( $h$ AChE, PDB code: 4EY4, UNIPROT code: ACES_HUMAN), Mus musculus (mAChE, PDB code: 1J06, UNIPROT code: ACES_MOUSE), and Drosophila melanogaster (DmAChE, PDB code: 1QO9, UNIPROT code: ACES_DROME). Amino acids defined as 'loop one' and 'loop two' are highlighted in yellow and blue, respectively.

AgAChE1 DANDNDPLVVNTDKGRIRGITVDAPSGKKVDVWLGIPYAQPPVGPLRFRHPRPAEK-WTG hAChE EGREDAELLVTVRGGRLRGIRLKTPGG-PVSAFLGIPFAEPPMGPRRFLPPEP-KQPWSG MAChE EGREDPQLLVRVRGGQLRGIRLKAPGG-PVSAFLGIPFAEPPVGSRRFMPPEP-KRPWSG DMAChE VCGVIDRLVVQTSSGPVRGRSVTVQG-REVHVYTGIPYAKPPVEDLRFRKPVPAE-PWHG TCAChE QADDHSELLVNTKSGKVMGTRVPVLSS-HISAFLGIPFAEPPVGNMRFRRPEP-KKPWSG

AgAChE1 VLNTTTPPNSCVQIVDTVFGDFPGATMWNPNTPLSEDCLYINVVAPRPRPKNAA-VMLWI hAChE VVDATTFQSVCYQYVDTLYPGFEGTEMWNPNRELSEDCLYLNVWTPYPRPTSPTPVLVWI MAChE VLDATTFQNVCYQYVDTLYPGFEGTEMWNPNRELSEDCLYLNVWTPYPRPASPTPVLIWI DMAChE VLDATGLSATCVQERYEYFPGFSGEEIWNPNTNVSEDCLYINVWAPAKNTTNGLPILIWI TCAChE VWNASTYPNNCQQYVDEQFPGFSGSEMWNPNREMSEDCLYLNIWVPSPRPKSTT-VMVWI

AgAChE1 FGGGFYSGTATLDVYDHRALAS-EENVIVVSLQYRVASLGFLFL-------GTPEAPGNA hAChE YGGGFYSGASSLDVYDGRFLVQAE-RTVLVSMNYRVGAFGFLALP------GSREAPGNV MAChE YGGGFYSGAASLDVYDGRFLAQVEGA-VLVSMNYRVGTFGFLALP------GSREAPGNV DMAChE YGGGFMTGSATLDIYNADIMAAV-GNVIVASFQYRVGAFGFLHLAPEMPSEFAEEAPGNV TCAChE YGGGFYSGSSTLDVYNGKYLAYTEE-VVLVSLSYRVGAFGFLALH-----GSQEAPGNV

AgAChE1 GLFDQNLALRWVRDNIHRFGGDPSRVTLFGESAGAVSVSLHLLSALSRDLFQRAILQSGS hAChE GLLDQRLALQWVQENVAAFGGDPTSVTLFGESAGAASVGMHLLSPPSRGLFHRAVLQSGA MAChE GLLDQRLALQWVQENIAAFGGDPMSVTLFGESAGAASVGMHILSLPSRSLFHRAVLQSGT DMAChE GLWDQALAIRWLKDNAHAFGGNPEWMTLFGESAGSSSVNAQLMSPVTRGLVKRGMMQSGT TCAChE GLLDQRMALQWVHDNIQFFGGDPKTVTIFGESAGGASVGMHILSPGSRDLFRRAILQSGS

AgAChE1 PTAPWALVSREEATLR-ALRLAEAVGCP--HEPSKLSDAVECLRGKDP-HVLVNNEWGTL hAChE PNGPWATVGMGEARRR-ATQLAHLVGCPPGGTGGNDTELVACLRTR-PAQVLVNHEWHVL MAChE PNGPWATVSAGEARRR-ATLLARLVGCPPGGAGGNDTELIACLRTR-PAQDLVDHEWHVL DMAChE MNAPWSHMTSEKAVEIGKALINDC-NCNASMLKTNPAHVMSCMRSVD-AKTISVQQWNSY TCAChE PNCPWASVSVAEGRRR-AVELGRNLNCN----LNSDEEL IHCLREKKP-QEL IDVEWNVL

AgAChE1 G---ICEFPFVPVVDGAFLDETPQRSLASGRFKKTEILTGSNTEEGYYFIIYYLTELLRK hAChE PQESVFRFSFVPVVDGDFLSDTPEAL INAGDFHGLQVLVGVVKDEGSYFLVY-GAPGFSK MAChE PQESIFRFSFVPVVDGDFLSDTPEALINTGDFQDLQVLVGVVKDEGSYFLVY-GVPGFSK DMAChE S--GILSFPSAPTIDGAFLPADPMTLMKTADLKDYDILMGNVRDEGTYFLLYDFIDYFDK TCAChE PFDSIFRFSFVPVIDGEFFPTSLESMLNSGNFKKTQILLGVNKDEGSFFLLY-GAPGFSK

AgAChE1 EEGVTVTREEFLQAVRELNPYVNGAARQAIVFEYTDWTEPDNPNSNRDALDKMVGDYHFT hAChE DNESLISRAEFLAGVRVGVPQVSDLAAEAVVLHYTDWL HPEDPARLREALSDVVGDHNVV MAChE DNESLISRAQFLAGVRIGVPQASDLAAEAVVLHYTDWL HPEDPTHLRDAMSAVVGDHNVV DmAChE DDATALPRDKYLEIMNNIFGKATQAEREAIIFQYTSWEG-NPGYQNQQQIGRAVGDHFFT TCAChE DSESKISREDFMSGVKLSVPHANDLGLDAVTLQYTDWMDDNNGIKNRDGLDDIVGDHNVI

AgAChE1 CNVNEFAQRYAEEGNNVYMYLYTHRSKGNPWPRWTGVMHGDEINYVFGEPLNPTLGYTED hAChE CPVAQLAGRLAAQGARVYAYVFEHRASTLSWPLWMGVPHGYEIEFIFGIPLDPSRNYTAE MAChE CPVAQLAGRLAAQGARVYAYIFEHRASTLTWPLWMGVPHGYEIEFIFGLPLDPSLNYTTE DMAChE CPTNEYAQALAERGASVHYYYFTHRTSTSLWGEWMGVLHGDEIEYFFGQPLNNSLQYRPV TCAChE CPLMHFVNKYTKFGNGTYLYFFNHRASNL VWPEWMGVIHGYEIEFVFGLPLVKELNYTAE

AgAChE1 EKDFSRKIMRYWSNFAKTGNPNPNTASSEFPEWPKHTAHGRHYLELGL - NTSFVGRGPR hAChE EKIFAQRLMRYWANFARTGDPN-EPRDPKAPQWPPYTAGAQQYVSLDL--RPLEVRRGLR MAChE ERIFAQRLMKYWTNFARTGDPN-DPRDSKSPQWPPYTTAAQQYVSLNL--KPLEVRRGLR DMAChE ERELGKRMLSAVIEFAKTGNPAQD-----GEEWPNFSKEDPVYYIFSTDDKIEKLARGPL TCAChE EEALSRRIMHYWATFAKTGNPN-EPHSQESK-WPLFTTKEQKFIDLNT--EPMKVHQRLR

AgAChE1 LRQCAFWKKYLPQLVAAT hAChE AQACAFWNRFLPKLLSAT MAChE AQTCAFWNRFLPKLLSAT DMAChE AARCSFWNDYLPKVRSWA TCAChE VQMCVFWNQFLPKLLNAT 


\section{SUPPORTING INFORMATION}

\section{Multiple sequence alignment $A a \mathrm{AChE1}$}

AaAChE1 (accession no: ABN09910) after multiple alignment ${ }^{3-4}$ with Torpedo californica (TcAChE, PDB code: 1EA5, UNIPROT code: ACES_TORCA), Homo sapiens (hAChE, PDB code: 4EY4, UNIPROT code: ACES_HUMAN), Mus musculus (mAChE, PDB code: 1J06, UNIPROT code: ACES_MOUSE), and Drosophila melanogaster (DmAChE, PDB code: 1QO9, UNIPROT code: ACES_DROME). Amino acids defined as 'loop one' and 'loop two' are highlighted in yellow and blue, respectively.

AaAChE1 DGTDNDPLLITTDKGKVRGLTLEAPSGKKVDAWLGIPYAQPPLGPLRFRHPRPVEK-WTG hAChE EGREDAELLVTVRGGRLRGIRLKTPGG-PVSAFLGIPFAEPPMGPRRFLPPEP-KQPWSG MAChE EGREDPQLLVRVRGGQLRGIRLKAPGG-PVSAFLGIPFAEPPVGSRRFMPPEP-KRPWSG DMAChE VCGVIDRLVVQTSSGPVRGRSVTVQG-REVHVYTGIPYAKPPVEDLRFRKPVPAE-PWHG TCAChE QADDHSELLVNTKSGKVMGTRVPVLSS-HISAFLGIPFAEPPVGNMRFRRPEP-KKPWSG

AaAChE1 VLNATTPPNSCVQIVDTVFGDFPGATMWNPNTPLSEDCLYINVVVPHPRPKNSA-VMLWI hAChE VVDATTFQSVCYQYVDTL YPGFEGTEMWNPNRELSEDCLYLNVWTPYPRPTSPTPVLVWI mAChE VLDATTFQNVCYQYVDTLYPGFEGTEMWNPNRELSEDCLYLNVWTPYPRPASPTPVLIWI DMAChE VLDATGLSATCVQERYEYFPGFSGEEIWNPNTNVSEDCLYINVWAPAKNTTNGLPILIWI TCAChE VWNASTYPNNCQQYVDEQFPGFSGSEMWNPNREMSEDCLYLNIWVPSPRPKSTT-VMVWI

AaAChE1 FGGGFYSGTATLDVYDHRTLAS-EENVIVVSLQYRVASLGFLFL------GTPEAPGNA hAChE YGGGFYSGASSLDVYDGRFLVQAE-RTVLVSMNYRVGAFGFLALP------GSREAPGNV MAChE YGGGFYSGAASLDVYDGRFLAQVEGA-VLVSMNYRVGTFGFLALP------GSREAPGNV DmAChE YGGGFMTGSATLDIYNADIMAAV-GNVIVASFQYRVGAFGFLHLAPEMPSEFAEEAPGNV TCAChE YGGGFYSGSSTLDVYNGKYLAYTEE-VVLVSLSYRVGAFGFLALH-----GSQEAPGNV

AaAChE1 GLFDQNLALRWVRDNIHKFGGDPSRVTLFGESAGAVSVSLHLLSALSRDLFQRAILQSGS hAChE GLLDQRLALQWVQENVAAFGGDPTSVTLFGESAGAASVGMHLLSPPSRGLFHRAVLQSGA mAChE GLLDQRLALQWVQENIAAFGGDPMSVTLFGESAGAASVGMHILSLPSRSLFHRAVLQSGT DMAChE GLWDQALAIRWL KDNAHAFGGNPEWMTLFGESAGSSSVNAQLMSPVTRGL VKRGMMQSGT TCAChE GLLDQRMALQWVHDNIQFFGGDPKTVTIFGESAGGASVGMHILSPGSRDLFRRAILQSGS

AaAChE1 PTAPWALVSREEATLR-ALRLAEAVNCP--HDATKLTDTVECLRTKDP-NVLVDNEWGTL hAChE PNGPWATVGMGEARRR-ATQLAHLVGCPPGGTGGNDTELVACLRTR-PAQVLVNHEWHVL mAChE PNGPWATVSAGEARRR-ATLLARLVGCPPGGAGGNDTEL IACLRTR-PAQDLVDHEWHVL DMAChE MNAPWSHMTSEKAVEIGKALINDC-NCNASMLKTNPAHVMSCMRSVD-AKTISVQQWNSY TCAChE PNCPWASVSVAEGRRR-AVELGRNLNCN----LNSDEELIHCLREKKP-QELIDVEWNVL

AaAChE1 G---ICEFPFVPVVDGAFLDETPQRSLASGRFKKTDILTGSNTEEGYYFIIYYLTELLRK hAChE PQESVFRFSFVPVVDGDFLSDTPEAL INAGDFHGLQVLVGVVKDEGSYFLVY-GAPGFSK MAChE PQESIFRFSFVPVVDGDFLSDTPEAL INTGDFQDLQVLVGVVKDEGSYFLVY-GVPGFSK DMAChE S--GILSFPSAPTIDGAFLPADPMTLMKTADLKDYDILMGNVRDEGTYFLLYDFIDYFDK TCAChE PFDSIFRFSFVPVIDGEFFPTSLESMLNSGNFKKTQILLGVNKDEGSFFLLY-GAPGFSK

AaAChE1 EEGVTVSREEFLQAVRELNPYVNGAARQAIVFEYTDWTEPENPNSNRDALDKMVGDYHFT hAChE DNESLISRAEFLAGVRVGVPQVSDLAAEAVVLHYTDWL HPEDPARLREALSDVVGDHNVV MAChE DNESLISRAQFLAGVRIGVPQASDLAAEAVVLHYTDWLHPEDPTHLRDAMSAVVGDHNVV DMAChE DDATALPRDKYLEIMNNIFGKATQAEREAIIFQYTSWEG-NPGYQNQQQIGRAVGDHFFT TCAChE DSESKISREDFMSGVKLSVPHANDLGLDAVTLQYTDWMDDNNGIKNRDGLDDIVGDHNVI

AaAChE1 CNVNEFAQRYAEEGNNVYMYLYTHRSKGNPWPRWTGVMHGDEINYVFGEPLNSDLGYMED hAChE CPVAQLAGRLAAQGARVYAYVFEHRASTLSWPLWMGVPHGYEIEFIFGIPLDPSRNYTAE MAChE CPVAQLAGRLAAQGARVYAYIFEHRASTL TWPLWMGVPHGYEIEFIFGLPLDPSLNYTTE DMAChE CPTNEYAQALAERGASVHYYYFTHRTSTSLWGEWMGVLHGDEIEYFFGQPLNNSLQYRPV TCAChE CPLMHFVNKYTKFGNGTYLYFFNHRASNLVWPEWMGVIHGYEIEFVFGLPLVKELNYTAE

AaAChE1 EKDFSRKIMRYWSNFAKTGNPNPSPPNSDFPEWPKHTAHGRHYLELGL - NTTYVGRGPR hAChE EKIFAQRLMRYWANFARTGDPN-EPRDPKAPQWPPYTAGAQQYVSLDL--RPLEVRRGLR MAChE ERIFAQRLMKYWTNFARTGDPN-DPRDSKSPQWPPYTTAAQQYVSLNL--KPLEVRRGLR DMAChE ERELGKRMLSAVIEFAKTGNPAQD-----GEEWPNFSKEDPVYYIFSTDDKIEKLARGPL TCAChE EEALSRRIMHYWATFAKTGNPN-EPHSQESK-WPLFTTKEQKFIDLNT--EPMKVHQRLR

AaAChE1 LRQCAFWKKYLPQLVAAT hAChE AQACAFWNRFLPKLLSAT MAChE AQTCAFWNRFLPKLLSAT DMAChE AARCSFWNDYLPKVRSWA TCAChE VQMCVFWNQFLPKLLNAT 


\section{SUPPORTING INFORMATION}

\section{Selection of template for homology modeling}

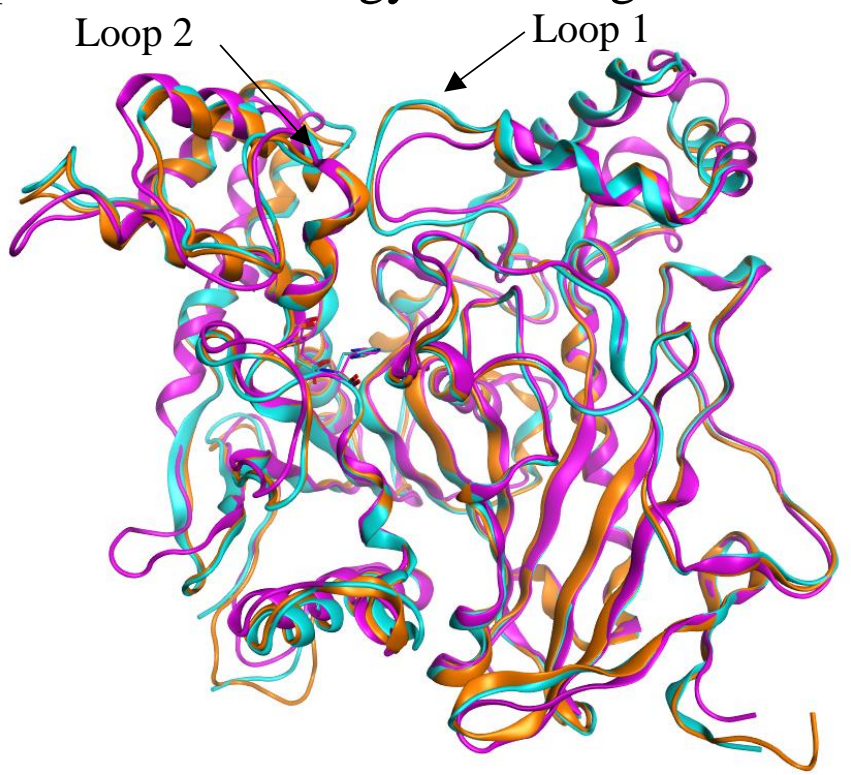

Figure S20. Superposition of $m \mathrm{AChE}$ (pdb code $5 \mathrm{FOQ}^{5}$; ribbon in orange), $h \mathrm{AChE}$ (pdb code $4 \mathrm{EY} 4^{6}$; ribbon in cyan), or $\mathrm{DmAChE}$ ( $\mathrm{pdb}$ code $1 \mathrm{DX} 4^{7}$; ribbon in magenta). The side chains of the amino acids in the catalytic triad are shown as sticks. AChE from three species were considered as template for the homology modeling, $m \mathrm{AChE}, h \mathrm{AChE}$, or DmAChE. After the multiple alignments, the identity of the possible templates $m \mathrm{AChE}, h \mathrm{AChE}$, and $D m \mathrm{AChE}$ and the sequences to be modelled were $48 \%, 48 \%$, and $39 \%$ for $A g \mathrm{AChE1}$, respectively, and 48\%, 48\%, and $38 \%$ for $A a \mathrm{AChE1}$, respectively based on residues 1-543 in $h \mathrm{AChE}$. One crystal structure from each species were superposed and visually analyzed. The analysis showed that both the general fold and the amino acids lining the active site are highly conserved among the different species. It could however be seen that the two loops at the entrance of the active site differs between DmAChE and the vertebrate AChEs. In more details, 'loop 1' is one residue longer and 'loop 2' is two residues shorter. The multiple sequence alignment showed that for $A g \mathrm{AChE} 1$ and $A a \mathrm{AChE} 1$ 'loop 2' contains the same number of residues as $\mathrm{DmAChE}$, but that 'loop 1' is one residue shorter (i.e. three residues shorter than vertebrate AChE). Although showing a lower sequence identity, DmAChE (pdb 1DX $4^{7}$ ) was selected as the main template, due to the higher similarity of 'loop 1' and 'loop 2'. This template was used to model all residues with the exception of three loops: 102112, 487-499, and 512-520 ( $h \mathrm{AChE}$ numbering). It was found that in 1DX4 these loops were either not modelled or that their lengths differed from $A g A C h E 1$ and $A a \mathrm{AChE} 1$, resulting in $m \mathrm{AChE}$ (pdb code 5FOQ $)^{5}$ being considered as a more suitable template for modelling of these residues. 


\section{Angles of Tyr337 in homology models of AgAChE1 and AaAChE1}

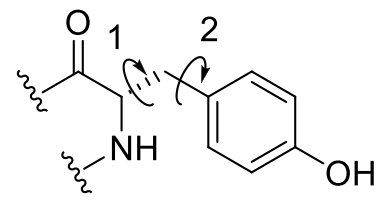

Figure S21. $\chi_{1}\left(\mathrm{C}_{\alpha}-\mathrm{C}_{\beta}\right)$ and $\chi_{2}\left(\mathrm{C}_{\beta} \mathrm{C}_{1}\right)$ dihedral angles for the side chain of Tyr337 (hAChE numbering) were adjusted to -157.0 and -157.1 degrees and $\chi_{2}\left(\mathrm{C}_{\beta} \mathrm{C}_{1}\right)-26.4$ and -26.3 degrees for $A g \mathrm{AChE1}$ and $A a \mathrm{AChE1}$, respectively. These angles resemble those in $2 \bullet m \mathrm{AChE}$ and have been observed in previously reported protein-ligand complexes of $m \mathrm{AChE}$ and $h \mathrm{AChE}$ (for examples see complexes with pdb codes $4 \mathrm{ARB}^{8}$ and $4 \mathrm{EY} 7^{6}$ ).

\section{Evaluation of $A g \mathrm{AChE1}$ and $A a \mathrm{AChE1}$ homology models}

Table S9. Statistics of the stereochemical quality of the generated homology models according to PROCHECK. ${ }^{9}$

\begin{tabular}{lcc} 
Ramachandran plot no. of residues $(\%)$ & $\boldsymbol{A g A C h E 1}$ & $\boldsymbol{A a A C h E 1}$ \\
\hline Most favoured regions & $364(81.3)$ & $368(81.8)$ \\
Additional allowed regions & $73(16.3)$ & $73(16.2)$ \\
Generously allowed regions & $7(1.6)$ & $4(0.9)$ \\
Residues in disallowed regions & $4(0.9)$ & $5(1.1)$
\end{tabular}


Compounds 1 and $\mathbf{2}$ modelled into the active site of $A g A C h E 1$ and AaAChE1.

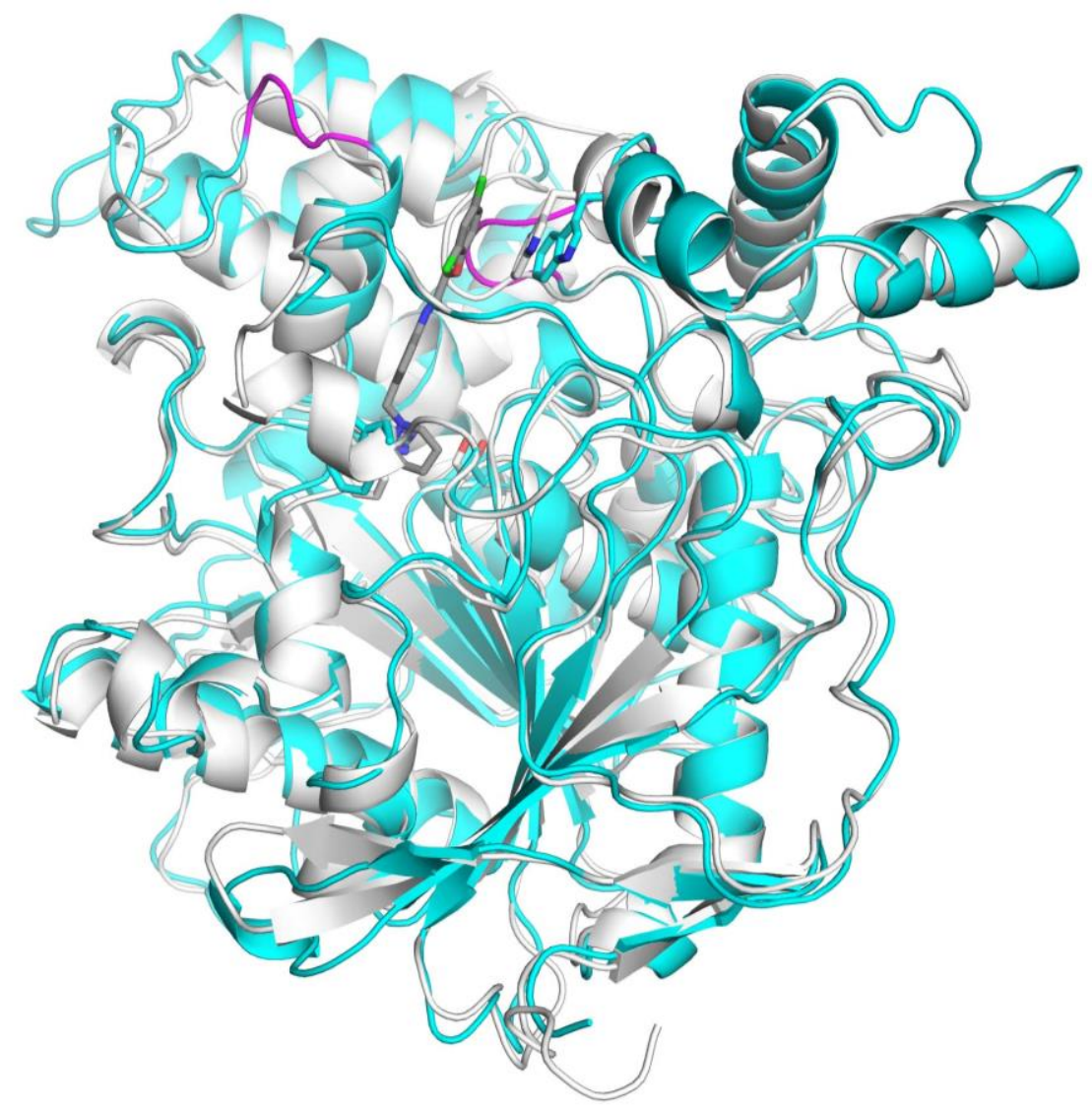

Figure S22. Superposition of the homology model of $A g A C h E 1$ (cyan ribbon) and $m A C h E$ (gray ribbon) in complex with 1 (dark gray). The differing loops (loop 1 and loop 2) at the entrance of the gorge of $A g A C h E 1$ are marked in magenta. 


\section{SUPPORTING INFORMATION}

a)

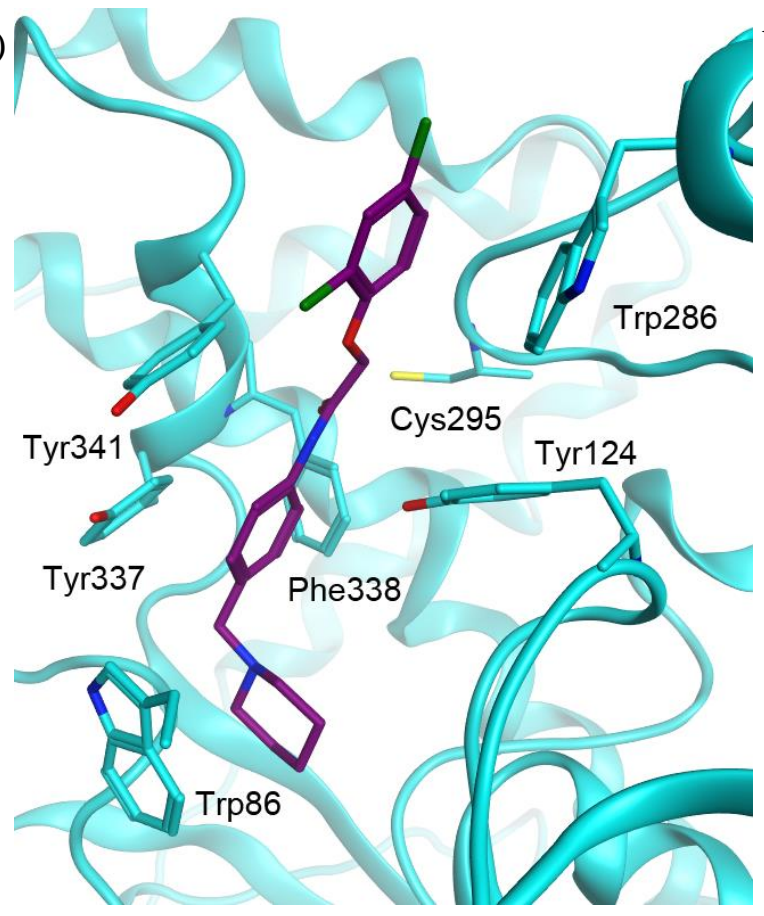

b)
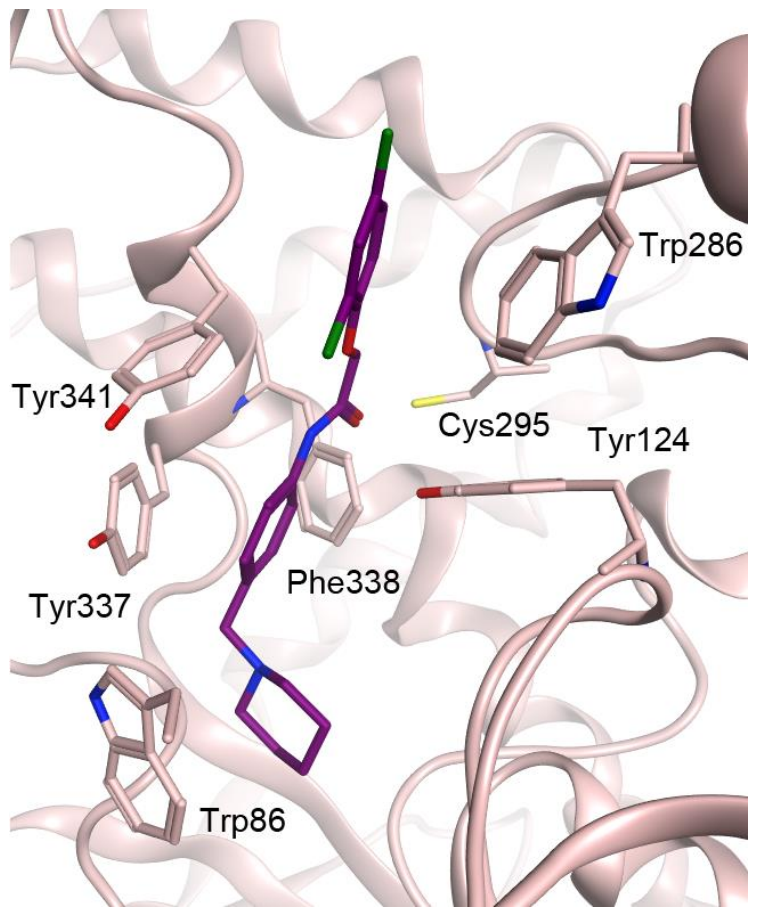

Figure S23. Homology model of $A g A C h E 1$ in cyan (a) and $A a A C h E 1$ in pink (b) showing a close up of active site with $\mathbf{1}$ (purple) modelled with the positively charged piperidine projecting down into the catalytic site (based on $1 \bullet \mathrm{mAChE}$ ).

a)

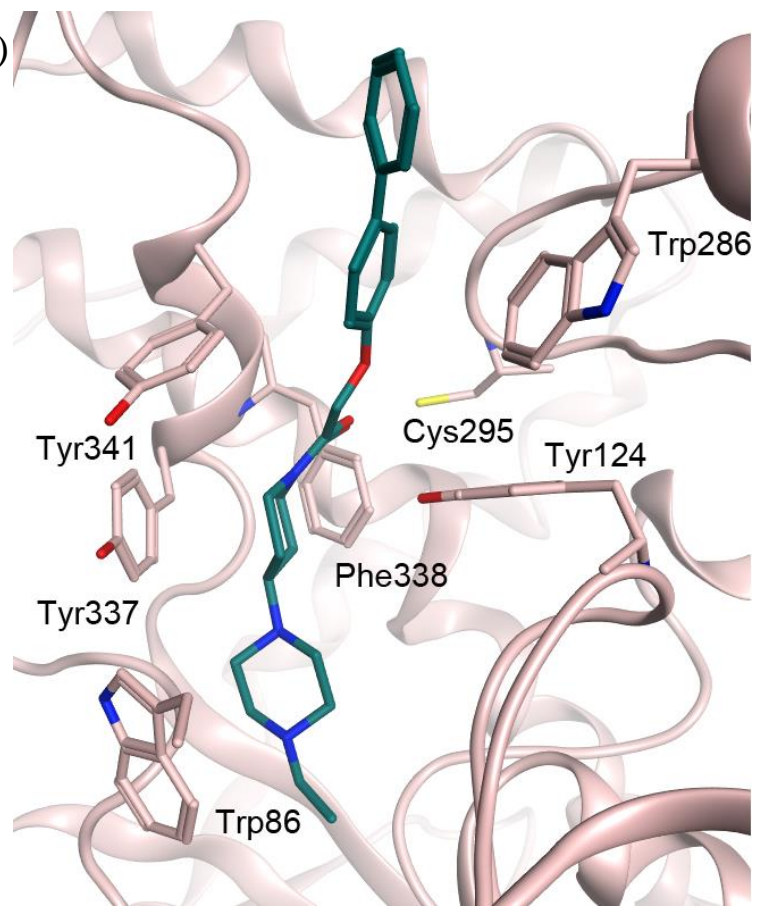

b)

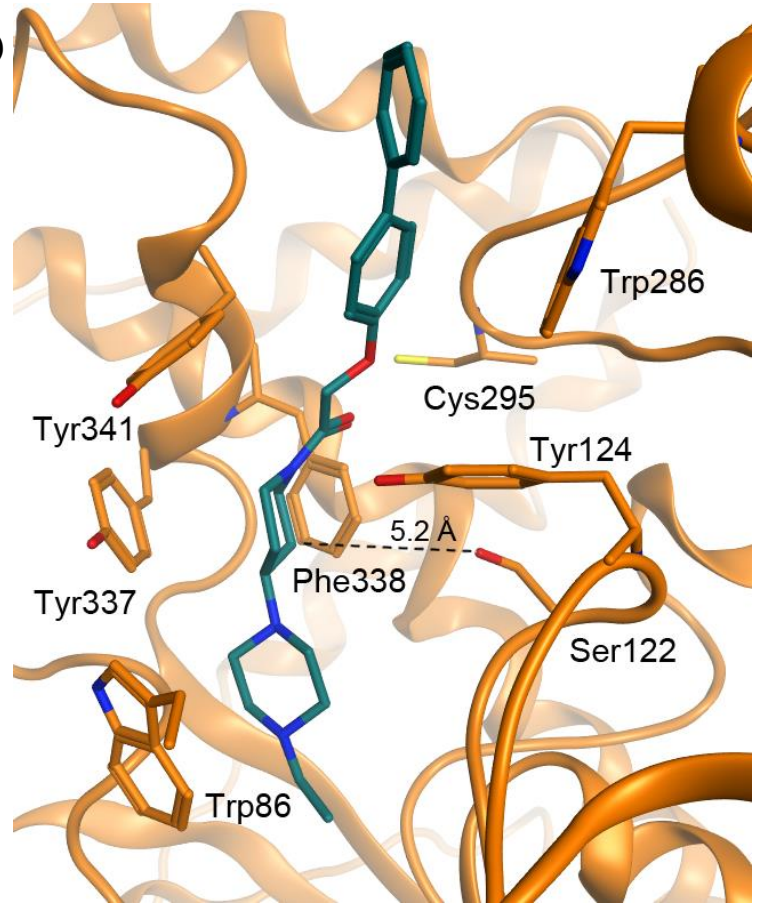

Figure S24. Homology models of $A a A C h E 1$ in pink (a) and of G122S-AgAChE1 in orange (b) showing a close up of active site with $\mathbf{2}$ (green) modelled with the positively charged piperazine projecting down into the catalytic site (based on $\mathbf{2}$ aligned on $1 \bullet \mathrm{mAChE}$ ). 


\section{Data collection and refinement statistics for 5FUM}

Table S10. Data collection and refinement statistics for 5FUM. Statistics for the highest-resolution shell are shown in parentheses.

\begin{tabular}{ll}
\hline pdb entry code & 5 FUM \\
Resolution range $(\AA)$ & $29.08-2.5(2.59-2.5)$ \\
Space group & P 21 21 21 \\
Unit cell $(\AA)$ & $78.7 \times 110.8 \times 227.6$ \\
Total reflections & $520714(51599)$ \\
Unique reflections & $69320(6799)$ \\
Multiplicity & $7.5(7.6)$ \\
Completeness $(\%)$ & $99.60(99.28)$ \\
Mean I/sigma(I) & $14.69(2.35)$ \\
Wilson B-factor $\left(\AA^{2}\right)$ & 51.2 \\
R-merge & $0.124(1.584)$ \\
R-meas & $0.1333(0.724)$ \\
CC1/2 & $0.998(0.885)$ \\
CC* & $0.999(0.969)$ \\
R-work & $0.196(0.3103)$ \\
R-free & $0.227(0.3888)$ \\
Number of non-hydrogen atoms & 8602 \\
macromolecules & 8350 \\
ligands & 123 \\
water & 129 \\
Protein residues & 1068 \\
RMSD from ideal values & \\
bond lengths $(\AA)$ & 0.004 \\
bond angles $\left({ }^{\circ}\right)$ & 0.89 \\
Ramachandran favored $(\%)$ & 95 \\
Ramachandran outliers $(\%)$ & 0.28 \\
Clashscore & 0.72 \\
Average B-factor $\left(\AA^{2}\right)$ & 62.00 \\
macromolecules & 61.60 \\
ligands & 87.50 \\
solvent & 58.90 \\
\hline
\end{tabular}

a These include compound 2 (modelled in both the A and the B chain) and fragments of six PEG750MME molecules modelled in the structure. 


\section{SUPPORTING INFORMATION}

\section{References}

1. Berg, L.; Andersson, C. D.; Artursson, E.; Hörnberg, A.; Tunemalm, A.-K.; Linusson, A.; Ekström, F. Targeting acetylcholinesterase: Identification of chemical leads by high throughput screening, structure determination and molecular modeling. PLoS One 2011, 6, e26039.

2. $\quad$ SIMCA-P+, version 13.0.3; Umetrics AB: Box 7960, Umeå, Sweden, 2013.

3. Molecular Operating Environment (MOE), version 2012.10; Chemical Computing Group Inc.: 1010 Sherbooke St. West, Suite \#910, Montreal, QC, Canada, H3A 2R7, 2012.

4. Larkin, M. A.; Blackshields, G.; Brown, N. P.; Chenna, R.; McGettigan, P. A.; McWilliam, H.; Valentin, F.; Wallace, I. M.; Wilm, A.; Lopez, R.; Thompson, J. D.; Gibson, T. J.; Higgins, D. G. Clustal W and Clustal X version 2.0. Bioinformatics 2007, 23, 2947-2948.

5. Berg, L.; Mishra, B. K.; Andersson, C. D.; Ekström, F.; Linusson, A. The nature of activated non-classical hydrogen bonds: A case study on acetylcholinesterase-ligand complexes. Chemistry 2016, 22, 2672-2681.

6. Cheung, J.; Rudolph, M. J.; Burshteyn, F.; Cassidy, M. S.; Gary, E. N.; Love, J.; Franklin, M. C.; Height, J. J. Structures of human acetylcholinesterase in complex with pharmacologically important ligands. J. Med. Chem. 2012, 55, 10282-10286.

7. Harel, M.; Kryger, G.; Rosenberry, T. L.; Mallender, W. D.; Lewis, T.; Fletcher, R. J.; Guss, J. M.; Silman, I.; Sussman, J. L. Three-dimensional structures of Drosophila melanogaster acetylcholinesterase and of its complexes with two potent inhibitors. Protein Sci. 2000, 9, 10631072.

8. $\quad$ Berg, L.; Niemiec, M. S.; Qian, W.; Andersson, C. D.; Wittung-Stafshede, P.; Ekström, F.; Linusson, A. Similar but different: thermodynamic and structural characterization of a pair of enantiomers binding to acetylcholinesterase. Angew. Chem., Int. Ed. 2012, 51, 12716-12720.

9. Laskowski, R. A.; Macarthur, M. W.; Moss, D. S.; Thornton, J. M. PROCHECK: A program to check the stereochemical quality of protein structures. J. Appl. Crystallogr. 1993, 26, 283-291. 